\title{
The Structural Reuse of Pinus Radiata in New Zealand By Nick Forbes
}

\author{
A 120 point thesis submitted to \\ Victoria University of Wellington \\ In fulfilment of the requirements \\ Of a Masters of Building Science (MBSc)
}

2018 
pg. 1 


\section{Personal Preface}

Unlike many other theses produced prior to this one, it is important to understand that complications arose during the conclusion of this particular thesis. Unknown to the author and surrounding involved members, a large central frontal brain tumour was developing and clouding certain parts of the brain. This tumour generated confusion and a general sense of tiredness, lack of judgement, an inability to concentrate for a sustain periods of time, and on some days even attending the university campus.

It is understood that this bears no relevance to the thesis of structurally reusing Pinus Radiata in New Zealand, but it acts more as a rationale behind something that has taken time and is the source of a lot of pride for the Author. Unfortunately, due to further complications there is currently no time to redevelop this document to become a more coherent, unified formatted document.

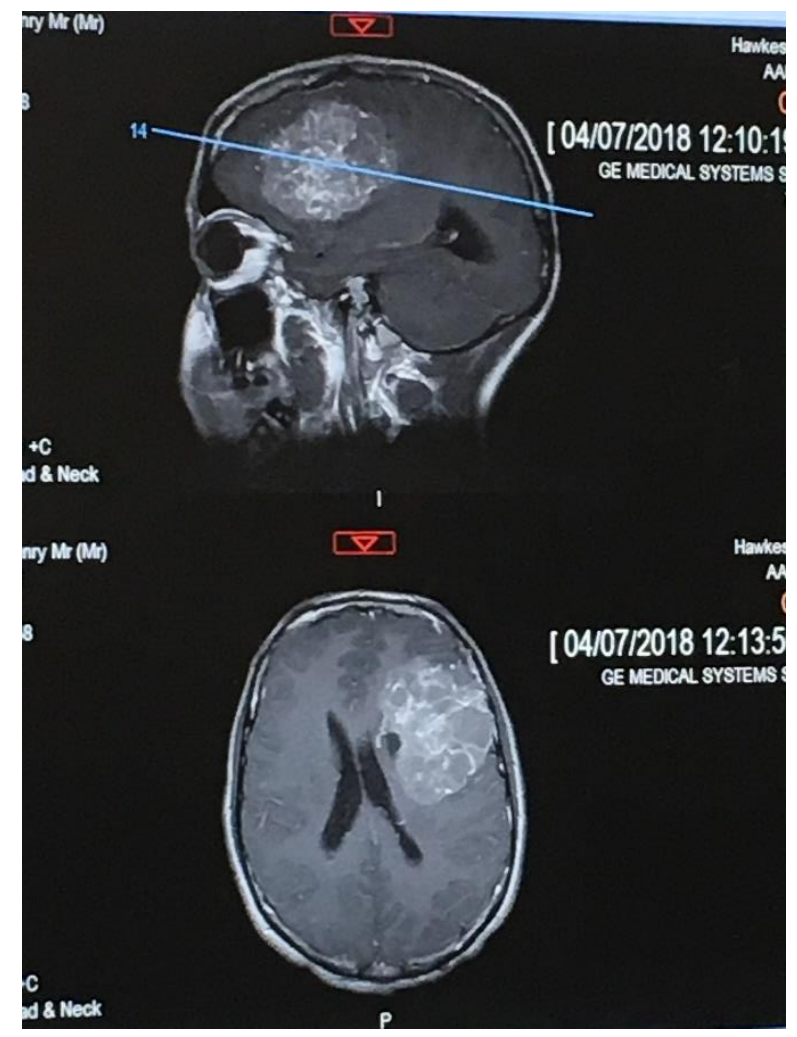

Figure 14/07/2018 MRI scan (authors own) 


\section{Preface}

Author:

Nick Forbes

School of Architecture

Victoria University of Wellington

Email: nickforbes94@hotmail.com

Primary Supervisors

Guy Marriage

Senior Lecturer, Architecture

School of Architecture

Victoria University of Wellington

Email: guy.marriage@vuw.ac.nz 
pg. 4 


\section{Acknowledgements}

Acknowledgements and thanks are due

To my supervisor Guy Marriage, you are a wonderful and beautiful man, and I want to thank you for everything you did for me, thank you.

To the beautiful GED and Cara, thanks for putting up with me and proof reading my work.

To all of the amenities surrounding the campus, Subway, CQ hotel, Raglan, Sushi shop, Kabab and Ekim.

To my acquaintance Chung from Calibre Equipment in Wellington.

To Elon at Crighton ITM Levin, for all the chats we had over this product.

To Regan, thank you for all your help with the testing side, and for your three point tester.

To Mike and Nigel, thank you for all your input into my work.

To my family and friends for all your hard work to push me further along in the thesis year.

To Alister, you sat next to me and put up with me and proof read all my emails, thank you.

To Chloe, for all the food.

To Issei, that one time you smoked, that was my favourite.

To Cyrus for all you smoking chats with me.

To Britt, even with my headphones on I could still hear you.

To Beth, your amazing chats keep me going. 
pg. 6 


\section{Abstract}

Masses of used Copper chromium arsenic (CCA) treated timber is deposited into landfill from light timber framed building deconstruction every year. This research explores the structural integrity of CCA treated timber and the feasibility of its re-use within the construction industry. To answer this question an appropriate methodology has been designed to achieve quality results. The first part of the methodology was to identify the profit margin for pinus radiata through communicating with individuals in the current market. This market all works around the concept that to reuse there needs to be a significant buying community as it needs to generate MONEY. Through doing this it was identified that only a few companies in New Zealand reuse CCA treated timber and the ways of which it is re-used varies greatly between companies. Some firms pull the nails out due to health and safety reasons, while others leave them in due to the overall cost of the sale. This gives a good understanding on what everyone is doing across the country and allows for the sale market to be set at $\$ 2.00$ a meter, which if done correctly comes in at around $\$ 0.16$ a meter of profit.

The next part of the methodology required a physical assessment of material itself in order to establish its structural integrity and identify other potential barriers to its reuse. This section covered all other possibilities to pinus radiata focusing on the different timber which have the same properties, and focus on separate treatments which will also conduct the same issues as CCA. This all found that there is much research to consider, which placed New Zealand in an area of profit, as any of these documents could be the focus point and all could eventually relieve CCA from the industry.

Existing research identifies how the use of CCA treated timber can be prevented, but does not consider the diversion of existing treated timber being deposited into landfill. The lack of research into the reuse of CCA treated timber is the main barrier found in this thesis. This required the series of events which occur between building deconstruction and deposition into landfill to be clearly defined, before they could be changed. The changes to how CCA treated timber is processed after deconstruction has the potential to divert the material from landfill for re-use. The primary addition to this process was an assessment of the strength which it holds. To accomplish this a three point bending test was carried out on each member, finding the alternate strength and the modulus of elasticity (MOE). These two figures could then be directly compared to NZS 3603:1993 timber structural standards allowing their long term history of testing to be the comparative point (New Zealand Government, 1993).

With the two figures it was found that all of this material strength was $91 \%$ above the minimum strength grading of SG6, and 55\% above the next area of SG8, which is the most commonly used 
framing timber. Although through doing this there was hope for the material to present themselves with a way of finding the general strength with minimal tools, this is not present in the research.

The most important finding of this research is that CCA treated timber is strong enough to be placed straight back into the construction industry and re-used for light timber frame construction. Future research is needed into the additional education required of builders in order for them to confidently re-use the timber in construction. 


\section{Contents}

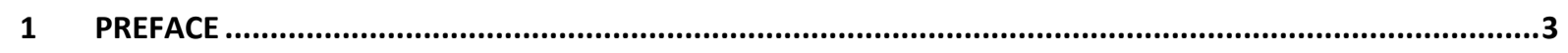

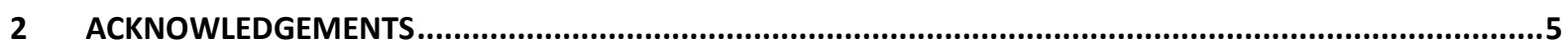

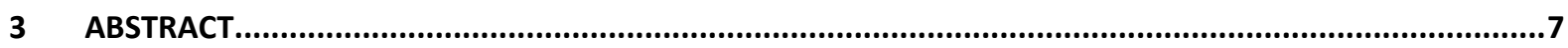

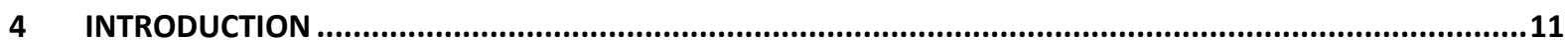

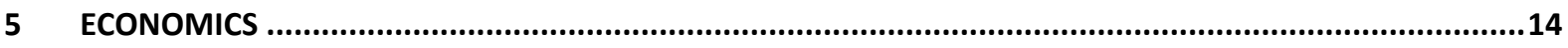

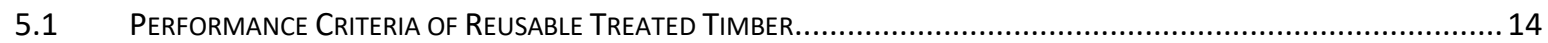

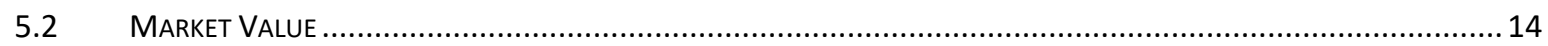

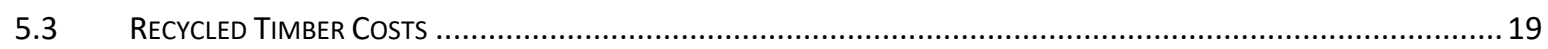

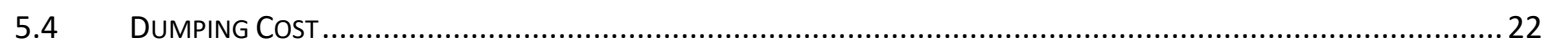

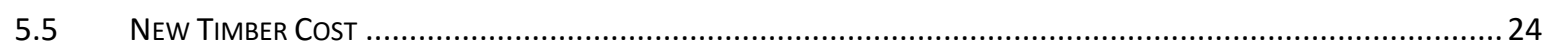

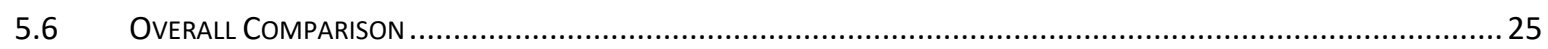

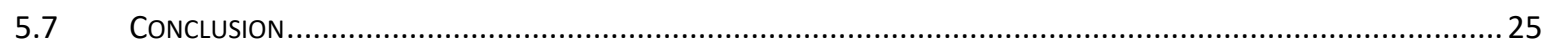

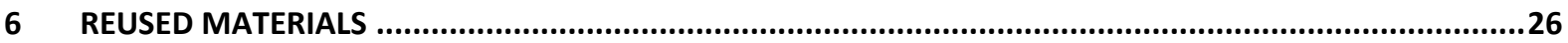

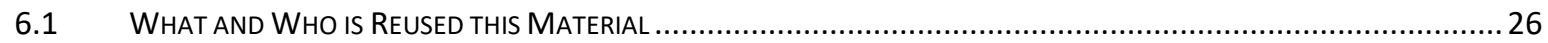

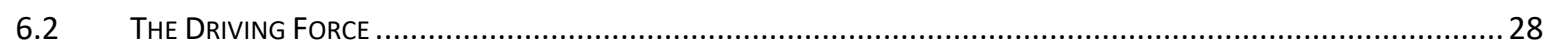

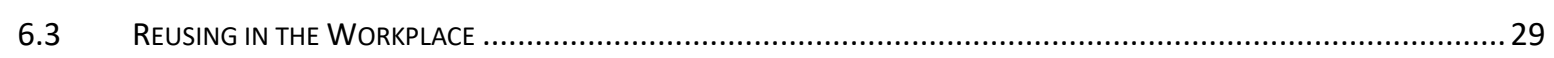

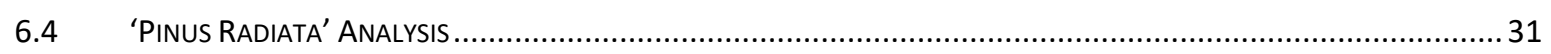

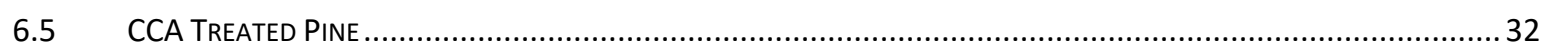

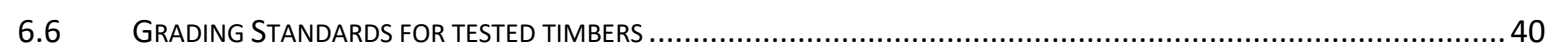

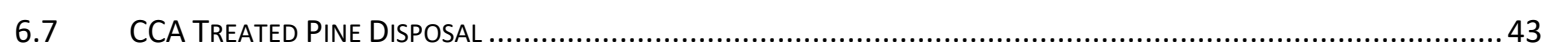

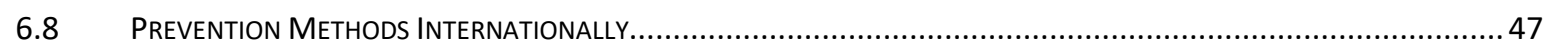

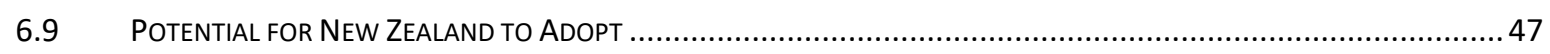

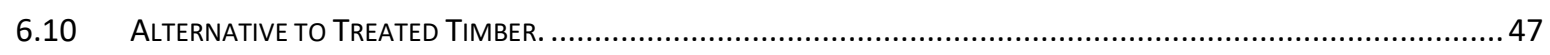

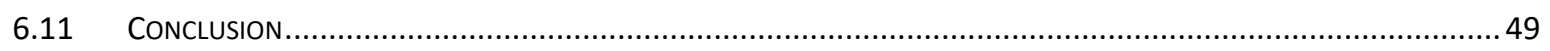

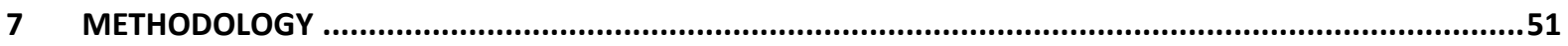

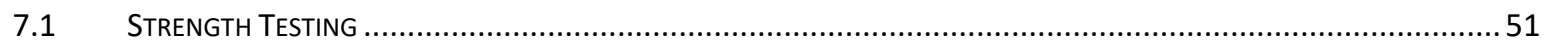

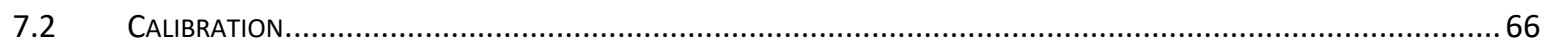

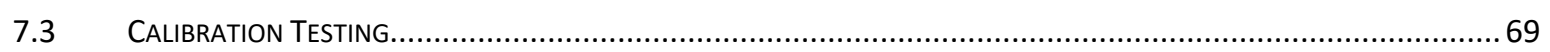

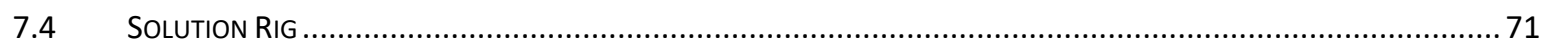

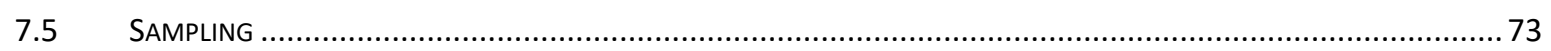

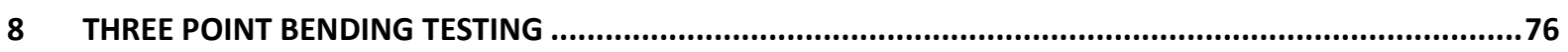

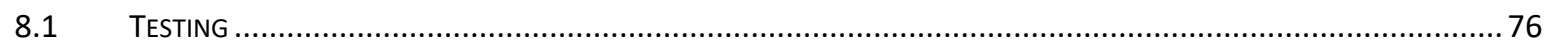

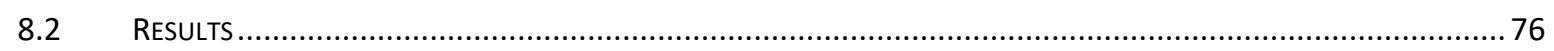

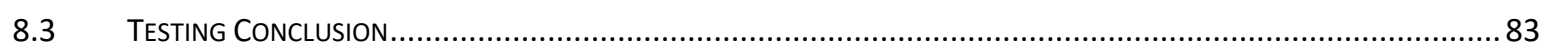

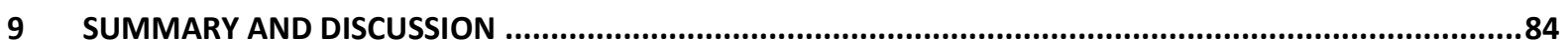

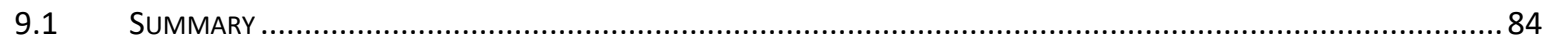

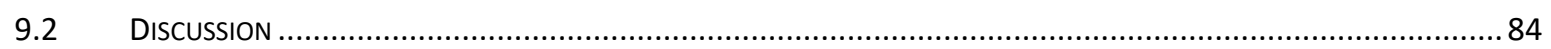

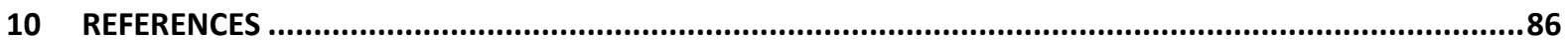

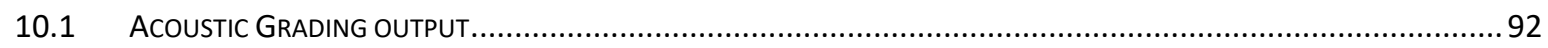

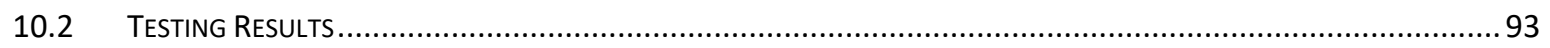

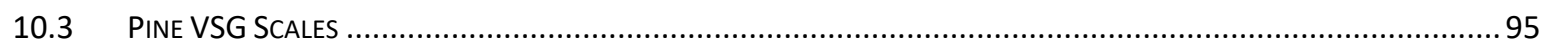

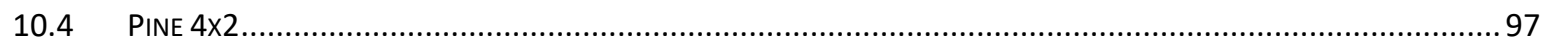


10.5 PINE $5 \times 2$

109

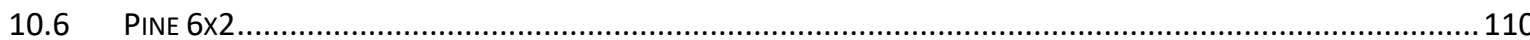

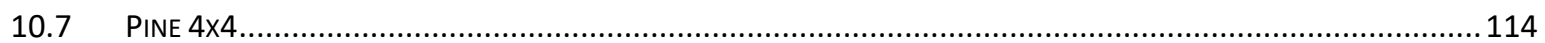

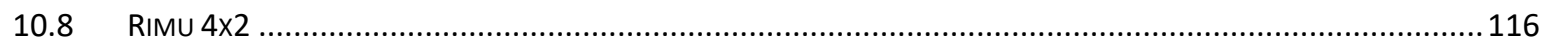

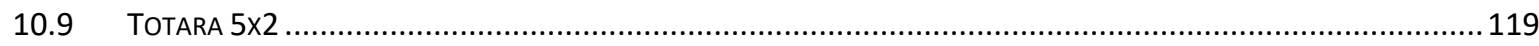




\section{Introduction}

In 2011 New Zealand threw away 2.461 million tonnes of waste into the landfill (Ministry of the Enviroment, 2012). If taken per capita this is 0.524 tons of waste per person in this country, including all the chemicals and other components of the waste product. All this product is then moved through the system of earth and water and is eventually released back into the surrounding environment and society. This leads to the underlying problem which is that 'waste is bad', but how can this thesis begin to solve this problem?

Construction and Demolition waste (C\&DW) contributes to 50\% of New Zealand's waste, with $26 \%$ dumped in landfills and the remainder dumped in clean fills ${ }^{1}$ (Inglis, 2009). This volume of C\&DW has increased from $17 \%$ to $27 \%$ between the years of 1997-2008 (Environmental Report Card, 2009). Following 2008, there is little to no accessible data released on the volumes of C\&DW being dumped in landfills or clean fills. If the previous trend continued the percentage could be as high as $37 \%$.

Recently, councils have been generating Waste Minimization reports to help slim down the volumes of dumping. The Auckland report states that $30 \%$ of the materials being dumped have the potential to be diverted from landfill (Auckland City Council, 2015). This suggests that a large percentage of materials have the potential for further use and that accordingly there is a large amount of unnecessary dumping.

One component of this dumping is copper chromium arsenic (CCA) treated timber. This material comes from a wide variety of different sources from power poles to stakes holding grape vines (Marston \& Singh, 2013). This material has been seen internationally as a hazardous material. To prevent usage, regulations have been put in place which withholds the material from being used in both Europe and the U.S.A (European Parliment, 2012) (U.S. Consumer Product Safety Commission, 2004). This international component does create a situation where this material is toxic and does need to be severally monitored when entering the landfill. These regulations bring to light new research which covers different treatment options allowing New Zealand to continue on using them.

An increasing problem with the excessive dumping is the large amount of chemicals going into concentrated areas (Zhang, Kim, Dubey, \& Townsend, 2017). Once this material enters landfills it does not biodegrade but leaches out all the chemicals which were initially applied to prevent timber

\footnotetext{
${ }^{1}$ Clean fills are similar to landfills but only accept inert waste such as earth and cement (Beca Carter Holling \& Ferner Ltd, 2002).
} 
degradation. These chemicals then find their way into the surrounding soil and water source, eventually finding their way into surrounding communities of landfill (Mercer \& Frostick, 2014).

Treated timber came about during a stage in construction which required the material to be much more durable. The main factor behind this change was the 'leaky homes' problem which New Zealand faced (NZ Parliamentary library, 2002). Although this did not begin the transition, it did enforce it through codes and compliance. Before, the industry was using untreated timber within residential construction. With the transition of water through poorly sealed holes in the cladding, the timber began to rot, which caused unhealthy diseases to form. This is when New Zealand government regulated CCA treated timber, which was used in all residential timber homes. As a result of this, the typical deconstruction practices of depositing timber into landfill are continuing with limited consideration of the impact of the newly chemically treated timber. This thesis is focusing on that disposal, using knowledge to prevent it, attempting to set up guidelines for its reuse through the codes and compliance regulations.

Moving back to the international codes of compliance, their ability to regulate this material has caused an increasing amount of research on the topic of treatment. This research which, if it hasn't already been used, could be used in terms of our treatment, and what our society is doing. This does go against New Zealand's government's attitude of "if it isn't broke don't fix it" which is causing difficulty in attempting to solve this problem. The regulation have not passed, and this material will be used in future builds.

CCA timber is also one of the largest components of landfill waste (Figure 1). Therefore reducing the amount of treated timber going to landfill will, in turn, reduce landfill waste and chemical accumulation by the largest amount.

This thesis is focused on the reduction of CCA treated timber into the landfill, doing this through the reuse of the material, which will be done through small deconstruction companies all over New 


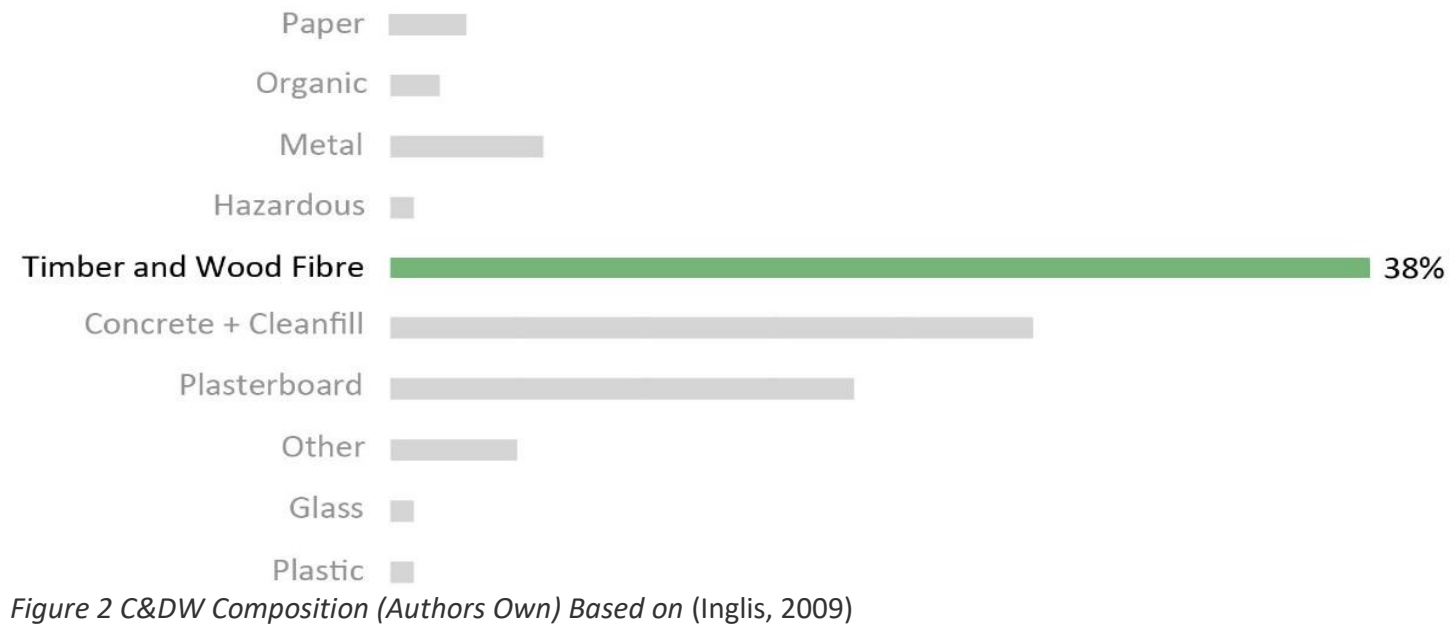

Zealand. To do this a question must be asked in order to begin to decipher the underline problem, and that is does the recycling of treated timber produce any profit in recycling companies? 


\section{Economics}

Economics is defined by the production, consumption, and transfer of wealth (Dictionary, 2017). When considering a natural product such as timber there are numerous problems due to the nature of its natural production.

Problems in this industry have come from workers not understanding the value of the materials that they come across. This value does vary around the country, but is inherently positive, and can be used to increase currency. Understanding this, society can begin to understand that not everything needs to be placed into landfill, and in particular CCA treated pine.

The problem which will be tackled in this section is to prove that the reuse of this material can be profitable. By demonstrating the profitability of reusing pinus radiata structurally it is hoped that this practice will become more widespread.

\subsection{Performance Criteria of Reusable Treated Timber}

To justify this thesis it refers upon work in a relevant economics study which covers a similar methodology. This method comes from a thesis by Van Tran at the Auckland University of technology. Tran talks about how Economics can be brought across into the real world, focusing on statistics and content analysis, all which follow along in this thesis (Tran, 2017).

The following section does not have any economic knowledge and is based off the knowledge of the building industry. This section outlines general understanding on what is being done, and how much of that small part of the industry is costing each individual person.

\subsection{Market Value}

New Zealand is a sustainable country, and therefore there may be a market for reused goods from construction and demolition sites. Market Value is the amount an asset would fetch at the marketplace (Investopedia, 2017). In terms of reused Pinus Radiata comes this down to who is reusing it, and how much they are selling it for. Each company which performs this task is bettering New Zealand and opens the door for the next stage of the material existence.

Underlying this is microeconomics, understanding how these individual firms are handling this product: finding whether or not they are selling it, and if so, what price is it being sold. This will give another point of reflection to base price off when it comes back to the sale of these goods. Sales which come from the small companies, as examples have shown in Figure 31. 


\subsubsection{Initial Contact}

To begin this process all the companies in Figure 2 were contacted via phone calls. All of these companies were asked about their interactions with pine, and whether or not their outfits recycled it. If so they were questioned on what price they resold at, whether or not it was de-nailed and what they thought about the treatment of the timber. This will be conducted for the companies shown in Figure 3. 


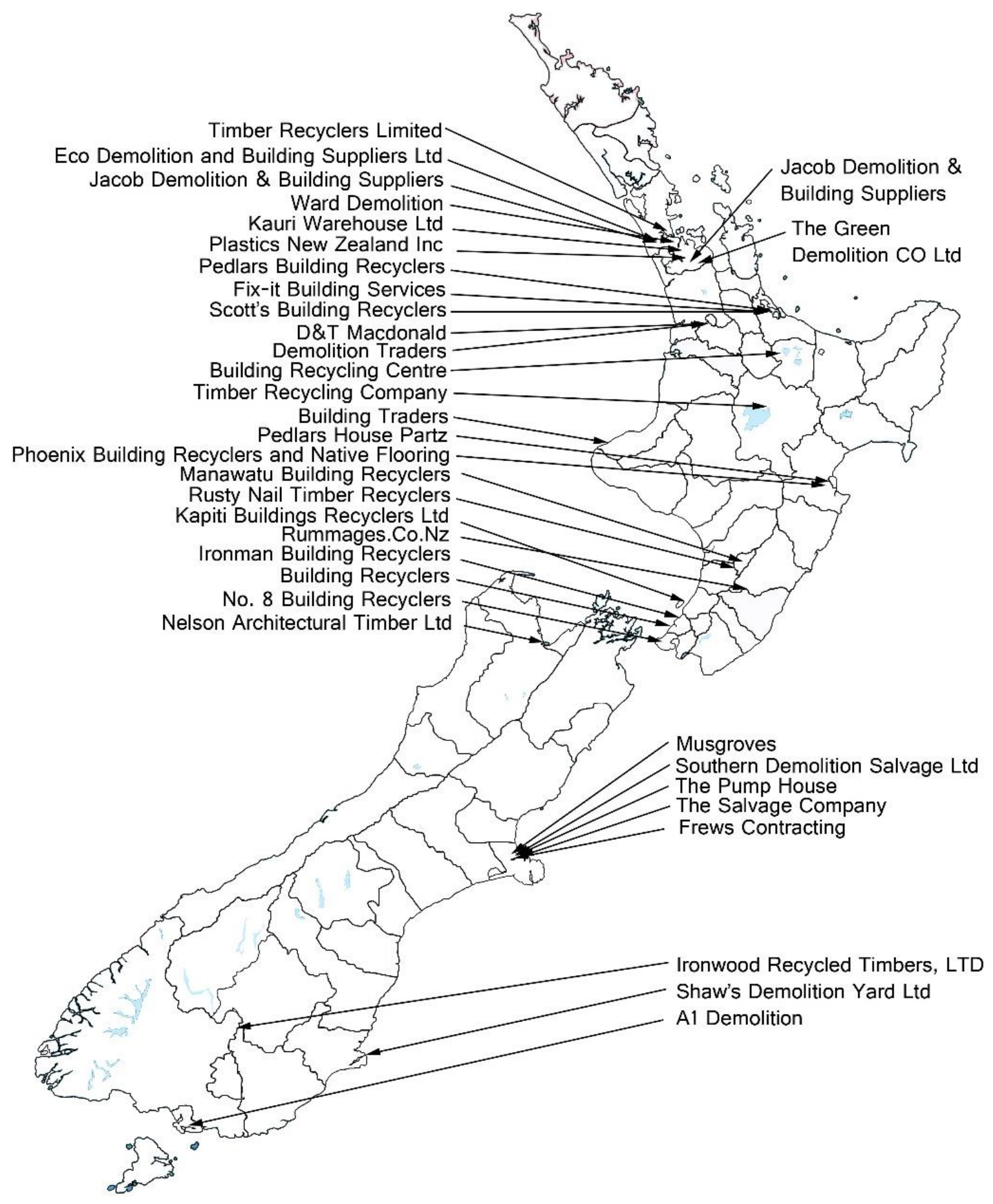

Figure 3 Demolition Yards over New Zealand (Googlemaps, 2017) 


\subsubsection{First Set of Results}

Table 1 Initial Phone Conversation

\begin{tabular}{|c|c|c|c|c|}
\hline Location & Company & Recycling Pine? & De-nailed? & Treatment? \\
\hline \multicolumn{5}{|l|}{ Auckland } \\
\hline & $A$ & $\mathrm{~N} / \mathrm{A}$ & N/A & N/A \\
\hline & B & No & No & No \\
\hline & & No - Space and the & & \\
\hline & $\mathrm{C}$ & economics of it & No & No \\
\hline & $\mathrm{D}$ & $\mathrm{N} / \mathrm{A}$ & $\mathrm{N} / \mathrm{A}$ & N/A \\
\hline & $\mathrm{E}$ & No & No & No \\
\hline & $\mathrm{F}$ & No & No & No \\
\hline & G & No & No & No \\
\hline & $\mathrm{H}$ & $\mathrm{N} / \mathrm{A}$ & $\mathrm{N} / \mathrm{A}$ & $\mathrm{N} / \mathrm{A}$ \\
\hline \multicolumn{5}{|c|}{ Tauranga } \\
\hline & 1 & No & No & No \\
\hline & J & $\mathrm{N} / \mathrm{A}$ & $\mathrm{N} / \mathrm{A}$ & N/A \\
\hline & $\mathrm{K}$ & $\mathrm{N} / \mathrm{A}$ & $\mathrm{N} / \mathrm{A}$ & $\mathrm{N} / \mathrm{A}$ \\
\hline \multicolumn{5}{|l|}{ Hamilton } \\
\hline & L & No & No & No \\
\hline & $M$ & Only New Pine & No & No \\
\hline \multicolumn{5}{|l|}{ Rotorua } \\
\hline & $\mathrm{N}$ & No & No & No \\
\hline \multicolumn{5}{|l|}{ Taupo } \\
\hline & $\mathrm{O}$ & $\mathrm{N} / \mathrm{A}$ & N/A & N/A \\
\hline \multicolumn{5}{|c|}{ New Plymouth } \\
\hline & $\mathrm{P}$ & $\mathrm{N} / \mathrm{A}$ & N/A & N/A \\
\hline \multicolumn{5}{|c|}{ Hawkes Bay } \\
\hline & Q & Yes $\$ 2.00$ a Meter & De-nailed & No \\
\hline & & $\$ 1000$ a cube cleaned & & Hard, but \\
\hline & & $\$ 2$ a meter uncleaned & & usually the \\
\hline & & $\$ 1.30$ for short uncleaned & & customer \\
\hline & $\mathrm{R}$ & $\$ 3.20$ for cleaned & Depends & sorts it out \\
\hline
\end{tabular}

Palmerston North 
Manawatu

$\begin{array}{lll}T & \text { No No No }\end{array}$

Kapiti
U
Closed Down
Closed Closed

Masterton
V
N/A
N/A
N/A

Wellington

$\begin{array}{llll}W & \text { N/A } & \text { N/A } & \text { N/A } \\ X & \text { No } & \text { No } & \text { No } \\ Y & \text { Yes-\$2.00 } & \text { No } & \text { No }\end{array}$

Christchurch

$\begin{array}{lllll} & & & & \text { No trouble } \\ \text { with }\end{array}$

It was found through the conversation had in Table 1 Initial Phone Conversation that the average price for reused pine is $\$ 2.00$ a meter. This price comes as a combination of de-nailed and nailed pine, as some company saw it as a hazardous material to be sold with nails in. The highest price sold was in Hawkes Bay, with one company selling reused pine for $\$ 3.20$, and the lowest price coming from Christchurch, which sold de-nailed reused pine for $\$ 1.80$. 
These two prices gives a spectrum for price to market this timber as in the future sales endeavours. Using it is easy to begin to gain understanding behind the price in which the material can be sold, and then working backwards to justify the stage of acquiring the timber.

\subsection{RECYCLED TIMBER COSTS}

The few companies which are selling this product state at an average price of $\$ 2.00$ per meter linear. Using this as an initial cost for this product, and then working backwards, an approximation can be made on the cost of generating it.

Table 2 First pricing audit

\begin{tabular}{|c|c|c|c|c|}
\hline \multicolumn{2}{|c|}{$\begin{array}{l}\text { Recycled Timber } \\
1 \mathrm{~m} \text { Length, ex } 100 \times 50\end{array}$} & \multirow[b]{2}{*}{ Labour } & \multirow[b]{2}{*}{ Total } & \\
\hline Process & Time (min) & & & \\
\hline Cleaning & 4 & $\$ 15.75$ & $\$$ & 1.05 (Employment New Zealand, 2017) \\
\hline Transport & 1 & $\$ 22.00$ & $\$$ & 0.37 \\
\hline Demolition & 1 & $\$ 25.28$ & $\$$ & 0.42 (Pay Scale, 2017) \\
\hline Total & & & $\$$ & 1.84 \\
\hline
\end{tabular}

Breaking down the recycling system into its three main components, cleaning the timber or (denailing), transporting it from the site and the demolition on the site itself on table 2 . These three processing stages will outline how the rest of this section will layout.

\subsubsection{Deconstruction}

When the concept of deconstruction is considered, it is important to understand the different scenarios in which this can happen. The first being a maximum reuse of all goods, which are removed from the building. Secondly, there is a maximum recycling scenario, and lastly there is the concept of soft stripping ${ }^{2}$, which is the removal of all goods which can be easily detached (Diyamandoglu \& Fortuna, 2015).

The economic factors of conducting this method involves a higher amount of skilled employees, and employees that have a better understand on how a building works. This is reflected in Table 2 with the price of a builder being input, rather than the price of a demolition who is much cheaper. This

\footnotetext{
2 The ability to move through a building dismantling all componentry which can be done easily and without little effort.
} 
price attempts to ensure that builders will remove the product with more care and will display a better understanding on how it all goes together.

\subsubsection{Transport}

Transporting this material does not change any usual application of this process. Although location dependent, the travel distance may increase, but this would be the case for any demolition job. Transporting the material now will be changed to moving material into working yards, rather than into landfill. There is a possibility for these yards to become moveable, in essence this 'yard' will be a few employees with access to a number of different de-nailing tools.

There have been situations in some companies who have gone out of their way to move the cleaning stage to their site. This has been evident when the demolition site is a large distance away from recycling site, and therefore only one truck is required to drop the large amount of material back (personal communication with company).

Unfortunately due to the transport industry being spread, it was difficult to find a price to associate to the work done. To compensate for this, transport was given $\$ 22.00$ in Table 2, which will cover all prices in that scenario. This is an assumed price, based around the timber being placed on the truck, transported and removed at the destination.

\subsubsection{Cleaning}

Once the material has been transported, there must be a cleaning of each length of timber. Some of the above companies have communicated that timber leaving their site must be cleaned, or else it is seen as a hazardous material (personal communication with company). This considers all reused timber as a currently hazardous material, but is open to speculation.

Auckland companies have been introduced to zero waste procedures, but as yet none have shown any ambition to use this reused material. This creates speculation on whether or not there is an ability to complete this highly difficult goal. In, Wellington, which has had a number of their news articles about their waste placement: again there is little or no effort to reuse or recycle this material. Christchurch has shown that through their traumatic experiences, through the earthquake, recycling companies can successfully reuse this material, and resale it.

Companies explain how their 'cleaner' have tools which make the process both quick, and stress-free. These processes (whatever they are) give a hope, and will change how all companies use there timber.

Cleaning timber is a particularly tricky job, both with the understanding of what is in the timber, to best practice when removing. Unfortunately there is more in timber than just nails, and cleaning this 
can vary based on what is found. Nail-guns have made recent building much more aggressive with the nailing, due to the ease in which the nail has been inserted.

Nail-gun nails also hold another instrument, which can hinder de-nailers, this being the adhesive which is applied to the nail. This adhesive is heated when application is made, and therefore the nail is not only held in by friction, but is also glued into place. This is the reason for some timber being extremely hard to de-nail, saving the appropriate lengths.

A part about this job is the lower pay rate in which is needed to fund the employees conducting the work. Their pay wage is minimum cost, and therefore more time can be spend conducting the task, as explained in Table 2 . 


\subsubsection{Resale}

Conducting this information against one another and also against the comparison generated in table 2.

Table 3 Cost Comparison

$\begin{array}{lrrr}\text { Companies } & \text { Cost } & \text { Comparison } & \text { Outcome } \\ \text { A } & \$ 2.00 & \$ 0.16 & \checkmark \\ \text { B } & \$ 2.00 & \$ 0.16 & \checkmark \\ & \text { Hirer price for clean material } & \$ 1.20 & \checkmark \\ \text { C } & \$ 2.00 & \$ 0.16 & \checkmark \\ \text { D } & \$ 2.00 & \$ 0.16 & \checkmark \\ \text { E } & \$ 1.80 & \$ 0.46 & \checkmark \\ \text { F } & \$ 2.00 & \$ 0.16 & \checkmark\end{array}$

The above cost comparison shows that all of these companies should be producing profit through their timber re-sale. Therefore this product is a profit producing item, and all industry should be conducting using it, De-nailed or not.

This is only examining the cost of reused against itself. More analysis is required by others, outside the scope of this thesis, going through the cost that is needed to dump the product, and also the cost of new product which will all be compared to the reused product.

\subsection{DUMPING COST}

In the current New Zealand society, the easiest solution to this problem is to place it into landfill and forget it. Even at an economic point of view, this is considered a positive.

Table 4 Dumping Cost Analysis

\begin{tabular}{lrrrrr} 
Demolition & \multicolumn{7}{c}{ Labour } \\
Process & Time $(\mathrm{min})$ & \multicolumn{2}{c}{. } & $\$$ & 0.18 \\
Demolition & 0.5 & $\$$ & 22.00 & $\$$ & 0.37 \\
Transport & 1 & $\$$ & 22.00 & $\$$ & 0.35 \\
Dumping & N/A & $\$$ & 155.00 & $\$$ & 0.90
\end{tabular}

The above table 4 outlines an approximation of all the costs which are associated with the dumping of C\&D waste. These costs come with the assessment of costs associated with the dumping of waste. 
These cost compare with Table 2, and use the transporting cost which was estimated for the transport agent.

\subsubsection{Demolition}

While often a building may have been sitting derelict for years, when the order to demolish finally is given, the timescale is unfeasibly short, and the quickest response is total destruction. Dumping all the materials, without salvage, if longer demolition timeframe could be negotiated, better recycling outcomes could result.

An example of such a time scale, is that one of the interview companies demolished 50 house in 50 days. This company understood how important it was to look for some areas in which cost could be salvaged. Therefore each house had the top storey removed through the use of a house moving trucks trailer, and replaced into a yard for resale. These homes have all the requirements for a new home, and all that is required is a new foundation. Undoubtedly the house could be demolished faster, but due to how these companies run, no improvement would be made.

Building on this basis of time related to work output, if the government was able to give more money to this fund, then the house could be deconstructed and waste could be resold for future homes in the relevant communities. The cost of doing this may be higher in comparison to what is already being spent.

\subsubsection{Transport}

The transport of this material will be completely dependent on site related locations. Therefore the builder must evaluate how this material is being transported, and how this could affect cost related issues. In terms of how this type of truck works, the difference will be in loading and unloading, as demolition is often reliant on a digger to simply pick up the objects and dump it in the demolition truck.

This digger truck scenario does not require much time or man power, and all the houses can be demolished in this way. The difference is when demolition is done, there is no requirement for the salvage of equipment, and therefore things can become broken.

\subsubsection{Dumping}

Dumping is the word used to describe what this thesis is attempting to prevent, which is the needless sense to place all waste directly into landfill. The act of dumping has a number of different costs associated with it. The average cost as associated with landfill is around $\$ 155$ a ton, this cost covers most New Zealand landfills (Denne \& Bond-Smith, 2012). Due to all sort of influences, New Zealand landfills have different prices depending on their location in the country. 
Although the above price was generated in 2012, and therefore there must be some changes in which have affected the pricing. In the report it forecasted that Westland was changed from $\$ 366$ up to $\$ 460$ (Denne \& Bond-Smith, 2012).

\subsection{NeW TIMBER COST}

It is always important to understand how new timber is placed into the construction industry. Through the use of Logs, and sawing them into the right size dimension lumber. This is all tested and the appropriate strength grading is applied to the timber.

\subsubsection{Sale Price}

Taking the cost of logs in New Zealand of $\$ 0.53$ (Ministry for Primary Industry, 2017) and then directly comparing that to the retail price of $90 \times 45 \mathrm{~mm}$ timber at $\$ 6.75$, it is clear to see that there is a lot of price unaccounted for. These price come from the sawing, treating, drying, transport of the timber and retail mark-up.

A thorough break-down of all costs also created with new timber relay is difficult due to the confidential and higher competitive timber industry. However, some info can be deduced from finished retail prices as found in a typical timber wholesale/ retail in 2017.

Table 5 Bunnings Prices on New Timber Sales (Bunnings Warehouse, 2017)

\begin{tabular}{|c|c|c|c|c|c|c|c|c|}
\hline New & & Strength & & & & & & \\
\hline Timber & Size $(\mathrm{mm})$ & Grade & Treatment & Wet - Dry & Pric & & & ers Price \\
\hline & & & & Dry & & & & \\
\hline Pukepine & $90 \times 45$ & SG8 & H3.2 & Gauged & $\$$ & 6.75 & $\$$ & 5.06 \\
\hline & & & & Wet & & & & \\
\hline Pukepine & $90 \times 45$ & SG8 & H3.2 & Gauged & $\$$ & 6.28 & $\$$ & 4.71 \\
\hline Carter Holt & & & & & & & & \\
\hline Harvey & $90 \times 45$ & SG8 & H3.2 & Kiln Dried & $\$$ & 6.75 & $\$$ & 5.06 \\
\hline & & & & Dry & & & & \\
\hline $3.6-4.2 \mathrm{~m}$ & $90 \times 45$ & SG8 & H3.2 & Gauged & $\$$ & 6.75 & $\$$ & 5.06 \\
\hline $3 m$ & & & & & & & & \\
\hline Framing & $90 \times 45$ & SG8 & H3.2 & Kiln Dried & $\$$ & 6.75 & $\$$ & 5.06 \\
\hline
\end{tabular}




\subsection{Overall Comparison}

Table 6 Overall comparison from pricing based on $90 \times 45 \mathrm{~mm}$

$\begin{array}{lccc}\text { New Lumber } 90 & \text { Pedestrians Price } & \text { Builders Price } & \text { Dumping Price } \\ \text { x 45mm } & \$ 6.75 & \$ 5.06 & \$ 0.90 \\ \begin{array}{l}\text { Reused Product } \\ 90 \times 45 \mathrm{~mm}\end{array} & \$ 2.00 & \$ 2.00 & \$ 2.00 \\ \text { Comparison } & -\$ 4.75 & -\$ 3.06 & \$ 1.10\end{array}$

Looking at all the costs assumed on this document, it is clear to see the all the timber sold from the above analysis conjoined at an appropriate cost. This all comes down to how the yard's are selling the products, which could be done in a more uniform way. Imagine if Bunnings or someone of that calibre sold it in their yard, what that would do to the new timber market.

\subsection{CONCLUSION}

Overall the cost of reusable timber needs to comply with a profitable sales objective; one which is being conducted in some of the contacted yards. The cost of this material is well below what is being sold, unfortunately the dump cost is still less. Now, this material must face the fact of who is reusing it, understanding that for this all to happening someone must be conducting the material through the stages of life.

Clearly the entire subject of material re-use in the construction industry is heavily reliant on the economics of slower and more carful demolition. Without financial incentives the reuse scenario is still highly reliant on the motivated individuals and companies with a wider world view. This may, or may not, change in the future. 


\section{Reused Materials}

Reuse and recycling are not new subjects in the construction industry. In recent years the landfill has become a major problems, as economically disposing materials is much more time efficient than reusing it. This blatant disregard for material use has formed the wasteful nature that surrounds the construction and demolition industry in its current position in society.

Before the process of mass landfill was instituted, materials which held their value would have been reconstituted and then reused in other buildings due to the high manufacturing cost. Now, after the industrial revolution, all construction materials can be produced for a mere fraction of their resale value. This has caused re-use to become almost obsolete, and therefore this has slowed the re-use of construction and demolition materials. The problem of reusing materials has become an often unprofitable practice. The only materials being reused are those with high resale value and durable natures, such as native timbers, and copper components. As shown in the graph below, the timber that is re-used/ recycled is Mainly Native timber (Mostly Rimu) and is often machined and used as separate timber products.

\subsection{What AND Who is ReUsed this Material}

Considering the low amount of re-using that is being conducted in New Zealand, it can be simply ascertained as to what is being reused, where it is being reused and who is reusing the products.

\subsubsection{Trademe}

The first place to consider is Trademe ${ }^{3}$, which holds over 1000 different listings under the search term "recycled buildings" (Trade me, 2017). Trademe's database holds the most practical listing, as all building supplies are of the directly reused kind. Each option has been removed from a site, photographed and placed on the website in the hope of producing profit for the seller. This reflects the defining concept which creates the object for sale: the desire for profit. As using the Trademe website incurs a relatively low cost to sell, the turnover can be relatively high particularly when the products being sold would otherwise be in landfill.

\footnotetext{
${ }^{3}$ Trade me is an online database for local New Zealanders to sell or buy items or things of value, companies are also run on trade me due to the much broader buyer community. http://www.trademe.co.nz/.
} 


\begin{tabular}{|c|c|c|}
\hline SEARCH: & RECYCLED BUILDINGS & \\
\hline \multirow[t]{16}{*}{ NARROWED: } & \multicolumn{2}{|l|}{ Buildings and Renovation } \\
\hline & Product & Amount of listings \\
\hline & Building supplies & 346 \\
\hline & Doors windows and mouldings & 334 \\
\hline & Heating \& cooling & 87 \\
\hline & Other & 42 \\
\hline & Portable buildings & 33 \\
\hline & Carpet, tiles \& flooring & 30 \\
\hline & Bathroom & 28 \\
\hline & Painting \& wallpaper & 27 \\
\hline & Tools & 26 \\
\hline & Kitchen & 24 \\
\hline & Electrical \& lighting & 17 \\
\hline & Plumbing \& gas & 13 \\
\hline & Fixtures \& fittings & 10 \\
\hline & Total & 1017 \\
\hline
\end{tabular}

Table 7 Trademe product amounts (27/07/2017) (Trade me, 2017)

Table 7 shows the amount of listing accounted for when Trademe is used as a search engine. With the top term "Building supplies" referring to main product such as timber and corrugated iron, products which are easily removed cleaned and resold for a financial gain. Within this section the largest subcategory of "Timber" holds 219 separate listing. This begins to identify what the largest category is located, and also the largest area for profit to be made.

\subsubsection{Trademe Conclusions}

Trademe explain how much reuse is being considered in the construction and demolition industry. Although this tool does not give help with who is buying the product as Trademe does not release buyer and seller information, due to commercial sensitivity.

Trademe is useful due to most recycling companies placing their products on there. Although numerous products are not placed on the website this is a reflection on the amount of materials which companies dispose into landfill (personal communication with company). Materials which could have another life, and could be reuse in the construction industry have not had the attempt to resale, and therefore are just waste. 


\subsubsection{Recyclers}

This is mostly done through specialist recycling companies, which can hide in the confines of other industry such as contracting (personal communication with company). These industries span the nation, varying in size and stock quantity, with some focusing on windows and doors, and others focusing on timber and joinery. These companies hold a corner of the market, which could be seen to grow rapidly in the near future.

This corner conducts its business through the addition of stock through demolition and construction companies. This comes from their operations: the pulling down of buildings or the construction of new ones. Some recycling companies have the addition of materials from sawmills which have conducted work which did not sell. All of this is in essence how these companies work, some have been built from the original demolition companies as a point of sales for the surplus stock.

The overall problem with the recycling companies is the lack of communication between them. There is a large amount of these companies, which are all holding different materials and in turn selling the materials at a different cost. This places confusion on the entirety of the market.

This is not helped through each member of society being able to bargain with a lot of materials in some of these yards. This places even more pressure on the pricing behind the materials.

Figure 3 shows the distribution of building recyclers in New Zealand. Mapping this data over New Zealand shows that most of these industries are concentrated in the North Island. Whilst the South Island still holds a few, they are more widely distributed across, and will not hold a similar quantity of materials. It is safe to assume that these companies are conducting the majority of all building recycling, with a few extra recyclers not notified on Google.

This comes back to the problem notified above that not all recycling goes through public information directives. This information can only be gathered through contacting these specific individuals, and asking what is happening. Unfortunately due to the time delays this is not a part that this research can conduct. There needs to be an understanding on what is driving this reuse.

\subsection{The DRIVING FORCE}

In any industry there is always one main driving force behind the decisions that are made, and construction and demolition runs on money. It is easy to see how money can be made in the recycling industry: the owner of Phoenix Contracting stated "that there is money in junk" (Walmsley, 2017a). Mike Walmsley has just bought out one of the other major recycling companies in Hawkes Bay, and 
now holds the largest yard in the region, which has a steadily increasing profit region, allowing for the hiring of a number of extra individual staff.

Unprofitability may cause rash decisions to be made about materials. Materials could become profitable with the help of a decent sales process. The process which enable native timbers to be so profitable, could be transferred into other CCA timber products which are not currently used in the reuse industry. This process requires the use of minimum wage workers who move through each length of timber cleaning all nails and other debris out of the material or cleaning it (Walmsley, 2017b).

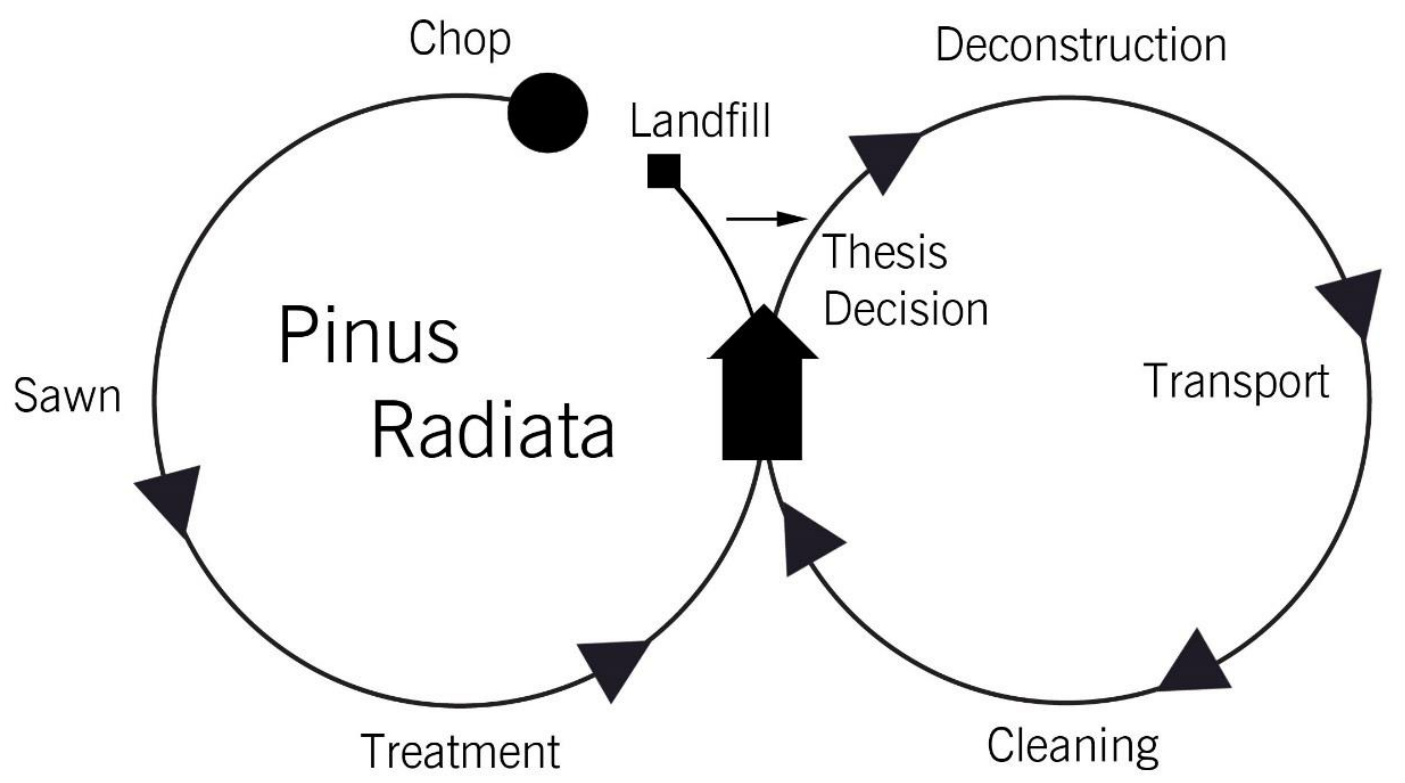

Figure 4 Thesis Model derived from the above information

As explained in Figure 4, this figure 8 system runs off the original circular system. As the above paragraphs suggest this system can be generated through adapting the cycle used for timbers like Rimu. This is explained above in three steps: deconstruction, and transport and cleaning. These three steps can be used where upon clean usable Pine will be generated.

\subsection{REUSING IN THE WORKPLACE}

A common misconception in the building industry is that the act of reuse is a recent development. This in incorrect, as reusing materials obtained from previous buildings is something which is as old as construction itself. An early example of this reuse is in an ancient Egyptian society with all stone being 
reused from previous buildings. This reuse was done due to the high cost of the generation of this material, with trade and transport being a much more sought after trade (P. Brand, 2010).

This relatively simple system was adapted throughout the years with different civilizations and social groups adapting it for their own needs. For example in the slums of India where houses were constantly under construction due to their owners finding materials and building on, even to the extent of leaving roofing areas open for higher floors to be added on at later dates (S. Brand, 2009). This intuitive design has created its own architecture, with the creation of incremental housing. This architectural concept builds houses with the idea that additions can be added with little structural work needed to be done to the building (Lizarralde, 2011).

This has helped create informal settlements (slums) as nearly all materials being used have been sourced locally and reused from surrounding construction sites. Informal settlements all over the world rely on informal acquisition of building materials: there is little profit in it for major corporations.

\subsubsection{Reuse Development}

This train of development from Egyptian stone temples, to slum buildings, has gone through many different organic transitions. These transitions have happened due to the need for housing, often arising in areas of the world not heavily controlled through codes and compliance. It is understandable on why these codes are in place in NZ, as they control the safety inside buildings and reduce liability, but they also stop the development of organically developed buildings.

In today's technologies and developments, there have been a number of clear problems with the issues of reuse. Codes and compliances have withheld this development, and throughout New Zealand's history have only been changed through outside effect. For example, the 'leaky homes' situation, which changed a number of the codes and compliance regulations around the treatment levels and locations.

\subsubsection{Reusing Treated Timber}

Currently in New Zealand there is only a small amount of reuse with this material, which is mostly through companies using it inside their own construction projects (Walmsley, 2017a). CCA treated timber has the potential to generate numerous options in construction. But to conduct this material back into the workplace there must be a clear understanding on what it is, what is in it, and how it is environmentally unfriendly. 


\section{4 'PINUS RADIATA' ANALYSIS}

Over the world there are 127 different species of pine. These species are all different sizes, coniferous, evergreens, with different characters New Zealand has applied focus primarily on pinus radiata, as the predominant (95\%) exotic planted timber species, which is a tall thin very fast growing pine tree, and gives excellent potential for usable timber.

With the understanding of the hazardous nature of CCA treated timber, it is important to understand what happened to create a situation where this treatment was necessary. Pine trees originating in the Northern Hemisphere in North America. This tree was immediately recognised for its timber producing abilities, as it grew straight long and fast (Thomas, 2000). Due this unique aspect, the seeds were transitioned to New Zealand in 1859 . These trees were to be the starting point of the New Zealand quick growth forestry (Forestry, 1994).

\subsubsection{The Product}

'Pinus Radiata' was large-scale planted firstly in 1896. It was not until the importation in the 1930's from Washington State, were the large-scale plantations understood (Forestry, 1994). This timber soon overtook the only competitor, Douglas fir, as the much higher profit rates were available due to faster growing times of pinus radiata. This being due to the better cash flow generated through the shorter rotation length.

Once the main planting were established and the product began to emerge, a competent research department was needed to study the practice. This came in the form of the forestry division of government, currently "Scion" department. Scion has been conducting research out of Rotorua for a number of years, changing its name from Forest Research Institute (FRI) to Scion in 1992 (Scion research, 2017). The introduction of this industry made New Zealand a leader in industrial production of forestry (Elspeth, 2013).

New Zealand has always exported its timber since the seeds arrived, as even before pine export New Zealand sold their native Rimu trees. This ended in a situation where Rimu trees needed to be protected due to rapidly reducing forests. This is when the concept of the fast growing straight pinus radiata tree came into action. Taking over the original Rimu tree in the forestry sector, allowing for more sales and a large profit margin. After this realisation, New Zealand has brought our forest to $95 \%$ pinus radiata, allowing us to sell more and make more (Jayawickrama \& Low, 1999). 


\subsubsection{Product Developments}

With a naturally grown product there is a lot of opportunity to make adjustments to the trees growth. This will adjust the trees initial growth, and has been done through the use of trimming and cloning trees.

The development that Scion was conducting investigated the cloning of the 'best' ${ }^{4}$ trees. The cloning was done to increase the structural properties of the trees, and thus increase the usable timber once milled (Burdon \& Harris, 1973). This research created accelerated trees with optimum strength for the construction industry. This was done through the forestry industry locating the densest tree, from the seedlings planted in 1927. Taking this tree and cloning it in vast entire orchards, which again were picked through to find the largest, fastest growing specimens (Eldridge, 1982).

This selective specimen seeding created large trees which were unfortunately not particularly durable (Dubey, 2010). These larger specimens provided much larger cells, which was a product of the fast growth. The lack of durability created the need for CCA treatment to need to be introduced into the market. As without this chemical treatment the material would not last the required amount of time specified in codes and compliance (Shelton \& Beattie, 2011).

\subsection{CCA TREATEd PIne}

Treated timber was created to make pinus radiata more applicable in the construction market. Due to the quick growth time, this timber is not durable, and does not last the necessary time set out in codes and compliance (50 years) (Department of Building and Housing, 2010). Couple this with the doubt placed onto the construction sector through the 'leaky homes' situation, and you have a situation which needs solutions.

Industry, led by Scion, faced a problem. Fast growing trees, capable of being harvested at 20-30 years, were not achieving required durability levels. The large cell side in the quick growth years meant that the trees were susceptible to rot and fungal decay. Decisions was taken to chemically treat the timber, to gain durability.

This justification has been the largest issue with this material, as no commercial entity really wants to change something which has been working well in industry. This thesis does not want to prevent the material, but instead allow its reuse in more than one way.

\footnotetext{
${ }^{4}$ The 'best' tree, grew the quickest, and would generate a number of separate trees which could do the exact same.
} 
Treated timber came into existence in New Zealand during the 1950's with a process known as tantalization, but the spread of this material did not happen until late 1960's (Read, 2003). This late spread was due to New Zealand still using native timber to build houses. This native timber (at the time) was much cheaper than the new treated timber, therefore was still used more acceptingly in construction.

Treated timber will not become a problem for New Zealand until around 2030, due to the insertion rate, and therefore the forecasted exit. But when this time comes, there will be a large amount being trucked to the landfills surrounding this country. Depositing the hazardous material into the ground, and water source surrounding these areas (Read, 2003). This will create problems, there is no possible way to concentrate such a large amount of arsenic and expect it not to have any affects.

Landfills are nothing more than the location for many hazardous chemicals, and in those chemical is arsenic. Arsenic is a by-product of the decomposition of treated timber. This leaves these landfills with a product that is harmful to the environment, and will leach throughout the surrounding lands.

\subsection{1 'Leaky Homes' issue}

'Leaky Homes' cause New Zealand to rethink its timber use, and in turn created the strong demand for treated material (NZ Parliamentary library, 2002). Due to the issue of moisture penetrating buildings, this caused the untreated timber framing the house to be more susceptible to mould. This mould created some issues with home member's health which caused major problems.

\subsubsection{Cause}

The 'Leaky homes' crisis was a combination of many factors such as the use of untreated timber, the relaxation of standards around kiln-dried timber, the reduction of training in the workforce, the introduction of different claddings, the disband of ministry of works and the apprenticeship scheme, change in details, more variety in building style, different windows, increasing insulation, and decreasing ventilation inside walls. This formed the perfect storm. With all these factors, homes all around New Zealand became infected by fungus and occupants began to become sick (NZ Parliamentary library, 2002).

Cause all follows along the idea of risk, and were that risk came from. This was both the problem with the buildings as it was with the architect who designed the building, without the consideration of the materials that were being used (Murphy, 2010). This is one of the reasons that solving this issue became so difficult, as all member, found a way to point the blame direction elsewhere. 


\subsubsection{One of the Solutions}

New Zealand in the mist of this problem came up with an appropriate solution. One of these solutions used one of the most hazardous chemical treated compounds copper chromium and arsenic (CCA). This material worked, resisting all the degradation components it came into contact with. This was due to the chemicals infused in the timber. Copper was the main resistant while arsenic resisted all fungicide that are immune to copper. Chromium was used to bind it all to the material.

The issue was not so much the material but with how it is typically disposed of in New Zealand. Disregarding that problem, CCA did solve the issues taking place in New Zealand homes, creating a material which will not rot even when moisture is introduced.

\subsubsection{Location in Use}

Again similar in understanding why CCA is being used in industry, it is equally good to understand where it is being used. NZS:3602 sets out the guidelines for treatment in timber products during the construction period (Standards New Zealand, 2003). 


\subsubsection{Treatment Types}

When New Zealand treats timber, there are numerous options in use, in different amounts. This document focuses on all treatment area which "could" contain CCA, and assumes that they have, thus allowing the location of this timber to be diagnosed.

The $\mathrm{H}$ is a representation of the hazardous level that each timber member is at. This level of identification gives a clear understanding on what each member is in terms its hazardous level. This all leaves the New Zealand builder with a hazardous material to put up around the country.

Table 8 Treatment Levels for Timber in New Zealand Construction (BRANZ Limited, 2017)

\begin{tabular}{|c|c|c|c|}
\hline $\begin{array}{l}\text { Hazard } \\
\text { Level }\end{array}$ & Why It is Treated & & What is used for \\
\hline $\mathrm{H} 1.1$ & $\begin{array}{l}\text { Where there is no risk of } \\
\text { dampness but borer protection } \\
\text { is required }\end{array}$ & CCA & $\begin{array}{l}\text { Interior joinery such as door frames, } \\
\text { stairs, architraves, skirtings and } \\
\text { cornices, built-in or freestanding } \\
\text { joinery items (excluding timber } \\
\text { window reveals and frames) }\end{array}$ \\
\hline $\mathrm{H} 1.2$ & $\begin{array}{l}\text { Where there is moderate risk of } \\
\text { dampness or water }\end{array}$ & Not CCA & $\begin{array}{l}\text { Structural framing timber including } \\
\text { subfloor framing (excluding piles) }\end{array}$ \\
\hline $\mathrm{H} 2$ & Exported to Australia & & \\
\hline H3.1 & $\begin{array}{l}\text { External use with a three-coat } \\
\text { paint finish to protect from } \\
\text { direct wetting of timber }\end{array}$ & $\mathrm{CCA}$ & $\begin{array}{l}\text { Fascias, weatherboards, facings and } \\
\text { other painted trim requiring a not less } \\
\text { than } 15 \text {-year durability } \\
\text { Exterior joinery and timber reveals for } \\
\text { aluminium windows } \\
\text { Timber cavity battens }\end{array}$ \\
\hline H3.2 & External use & CCA & $\begin{array}{l}\text { Cantilevered enclosed deck joists and } \\
\text { associated framing (joist trimmers, } \\
\text { nogs, dwangs and blocking), decking } \\
\text { and outdoor structures, rafters } \\
\text { exposed to the weather, uncoated or } \\
\text { stained radiata pine weatherboards } \\
\text { and trim, fence rails and palings }\end{array}$ \\
\hline $\mathrm{H} 4$ & $\begin{array}{l}\text { In contact with ground or } \\
\text { concrete }\end{array}$ & CCA & $\begin{array}{l}\text { Fence posts, horizontal timbers for } \\
\text { retaining walls }\end{array}$ \\
\hline
\end{tabular}




\begin{tabular}{|l|l|l|l|}
\hline H5 & $\begin{array}{l}\text { In contact with ground water or } \\
\text { concrete }\end{array}$ & CCA & $\begin{array}{l}\text { House piles and poles, crib walling, } \\
\text { retaining wall poles }\end{array}$ \\
\hline H6 & $\begin{array}{l}\text { In contact with seawater or } \\
\text { estuarine ground water }\end{array}$ & CCA & Wharf piles, sea walls \\
\hline
\end{tabular}

Applying this concept allows this problem to be explained in full, showing all locations which have this problem to be outlined in Table 8. NZS 3602 breaks down the building, focusing some points on those which were created through the 'Leaky Homes' problem. These include monolithic cladding, and how the timber behind it should be treated to again prevent the rotting of timber (Standards New Zealand, 2003).

In this section there are many other treatment options, which New Zealand is beginning to bring in the construction industry. These different chemical all do similar effects to CCA, but are not used as much as they should be. Listed below are the chemicals and their apparent properties.

- Boron - Throughout the timber industry, boron has been used for the lower treatment areas such as H1.2. But even this 'natural' product holds protection notes such as do not burn it, and do not use it for garden mulch for an obvious fear of death or injury. It is also used in situations were H3.1 is considered, focusing on external joinery, weatherboards (Zealand, 2018).

- Copper Azole - This treatment is useful in the areas of $\mathrm{H} 3.1, \mathrm{H} 3.2, \mathrm{H} 4$ and $\mathrm{H} 5$, all situation with heavy decay. This Treatment differs from CCA, as it does not contain the chromium and arsenic, two of the ingredients which are harmful. This contains triazole fungicide (tebuconazole), which will kill all the fungi's attempts to degrade the material during its use (DZ 3640, 2017).

- Propiconazole/tebuconazole/permethrin (PTP) - Again this alternative to the CCA treatment is useful in situation for H1.2 and H3.1. This treatment option also contain azole, which is what the above treatment option includes.

- Light organic solvent preservatives (LOSP) - Is a combination of the above treatments, and focuses on H3.1 and H3.2. These solvents all complete the preservative class that CCA does and all show respectable results (DZ 3640, 2017).

Even with the above treatment options there is little information released on what the saw mills are currently treating with. This slows down the idea with what treatment level to focus the effort into. 
This thesis has focused on H3.2, which is used in the structural walls of buildings. But due to how New Zealand treated in recent years it will be difficult to conduct this without the correct markings on the material.

Timbers are now marked using colour to represent how hazardous they are. Pink indicates timber treated with boron and is currently used in the industry. Green indicates CCA treated timber, with this one shade representing all CCA treated timber regardless of how heavily treated the timber might be (BRANZ Limited, 2017).

\subsubsection{Degraded Timber}

'Leaky Homes' demonstrated to the New Zealand public that problems were not limited to buildings that were not up to regulation. Buildings that meet all the specified standards were still vulnerable. These problems mostly come from toxic mould which can cause harm in human health. The risk of houses causing harm to their occupants justified the use of treating timber with hazardous substances such as CCA.

There are many different types of mould which can grow inside a homes, but the toxic one typically seen in New Zealand houses is Stachybotrys chartarum (S.chartarum). This mould grows in areas which have become warm and damp and then remain in this state over a long period of time. However this dampness does provide some protection as during the mould's growth it is covered in a thick wet slime which traps the spores. Only when the environment is dried out and has begun to be removed will the spores become airborne and begin to cause respiratory problems among occupants (Building Performance, 2018).

When these spores become airborne the effects on the occupants include allergies, aggravation of respiratory problems, eye and skin irritation, headaches and nausea, and flu-like symptoms. All of these problems can interfere with the occupants daily routine and potentially have severe consequences on their health (Building Performance, 2018).

Mould also has the potential to weaken the building's structure through infecting the timber and causing warping and other timber failures. This warping is even more likely to occur if the timber framing remains damp for long periods of time and may potentially cause other problems in the process ("Moisture and Mold in My Home," 2018). This is why the eradication of mould from a building is a good idea, and hence, why building durable, leak proof, rot-resistant buildings is a central aim of NZBC. 


\subsubsection{Chemical compounds}

To gain the full understanding of the material, it must be broken down, and each component looked at separately. Although all these materials are organic to the environment, concentrating them in a natural material can cause problems. This is then further exacerbated when that material is concentrated in a landfill, which will cause problem with the surrounding environment.

Table 9 Chemical Breakdown of CCA formulations (Read, 2003)

\begin{tabular}{|l|c|c|}
\hline Element & Class 1 & Class 2 \\
\hline Copper sulphate & $23-25 \%$ & $20-30 \%$ \\
\hline Chromium hexavalent & $43-47 \%$ & $25-47 \%$ \\
\hline Arsenic pentoxide & $30-32 \%$ & $30-50 \%$ \\
\hline
\end{tabular}

\subsection{Copper/Chromium}

To begin this breakdown the focus has been drawn to Copper, and it's potential to divert most of the bacterial mould that could grow. Copper shown in Table 9, is the lowest chemical compound, and one which does not harm the environment as severely as some of the other compounds. Copper has been used internationally to prevent water entering properties. This creates a situation as most builders are familiar with the product, and have the ability for installation (Read, 2003).

Copper has been an integral part of Architecture over the years, this element, when polished, is a visually pleasing brown. Copper is also heavily used in services, being used in wiring throughout the homes. It wasn't until after this that it became an important part of treated timber, where it is used (European copper in architecture, 2006).

Chromium is another chemical added to the salts, although this chemical is not for preventing mould. Chromium acts as a binder for the other two materials, holding all together upon entry into the timber material. Through this strong bond, these chemicals can hold in the material for the introduction of moisture, and will resist mould.

Chromium is also another chemical with the potential to harm humans who come in contact with it. This substance has the potential to cause harm through lung cancer, irritation and damage to the nose throat and lungs and also irritation and damage to the eyes and skin. Therefore this substance should also be thought about strongly when it thought to be used (US Department of Labor, 2006).

Copper is not the most harmful out of the three ingredients: the most harmful is Arsenic. 


\subsection{Arsenic}

Arsenic is a toxic chemical which has a deadly effect on many life form, including mould. Arsenic has been used as a central poison for centuries against human life, as it has only a slight taste easily disquieted in the tannin in tea (Gorby, 1988).

Arsenic is main reason for this investigation, as the timber industry has treated a large amount of timber with this substance, and continues to treat to this day.

\subsubsection{Treated Timber Implications}

CCA treated timber is bad enough to create a situation where it has been banned in some countries, and fills are required to adapt their holding process (European Union, 2006) (U.S. Consumer Product Safety Commission, 2004), but not New Zealand.

\subsubsection{Environmental}

This all comes down to the environmental problem associated with this material. Unfortunately, CCA treated timber is made using arsenic, a substance which is highly problematic for the surrounding people of landfills (Read, 2003). New Zealand imports the arsenic in which to treat the timber, therefore when considering that this is organic material importing can unbalance the environment in New Zealand. Arsenic is produced through non-ferrous and precious metal refining, and without treatment would become a wasted by-product of this process (Hedley, 1997). CCA treatment is therefore safe to use only when permanently locked into place as part of a completed structure.

Placing this material in fill can condense these chemicals and allows them to leach into the surrounding environment. This leaching can eventually enter the ground water systems, which will take it out to sea, but in between there are cities which require a protected water source. This causes problems for this country, and will only begin to get worse once these homes begin to be demolished and placed in fill.

\subsubsection{Human health}

This all comes back to human health, as through the consumption of these chemicals there is the potential to cause harm. There are many different possible routes where this material can reach humans, and cause harm. The Environmental Protection Agency (EPA) in the USA have banned the use of this material in areas which have an interaction with humans (Gezer, Yildiz, Yildiz, Dizman, \& Temiz, 2006). This ban shows that there are issues with this material abroad, and action has been taken. EPA created this ban in 2002, and it was in full effect in 2004. New Zealand (as it stands in 2017), has still not taken any action to prevent the material from being introduced in houses. 
It has been noted through banning the EPA application that this material can cause eye irritation, skin irritation and may have the potential for skin sensitizer (US Department of Labor, 2006)(TUFF-BRITE, 1999). This brings up the alarm that should be had on this product, an alarm which should absolutely ban it from the work force.

Due to the international concern for this material ability to harm, New Zealand needs to control it from entering these types of areas, possible allowing it the home, but not near people. The government, or other entity, presumably needs to take action and at least slow down the production. Preventive action against the harm of our society is what will change this country for the better.

\subsection{GRADING STANDARDS FOR TESTED TIMBERS}

\subsubsection{History}

Before Machine Strength Grading (MSG) was introduced, all grading was done visually. Prior to this being introduced in the early 2000, Visual Grading Standard (VSG) were used which was conducted by all professionals (Gaunt, 2012). During the VSG stage of the timber industry, there were only two different grades, No1 Framing and No 2 Framing.

Table 10 VSG and MSG Grading Standards(Walford, 2001)(Carpenter, 2004)

\begin{tabular}{|c|c|c|c|}
\hline VSG standards & Mpa & Gpa & \\
\hline NO.1 Framing & 17.7 & 8.8 & (Walford, 2001) \\
\hline NO.2 Framing & 13 & 6.1 & (Walford, 2001) \\
\hline MSG standards & Mpa & Gpa & \\
\hline SG12 & 28 & 12 & (Carpenter, 2004) \\
\hline SG10 & 20 & 10 & (Carpenter, 2004) \\
\hline SG8 & 14 & 8 & (Carpenter, 2004) \\
\hline SG6 & 10 & 6 & (Carpenter, 2004) \\
\hline
\end{tabular}

As extracted from the literature, this document explains how the VSG's are in comparison to the new codes set out by the MSG's. Theses correlations explain in some sense how each MSG codes was set up, with the $8.8 \mathrm{Gpa}$ and $6.1 \mathrm{Gpa}$ being similar to the SG6 and SG8 codes Table 10. Strength Grade (SG) codes was set by the combination of MSG and VSG to become just SG (Carpenter, 2004). This 
combination allows for VSG codes to still be used even in today's time with the introduction of sounds grading.

\subsubsection{VSG Grading}

This thesis endeavours to use VSG as it allows for an initial grade to be identified before the three point bending test is conducted. These grades will give an initial understanding of what grade the member could be, even after a full first life. These VSG's will need to incorporate factors that the first life cycle will have created, such as nail and bolt holes, and recycler's damage. These factors are not covered in the VSG's set out by the grading committee.

There are a number of different possible degrading factors, although the Australian study was conducted on Gum timbers (Eucalyptus) (Crews, Hayward, \& MacKenzie, 2008). This being closer to conducting this thesis on Rimu (Dacrydium cupressinum), a native New Zealand timber, which could show some possible overlaps. This concept of only testing one timber decreased the need to test multiple times, as this report focused on section cuts from larger members (Crews, 2007). This method, although different, does overlay with this thesis's aim and methodology.

The Australian method for using VSG's breaks down each piece of damage from fixings, and explains what size and location that is permissible. These simple rules outlined, can be used directly in a similar manner for the understanding on how New Zealand materials have been effected through their own first life. This material being treated pine, a durable material, but on which is heavily fixed due to nail guns. VSG grading test al timbers, and is not held by any one, the only way in which this material can fault is if the person testing does not understand timber weakness.

\subsubsection{New Zealand Grade Pinus Radiata}

For the results of the Australian study to be directly applicable to this thesis there must be some correlation between gum and pine. Although this may seem to be a simple question, both tree species have a number of unique factors which affect how each type of tree grows.

In the Australian document they cover 92 different types of gums which could be reused (Crews et al., 2008). Internationally there are 1719 different variation of pine, but for this instance Pinus Radiata will be the prime focus (Gardens, 2017). The term Pinus Radiata covers 11 different species, all discovered at different times by different people. The one focussed on in this thesis is the Pinus Radiata grown in New Zealand, originating from Monterey Peninsula in California (NZ Wood, 2017).

Due to the intensive breeding program by scion and its predecessors, New Zealand-grown pinus radiata has significantly different growth characteristics from the pinus radiata found growing wild in Monterey. Most notably, the New Zealand version grows far more quickly. 


\subsubsection{The Aim of Codes.}

It is important to understand the objective of grading rules. Timber grading focuses primarily on the member's strengths, which has changed over the years for timber to be more appropriate for New Zealand conditions.

\subsubsection{Correlation}

In the interim Australian Standard for recycled timbers (PN06:1039), it states that the lower the specification that they should be applied to all members in the corresponding bundle (Crews et al., 2008). Australia currently uses Radiata, similar to New Zealand, but their Interim standard focus is on Gum and its variations. This makes it difficult to compare the standards used in each country and to review whether it would be appropriate to apply the Australian standard in a New Zealand setting. The fact that there are so many different species of gum, all of which have different Modules of Elasticity (MOE) qualities, makes it more likely that at least one type of gum will share similar qualities with 'pinus radiata'.

All timbers have a lot of variation due to factors such as location, which could allow the tree to grow at an accelerated rate, or its access to water and other requirements for its growth. This in New Zealand has created the need for four different grades (SG6, SG8, SG10 and SG12), all covering one timber species. 


$\begin{array}{lc}\text { Eucalyptus Species } & \text { Modulus of Elasticity } \\ & \text { GPa } \\ \text { E. Delegatensis } & 12.4 \\ \text { E. Obliqua } & 14.1 \\ \text { E. Regnans } & 13.4 \\ \text { E. Botryoides } & 11.0 \\ \text { E. Saligna } & 11.1 \\ \text { E. Globoidea } & 14.6 \\ \text { E. Muelleriana } & 10.1 \\ \text { E. Pilularis } & 13.4 \\ \text { Average } & 12.89\end{array}$

The above graph shows the MOE of each species of Eucalyptus. These stats show a significantly higher performing tree than that of Pinus Radiata based on the MOE. All of the above species of gum are specified in the Australian interim standards, which have all been specified in the VSG set up through that research. This creates a situation where comparing the two timber types creates the ability to change the VSG to better incorporate the 'pinus radiata'. 'Pinus radiata' only has a MOE strength of 8.3 GPa, which is considerably lower than Eucalyptus (by a percentage of $36 \%$ ). Although giving a clear way to change the standards set out by Australia, allowing for the VSG to transfer directly over into the Pine work in this thesis.

\subsection{CCA TREated Pine Disposal}

\subsubsection{Current Practice}

New Zealand's current practice is to simply landfill the hazardous waste. Landfilling which is done through specific sites, such as Kate Valley in Christchurch and Hampton Downs in the Waikato, two of the biggest fills in New Zealand. These landfills have deemed themselves safe - which in some case may be true - but unfortunately safe is not what this thesis is focusing on (Canterbury, 2017; Is dam lining, 2017)

This is not to place pressure on landfills, as it is understandable what role they play in our society. A role to "hide" all the disregarded rubbish underground, so that the rest of society can continue with their existence. This focuses on acquiring a full understanding on landfills in New Zealand, a case study 
will be conducted on two separate landfills. One in the North Island (Hampton Downs) and one in the South Island (Kate Valley), both fills are up to code on their resource consent.

\subsubsection{Resource Consent}

The Resource Management Act (1992) governs where landfills are established. This act has been established to control how New Zealand treats the environment, and therefore also includes how New Zealand creates and operates landfills. A landfill guide was created in 1999/98 as a response to the large amount of territorial authorities who were managing landfills in different ways. The resource consent focuses on where the landfill will be, what they will be dumping into it, and how this waste will affecting the surrounding environment. This works in conjunction with a number of secondary clauses which focus on sound, infrastructure and the visual effects of the landfill itself (Ministry of the Enviroment, 2001).

When it comes to the concept of what will be placed into the landfill, the point of "hazardous waste" or "special waste" comes to light. This part regulates this particular type of waste, on whether or not it can be accepted into the landfill. When this waste is disposed into these fills, the consent holder should be monitoring the ground water for the hazardous contaminates, including contaminates that come from CCA timber. When it comes to monitoring how CCA treated timber is affecting the surrounding environment, the only two requirements are to check the surrounding water for contaminates and to confirm that these are up to code (Ministry of the Enviroment, 2001).

This concept of checking for contaminates could present issues in future, as when this begins to become a problem it could be too late. As the substance will inevitably begin to leach, and considering the amount that is already being landfilled, this presents a massive issue that needs to be addressed.

\subsubsection{Kate Valley/ Hampton Downs Landfill study}

Kate Valley has been developed to be capable of collecting and holding materials which will leach Hazardous substances. This landfill's response to this threat to their business, was to place a 'Linear System', which traps the hazardous material. This system traps the material and transfers into "storage tanks ready for treatment" (Canterbury, 2017).

Hampton Downs landfill runs again a liquid landfill prevention method, which will again prevent the leaching hazardous materials from entering the ground (Is dam lining, 2017). Their 'Linear System' was installed by I.S. Dam Lining, and covers $21,500 \mathrm{~m}^{2}$ of area.

Both these landfills have attempted to control the problem of materials such as CCA which is being filled in their domain. This solution will work, but there are problems associated with lining fills with 
this sort of material, in particular animals or other vermin penetrating the material and allowing the hazardous substances to leak into the ground water.

\subsubsection{Assessment}

The unfortunate situation is that these two landfills are on the cutting edge of their technology, and this cannot be expected from every system in New Zealand. This being compounded with the fact that there are also "clean fills", which will have little to no regulation behind what is happening on their faces (personal communication with company). Therefore almost anything can be dumped into them, and no one will be monitoring the situation to control the problem.

As the visible difference between types of timber is often only a slight difference in colour, fills can often mistake untreated timber for treated timber and allow it into their landfill. This bring forward a wall of new problems, as the country is needlessly allowing treated timber into fill, which will cause harm to the surrounding environment and potentially the people living in the general area.

\subsubsection{Researched Potential}

In a 2013 study, Fraser examined options in recycling includes that of waste timber. Fraser concluded in Table 12 that:

Table 12 Recycling Assessment (Fraser, 2013)

\begin{tabular}{|c|c|c|c|c|}
\hline Option & Advantages & Disadvantages & $\begin{array}{l}\text { Assessed } \\
\text { Feasibility }\end{array}$ & $\begin{array}{c}\text { Further } \\
\text { Investigation } \\
\text { Warranted }\end{array}$ \\
\hline Recycling & $\begin{array}{l}\text { Production use of waste } \\
\text { Extends life of wood } \\
\text { Low energy input to } \\
\text { process and reuse } \\
\text { Relatively low cost }\end{array}$ & $\begin{array}{l}\text { Simply delays the issue - } \\
\text { doesn't deal with hazardous } \\
\text { substances } \\
\text { Options and volumes very } \\
\text { limited }\end{array}$ & Low & No \\
\hline & $\begin{array}{l}\text { Replaces 'new' wood in } \\
\text { products }\end{array}$ & $\begin{array}{l}\text { Potential recycled products } \\
\text { not made in New Zealand } \\
\text { Little incentive to use } \\
\text { treated timber over } \\
\text { untreated timber given } \\
\text { chemical risks }\end{array}$ & Low & No \\
\hline
\end{tabular}


When considered it does just delay the problem of dealing with the material, but does this through carbon storage ${ }^{5}$ in new homes. The disadvantages outlined above do have some credibility, but there is little sense to be made from each one.

"Options and volumes very limited" this statement can be changed if the demolition companies begin to realise the potential for the product, which are normally being dumped in fill. "Potential products not made in New Zealand" this statement again does not consider what could happen in this industry (Fraser, 2013).

All our society needs is for the economic scale to tip in recycling's favour, out pricing new materials with the old. Some of which have not been used in a situation which will even degrade their structural properties. The problem with recycling CCA timber, is how we have created timber without any recognition to what treatment is.

\subsubsection{Toxic Sites}

Over the course of the last 70 years a number of different areas across New Zealand have been used to treat timber, and in doing so have caused these areas to be toxic. When considering this problem in New Zealand, there are many different entities which would rather not communicate this information. This hazardous substance has been recorded to be releasing $3200 \mathrm{mg} / \mathrm{L}$ of copper into the water way around the sites. Although that information was taken in 1997, there is still the product being released and therefore the problem will still be had (Thiagarajan, 1997). This is again shadowed by the concept that most treatment plants around New Zealand are using oxide formulations, and of these the solution strength is around 60\% (Read, 2003).

It has been noted that around New Zealand there are 165 treatment plants, which are all treating timber in one way or another (Read, 2003). On top of this, the best practice guidelines states that for plants already set up, the employees must negotiate an acceptable level of protection with the regional council (End-of-life Care, 2010).

This all come down to a story that came across my desk, which was orientated around the closure of an (un-named) treatment plant in New Zealand. This storey talked about the plant being closed and leaving behind what can only be described as an extremely toxic area. An area which no one can build on or even go on due to the large amount of arsenic and chromium in the soil and surround

\footnotetext{
${ }^{5}$ Carbon storage is the ability to repurpose something which holds carbon, thus delay its inevitable end in the environment (Nowak \& Crane, 2002). But like carbon, arsenic and chromium are both chemicals which can be stored for future use inside new building.
} 
infrastructure. Although the area was not identified, there is definitely something serious to think about when engaging in these situation.

\subsection{PreVention Methods InTERnAtionally}

New Zealand still uses this CCA treatment, but internationally there are a number of countries which have banned its use, due to the harmful nature of the material, and they have limited its future existence in the construction industry in their countries.

\subsubsection{Europe/ United States}

Europe has placed bans on the use of CCA since 2002. The US EPA have also placed the same ban on the material since 2002, although it was not completely banned from residential use until January 2004. At this time EPA had not finished the research need to create this ban, but due to arsenic being a hazardous substance any removal from society was seen as worthy (University of Wollongong, 2017).

Although the US EPA conducted this ban, there are still many people in the treated area who are concerned. Therefore possible the banning is not enough of a solution, and there needs to be more work done to stop the manufacture and use of this material (University of Wollongong, 2017).

\subsection{Potential for NeW Zealand to Adopt}

New Zealand has not adopted any such banning laws into the construction industry. The introduction of this CCA treated timber was done in 2002 , which is very similar to the date that Europe and the US banned it (University of Wollongong, 2017). This slow update has left New Zealand with a problem, as we import arsenic and generate one of the most harmful treated timber creations.

Before CCA was introduced into the system, Tanalised was used. This material is the same combination of copper chromium and arsenic, and is still being dumped into the landfills surrounding our country (Salmond, 2010).

\subsection{Alternative to TREATED TIMBer.}

Of course when considering this material there must be consideration on the other materials, which bear similar durability in moist situations. New Zealand's climate is what creates these bad situations, as most materials which are used are required to be of stated levels, hazard. But regardless of this there are four separate tree species which could hold the potential to replace pine in the construction market (NZ Wood, 2018). 
Comparing pine to alternative timbers, two different qualities must be examined. These are the bending strength and Modulus of Elasticity (MOE), two separate measurements which together allow the codes and compliance regulations to be made. Pine typically has an average bending strength of 85.8MPa (mega pascals) and an MOE of 8.23GPa (giga pascals).

- Douglas-fir - This species of timber is very similar to pine and has a bending strength of $78 \mathrm{MPa}$, and a MOE of $10 \mathrm{GPa}$, putting it as a higher functioning timber than pine, and definitely one which could be an alternative.

- Macrocarpa - Macrocarpa is a New Zealand timber. It holds a bending strength of 87.8MPa, and an MOE of 5.79GPa. Based on these figure this material would be less likely to replace pine in a construction sense, but it does have some limited natural resistance to rot and mould.

- Lusitanica/ Lawson Cypress - This species holds an excellent durability rating, which is that of H3.1 in codes and compliance. Both materials are good for construction, but Lawson has the higher results, with a bending strength of 97.7MPa, and an $\mathrm{MOE}$ of $12.1 \mathrm{GPa}$, which makes it an appropriate alternative to pine.

Although all these results make a compelling argument, that all of these results have come from laboratory studies on the materials. These are always based on small segment, whereas in industry these materials grading rules can fluctuate drastically (NZ Wood, 2017).

\subsubsection{Alternative treatment options}

Through the use of alternative treatment process a lot of important deductions can be made. The most of all is the reduction of damage to the environment, which will come to help reducing the factors which are explained above.

\subsubsection{International}

Internationally there has been lots of research into the other treatments which could effectively cover what was left behind after the banning. These different treatments contain the integral component to prevent all fungi and moulds, but do not have the harmful arsenic substance. This alternative typically comes in the form of light organic solvent preservatives (LOSP) (Cookson, 2013). LOSP is a preservative which doesn't contain arsenic and through their trials is just as effective. This treatment is already being used in New Zealand, but codes left it at only H3.1, therefore when using a scenario at H3.2 CCA must be used (Cookson, 2013). This still leaves a lot of our product to be treated using a harmful method as LOSP washes out, which again will cause problems. 
A secondary research paper again considered the durability effects that separate treatments had on a product. Again this thesis focus is on creating and specifying a treatment option which is environmentally friendly. This thesis focuses on the idea of replacing arsenic with different chemical compounds (Ahn et al., 2010). This document shows that four of the tested compounds are effective against the surround degrading factors.

Table 13 A compiled version of the (Alternative to Chromated Copper Arsenate for Residential Construction) focusing on the main points.

\begin{tabular}{|c|c|c|c|c|}
\hline \multirow{3}{*}{$\begin{array}{l}\text { Preservative formulation as } \\
\text { listed in AWPA standards }\end{array}$} & & & \multicolumn{2}{|c|}{ Retention $\mathrm{kg} / \mathrm{m} 3$} \\
\hline & \multirow{2}{*}{\multicolumn{2}{|c|}{ Portion of preservative component }} & Above & Below \\
\hline & & & Ground & Ground \\
\hline Acid copper chromate (ACC) & $32 \% \mathrm{CuO}$ & $68 \% \mathrm{CrO} 3$ & $4.0(0.25)$ & $6.4(0.40)$ \\
\hline Alkaline copper quat(ACQ-B, D) & $67 \% \mathrm{CuO}$ & $33 \%$ DDAC & $4.0(0.25)$ & $6.4(0.40)$ \\
\hline Alkaline copper quat(ACQ-C) & $67 \% \mathrm{CuO}$ & $33 \% \mathrm{BAC}$ & $4.0(0.25)$ & $6.4(0.40)$ \\
\hline Copper citrate (CC) & $62 \% \mathrm{CuO}$ & $38 \%$ critic acid & $4.0(0.25)$ & $6.4(0.40)$ \\
\hline
\end{tabular}

Above it can be shown that these alternatives are the best chemical combinations to combat the degrading factors. None of the above chemicals contain arsenate, and only one contains the chromate, therefore this can be avoided easily. Although there is a large distance between the place where this research was conducted in America, and what it is planning to be an alternative in New Zealand (Lebow, 2004). This again shows that this treatment option can be revoked through the use of research which has been proven through international studies.

\subsubsection{New Zealand interaction}

New Zealand's current preservative plan does incorporate a number of separate treatment options, which do have the potential to slow down the CCA usage across the country. These all interact with New Zealand government through codes and compliance, but none are, as yet, mandatory.

\subsection{CONCLUSION}

Beyond all the recent research it is clear that CCA - treated timber is being reused, even if it is a small amount, and that this use will grow. It is also clear to see that this product is a problem when placed in landfill, there are far too many chemicals which when disposed of with little thought can move through to the surrounding environment, and eventually into the water and soil supplies for homes. 
Unfortunately, there are no real ways to change the fact that New Zealand is built on pinus radiata, and that that point will not change even with the diversified timber of choice. Overall there are many different alternatives for treatments, and New Zealand will eventually make the right decision in terms of what is going into their land. All that is needed is a little push from someone of influence, a push which will change all the saw mills over their treatment schedules.

With all this, the main problem for CCA treated timber is whether or not it has the structural integrity to be reused in a structural form. Finding this out will give the timber industry a lot of freedom with their ability to reuse the material. The next chapter therefore research moving toward a methodology of three point testing, bringing in samples from construction sites and putting them through testing allowing the results to be measured and recorded. 


\section{Methodology}

The original aim of this thesis, was to provide adequate information on the strength of reused pine, enabling confident use in structural condition. The thesis takes a number of directions in the methods of extracting the appropriate information. Reusable treated timber is one of the key performance members in structurally sound buildings. This timber is needed to be treated due to the degrading factors which can bring down the structural properties. These treatments bring the timber durability up much higher, and thus gives opportunity to reuse the material again rather than dumping it into the landfill. This can be done through methodology of strength testing, finding whether this material still has the necessary structural qualities.

New virgin material is always tested against the codes and compliance, which is the set of regulations for checking timber properties. This thesis conducts tests, allowing this information to be directly compared to the trials of the past. The main issue though is whether or not this material is up to code, and if so by how much. Proving that this material can be used structurally will create opportunities for more sale, and therefore more people will recycle the material.

\subsection{StRENGTH TESTING}

The methodology chosen for this material test has been the three point bending test method as outlined in the NZS3605. This method, facilitated by the university, bends the material and furnishes the necessary final information.

\subsubsection{Literature of Testing}

There has been speculation of three point bending test, as the loads connection point has the potential to endue shear and therefore create problems with the final bending test (interview with Australian academic). The more commonly used method now is the four point testing machine, which will conduct the material in a slightly different way, as the rams are positioned at two places across the top. But New Zealand codes specifies a three point bending test and therefore this thesis is using three point bending tests (Horrigan, Crews, \& Boughton, n.d.).

Vanijika stated that the four point bending method overestimated the flexural modulus (Mujika, 2006). This again sways the resulting test method towards the three point bending method. Three point bending has been stated through another study to miss $19 \%$ of the elastic results, which in the case of this study will indicate problems (Brancheriau, Bailleres, \& Guitard, 2002). 


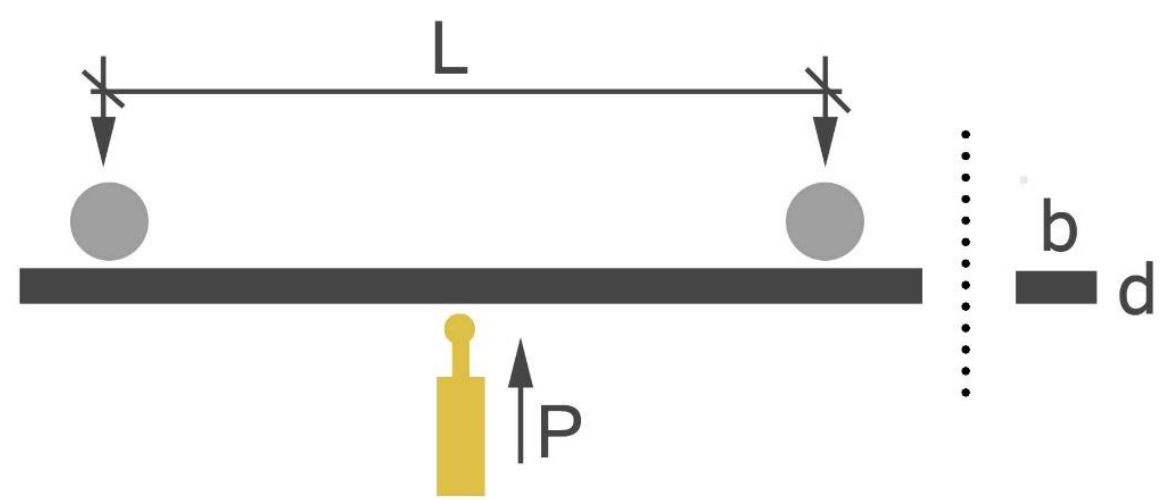

Figure 5 Three point bending test schematic (authors own)

\subsubsection{Three Point Strength test}

\subsubsection{Aim of Strength Testing}

Timber varies in characteristics as it is produced in a wide range of environmental conditions across New Zealand, the strength can vary in similar amounts. This has forced the timber producing industry to machine grade each member as it passes through the timber mills. This characterises timber members into particular strength grades, such as Strength Grade 8 (SG8). SG8 consist of timber which has a bending strength of at least $14 \mathrm{Mpa}$, and a bending stiffness of minimum of $8 \mathrm{Gpa}$ (Standards New Zealand, 1988).

With these minimum sets of timber strength qualities, comparisons can be made with simplicity through similar testing, and expressed formula. Equations which allow for the calculation of strength and stiffness in the sample. With each comparison a detailed description of the sample will be provided to attempt to understand the VSG, against the actual strength.

With this three way comparison, conclusions can be drawn on quick visual assessment in the timber which show areas of inadequate strength. With the information, the beginning of structural analysis codes and compliance document can begin to appear on recycled 'pinus radiata'. Allowing for the confident use of this material in a structural context in New Zealand, and increasing on NZS: 3604's statement:

"The Standard's provisions may be applicable to timbers other than Radiata pine and Douglas fir such as other softwood species. Such use however, needs to be subject to demonstration of adequate structural performance and durability." 


\subsubsection{The Process}

Adequately demonstrating the structural performance requires the timber to be up to New Zealand codes and compliance.

\subsection{Calculating the Force}

The research involves the use of a three point hydraulic system Figure 4. This is represented through a hydraulic pressure gauge which reads the kilogram pressure being displaced through the hydraulic ram. This multiplied with the area of the ram gives the force acting on the member.

\subsection{Calculating the Bending Strength (MPA)}

Using the above force, equations must be solved in order to calculate the relative bending strength.

$$
\begin{aligned}
& \qquad ð=M_{z} y / I_{X} \\
& ð=\text { is the bending stress } \\
& \mathrm{M}_{\mathrm{z}}=\text { the moment about the neutral axis } \\
& \mathrm{Y}=\text { the perpendicular distance to the neutral axis } \\
& \mathrm{I}_{\mathrm{x}}=\text { the second moment of area about the neutral axis } \mathrm{x} .
\end{aligned}
$$

The above formula is required in the accurate generation of the maximum bending strength acquired through the tests. This formula can therefore be broken down into its components, which will then be reinserted generating the outcome.

$$
\begin{aligned}
& \qquad M=F l / 4 \\
& \mathrm{M}=\text { the bending moment } \\
& \mathrm{F}=\text { is the load (force) at the fracture point }(\mathrm{N}) \\
& \mathrm{L}=\text { is the length of the support span }
\end{aligned}
$$

Finding this, uses the force applied as calculated above, multiplied by the length in which the sample is be bent, and then all divided by six.

$$
Z=b d^{2} / 6
$$

$Z=$ is the section modulus

$\mathrm{b}=$ is the width

$d=$ is the thickness 
When calculating the moment of inertia, $\mathrm{Z}$ is used, as this equation renders the y extremity out of the equation, as $Z=1 / y$.

$$
\begin{aligned}
& \qquad \text { đmax }=\frac{M}{Z} \\
& \text { ðmax }=\text { is the maximum bending strength } \\
& \mathrm{M}=\text { is the bending moment } \\
& \mathrm{Z}=\text { is the section modulus }
\end{aligned}
$$

This leaves the final equation to be solved, producing the final result of the maximum bending strength, which can be directly compared to the results from the industry on new timber testing.

\subsection{Calculating the Modules of Elasticity (MOE) (GPA)}

Finding the MOE, which is what the timber is graded against in industry, will require the rearranging on the displacement equations and insertion of the inertia equation. With both these two inserted into one equation, solutions can be immediately derived from the sourced figures.

$$
\begin{aligned}
& \qquad W=\frac{F^{3}}{48 E I} \\
& W=\text { is the deflection at the centre of the material } \\
& F=\text { is the load exerted on the material } \\
& L=\text { is the support span ( } m m \text { ) } \\
& E=\text { is Young's modulus of elasticity } \\
& I=\text { is the second moment of area defined below, } \\
& \quad I=\frac{h^{3} b}{12} \\
& I=\text { is the inertia involved } \\
& h=\text { is the height of the material } \\
& b=\text { is the width of the material. }
\end{aligned}
$$

This can be rearranged to:

$$
E=\frac{F L^{\wedge} 3}{4 b\left(h^{\wedge} 3\right) D f}
$$


In this equation the force acting is multiply by the spanning length which has been cubed. All of this is then divided by the inertia calculation, which is then multiply by the deflection and a constant force of 1000. Doing this gives the final figure, which is the Young's modulus of elasticity, a crucial point in finding the materials overall strength.

Provided all inserted numbers are accurate, the solution will be calculated. But to accomplish accurately this must be calculated at three point's minimum along the bending strength line shown in the graph below Figure 5 . 


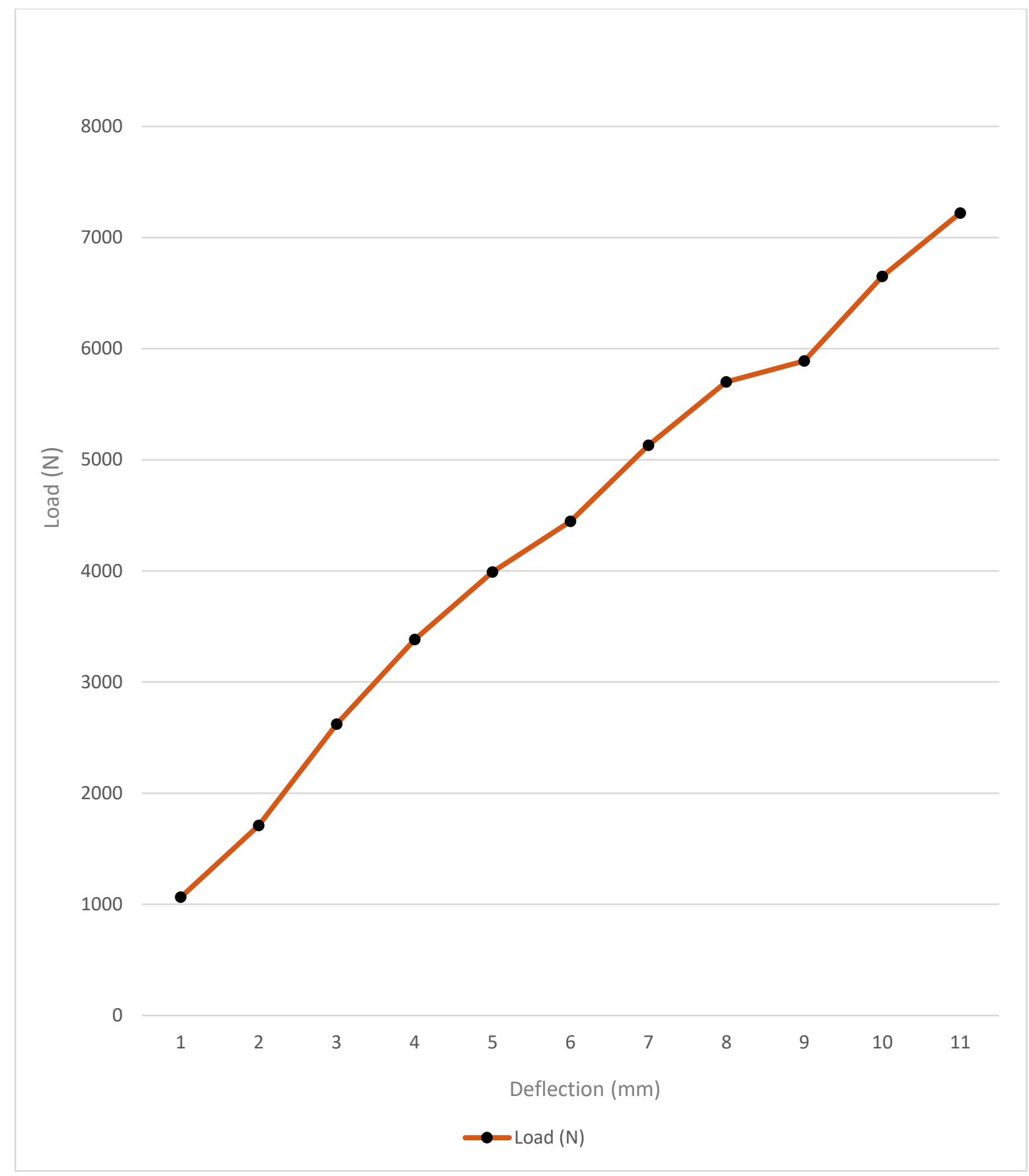

Figure 6 Load vs. Deflection, Constructed from Table 14

This has been calculated at three points, the mean can be used as Young's Modulus of Elasticity. This was done through the first stage of testing, and with this information it is clear to see that there is a trend line across the graph. Thus enforcing the Young modulus of elasticity, and allow this thesis to move forward into the next stage. 


\subsubsection{Initial test}

Once the appropriate testing equipment had been acquired, an initial test could be carried out on a recently recycled member. This would be the benchmark, so to create a set of results which will add in the setting of a results sheet. This sheet will contain all equations, results, the bending strength graph, a comparison table, and all the required description and photos. Creating a situation where figures can be input and results immediately generated.

Table 14 Results from initial test

$\begin{array}{llllll} & & & \text { Bending } & \text { Strength } & \text { Bending } \\ \text { Deflection(mm) } & \text { Load (Bar) } & \text { Load }(\mathrm{N}) & \text { (Mpa) } & \text { (GPA) } \\ 1 & 28 & 1064 & & 13.14 \\ 2 & 45 & 1710 & 10.56 \\ 3 & 69 & 2622 & 10.80 \\ 4 & 89 & 3382 & 10.44 \\ 5 & 105 & 3990 & 9.86 \\ 6 & 117 & 4446 & 9.15 \\ 7 & 135 & 5130 & 9.05 \\ 8 & 150 & 5700 & 8.80 \\ 9 & 155 & 5890 & 8.08 \\ 10 & 175 & 6650 & & 8.21 \\ 11 & 190 & 7220 & 44 & 8.11\end{array}$

The load was recorded every $1 \mathrm{~mm}$ of deflection, with the use of a camera as the hydraulic and deflection gauge did not hold the readings. The camera provided an adequate amount of data, with the maximum load being slightly hard to read, as the camera holder jumped when the wood broke.

Although with the slight uncertainty through the human error in filming the test, the results were still capable of being converted into the correct units. Thus allowing the appropriate overlay of industry results show in Table 14 Results from initial test.

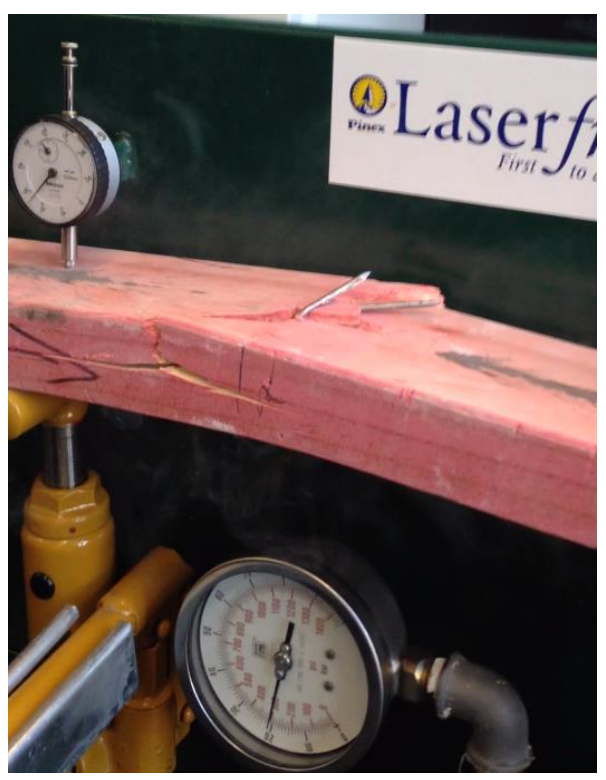

Figure 7 Tested member after breaking point 
Table 15 Comparison against new timber, and stamp on timber

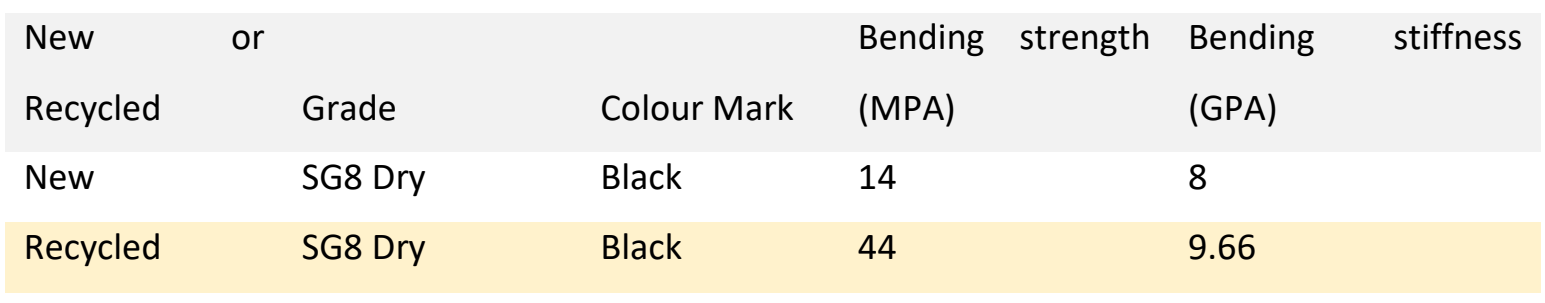

Description

Stamp - CHH Laserframe 90 x 45 MCKı26\% MSG AS/NZ 1748015 WEEK 300710 KEEP DRY BY

Using the description and colour mark on the timber a number different variable can be drawn before the test is conducted. These are the pre-test MSG factors of bending strength and bending stiffness for a SG8 length, which are $14 \mathrm{MPa}$ and $8 \mathrm{GPa}$.

These figures have come from the testing conducted at the saw mills, which have conducted this in a similar way to how this thesis has conducted the testing. This is where the location of MPa and GPa have come from, two results which both are comparable to once source.

This shows that this particular material was well over its graded rates, and would then be considered up to code, as shown in Table 15. Therefore this gives an appropriate result for the beginning of this experiment. 


\subsubsection{Timber images and Description}

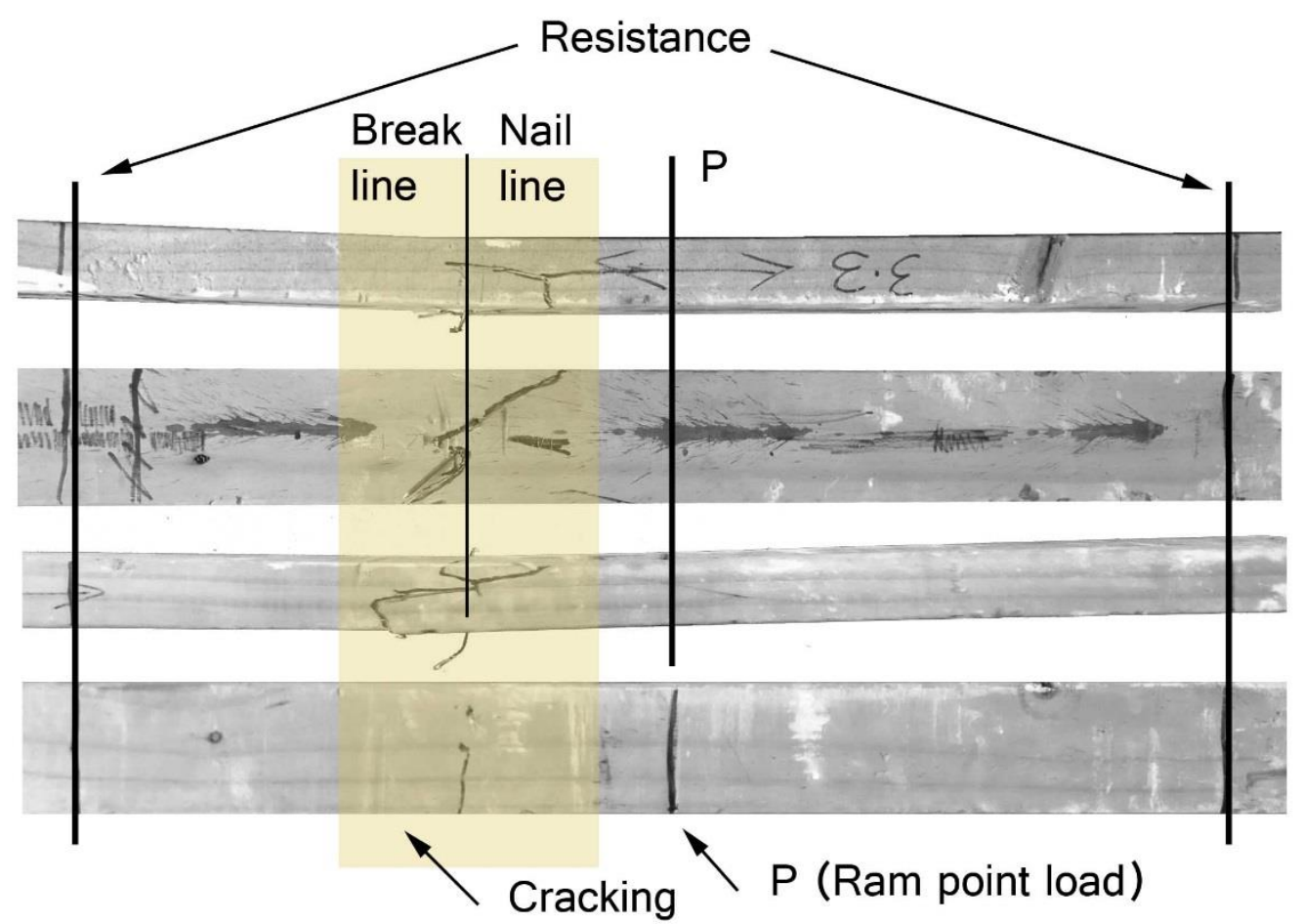

Figure 8 Beam breakdown after testing (Black lines in Highlighted area are break lines)

\subsubsection{Observations of Initial Test}

Before conducting the test, assumptions were made on potential problems with the equipment. The main assumption was that the hydraulic ram would imprint the timber member causing a shear point. Although once the test had been conducted this was not found. The member instead broke on the nail line, which is $150 \mathrm{~mm}$ away from where the ram that was applying the pressure.

This illustrated in the above Figure 6 shows where the breaking point was in relation to the ram point load. This break builds on the concept of fixings having a major impact on how a timber member will break when pushed to its ultimate strength.

\subsubsection{Amendments Due to initial testing}

Doing this test allowed for a number of insights into how the results were affected by certain variables. The following amendments have been made through these visual insights.

- Due to the hydraulic gauge and deflection gauge not holding their representative values. A cameraman was employed to film the gauges whilst the hydraulic ram increased pressure on the timber beam. Due to movement of the videographer some of the footage was unreadable and it proved difficult to extract appropriate values. This led to inconsistency in results. The setup was changed to ensure that this would not happen again. 
- Along with the poor footage, the choice to break a solid $90 \times 45 \mathrm{~mm}$ member exceeded the recording ability of the pressure gauge by 90bar. Doing this for all experiments would eventually lead to the eventually premature demise of the pressure gauge, which is an important part of the testing rig.

- Problems occurred when placing pressure on the crank for the ram. This came in the form of the testing equipment beginning to rotate with the downward application of pressure. To fix this, pressure was placed on each end of the testing equipment to lock it to the backing draws. This prevented twisting, and to further counteract this the equipment is fixed to a board and clamped onto a table.

- When recoding the information from the hydraulic pressure gauge, readings were taken at $1 \mathrm{~mm}$ intervals. Assuming that when the filming gear is upgraded, this will be replaced with $0.5 \mathrm{~mm}$ reading intervals, thus creating a more accurate graph, and more accurate results of bending stiffness.

\subsubsection{Initial Test Conclusion}

Through conducting this test a number of important changes can be made in order for the future testing to both easier to conduct, and record more appropriate results.

\subsubsection{Grading Outline}

A VSG section will provide accurate results while testing. This testing schematic is based on a number of different areas of knowledge, with the NZ VSG standard from 1988 (New Zealand Government, 1998) being the first to set out guidelines. The VSG standards explains where knots can be located and what the maximum acceptable size of those knots can be, this goes the same with the other degrading factors such as the holes, shake and others.

The second is the Australian VSG standard (PN06.1309) which have been based on the reuse of gum, which has some species with similar traits to pinus radiata. The section outlined in red in Table 14, was input to account for damage occurred through the first life of the timber. This section covered areas, such as holes from bolts and nails, and other problems which could have come about.

The bottom section is derived from work at Phoenix Contracting, focusing on damage incurred through the use of forklifts and other equipment. These rules have come from the NZ VSG Standards (New Zealand Government, 1998), focusing on area which have problems with the materials overall stability. 
Table 16 Grading outlines for Tested Timber Members (Crews et al., 2008)(Standards New Zealand, 1988),

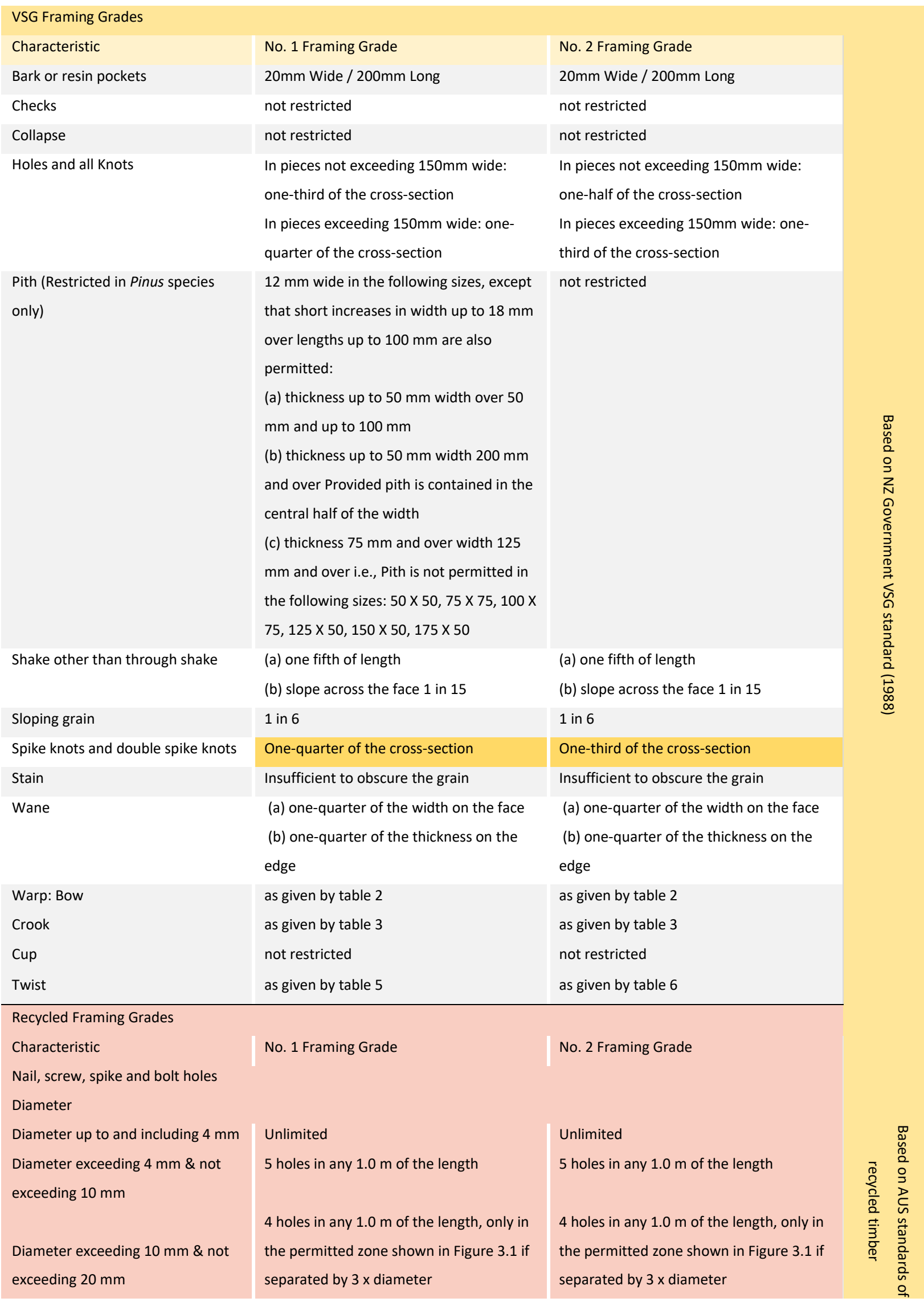




\begin{tabular}{|c|c|c|c|}
\hline $\begin{array}{l}\text { Diameter greater than } 20 \mathrm{~mm} \\
\text { Borer holes not associated with } \\
\text { decay }\end{array}$ & $\begin{array}{l}4 \text { holes in any } 1.0 \mathrm{~m} \text { of the length not } \\
\text { exceeding } 1 / 4 \mathrm{~W} \text { on face are permitted } \\
\text { only in the permitted zone, as shown in } \\
\text { Figure } 3.1 \text { if separated by } 5 \mathrm{x} \text { diameter }\end{array}$ & $\begin{array}{l}4 \text { holes in any } 1.0 \mathrm{~m} \text { of the length not } \\
\text { exceeding } 3 / 8 \mathrm{~W} \text { on face are permitted } \\
\text { only in the permitted zone, as shown in } \\
\text { Figure } 3.1 \text { if separated by } 5 \mathrm{x} \text { diameter }\end{array}$ & \\
\hline $\begin{array}{l}\text { Diameter up to and including } 3 \mathrm{~mm} \\
\text { Diameter over } 3 \mathrm{~mm} \text { or where } \\
\text { separated by less than } 2 \times \text { diameter }\end{array}$ & $\begin{array}{l}\text { Not exceeding } 20 \text { holes per } 100 \times 100 \mathrm{~mm} \\
\text { As for knots }\end{array}$ & $\begin{array}{l}\text { Unlimited, provided the distance between } \\
\text { holes is at least } 2 x \text { their diameter } \\
\text { As for knots }\end{array}$ & \\
\hline End splits, aggregate length & Not exceeding lesser of $W$ and $100 \mathrm{~mm}$ & Not exceeding lesser of $1.5 \mathrm{~W}$ and $150 \mathrm{~mm}$ & \\
\hline Damage & & & 뭉 \\
\hline Timber cleaning (Hole) & One-quarter of the cross-section & One-third of the cross-section & $\begin{array}{l}\text { O } \\
\frac{D}{2} .\end{array}$ \\
\hline Movement damage & $\begin{array}{l}\text { (a) one-quarter of the width on the face } \\
\text { (b) one-quarter of the thickness on the } \\
\text { edge }\end{array}$ & $\begin{array}{l}\text { (a) one-quarter of the width on the face } \\
\text { (b) one-quarter of the thickness on the } \\
\text { edge }\end{array}$ & 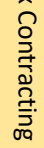 \\
\hline
\end{tabular}

These rules, although good, do require some changes. In particular the rules devised from the Australian standards, as the Eucalyptus species bears a much higher bending strength, and therefore a much higher strength. This comes from the section 7.6.3.2, a section which focused on how Eucalyptus could be used in correlation to pinus radiata. This section will focus on how the Eucalyptus is $36 \%$ higher, and how this can allow the rules to be changed to bring all the remarks down.

Table 17 Rules based around the Australian Interim Standards PN06.1039 (Crews et al., 2008)

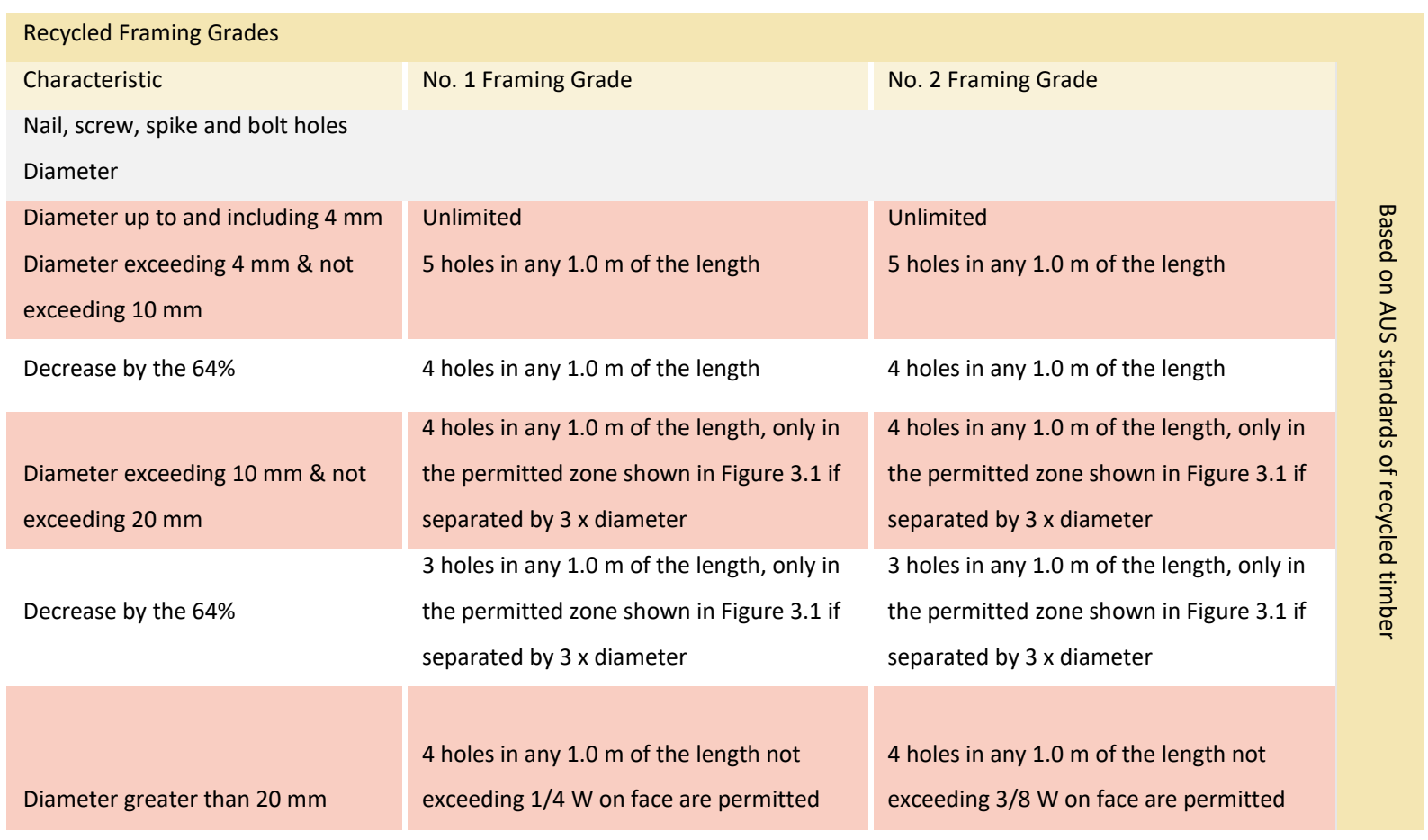




\begin{tabular}{|c|c|c|}
\hline & $\begin{array}{l}\text { only in the permitted zone, as shown in } \\
\text { Figure } 3.1 \text { if separated by } 5 \mathrm{x} \text { diameter }\end{array}$ & $\begin{array}{l}\text { only in the permitted zone, as shown in } \\
\text { Figure } 3.1 \text { if separated by } 5 \mathrm{x} \text { diameter }\end{array}$ \\
\hline Decrease by the $64 \%$ & $\begin{array}{l}3 \text { holes in any } 1.0 \mathrm{~m} \text { of the length not } \\
\text { exceeding } 1 / 4 \mathrm{~W} \text { on face are permitted } \\
\text { only in the permitted zone, as shown in } \\
\text { Figure } 3.1 \text { if separated by } 5 \mathrm{x} \text { diameter }\end{array}$ & $\begin{array}{l}3 \text { holes in any } 1.0 \mathrm{~m} \text { of the length not } \\
\text { exceeding } 1 / 4 \mathrm{~W} \text { on face are permitted } \\
\text { only in the permitted zone, as shown in } \\
\text { Figure } 3.1 \text { if separated by } 5 \mathrm{x} \text { diameter }\end{array}$ \\
\hline \multicolumn{3}{|l|}{$\begin{array}{l}\text { Borer holes not associated with } \\
\text { decay }\end{array}$} \\
\hline Diameter up to and including $3 \mathrm{~mm}$ & Not exceeding 20 holes per $100 \times 100 \mathrm{~mm}$ & $\begin{array}{l}\text { Unlimited, provided the distance between } \\
\text { holes is at least } 2 x \text { their diameter }\end{array}$ \\
\hline Decrease by the $64 \%$ & Not exceeding 13 holes per $100 \times 100 \mathrm{~mm}$ & $\begin{array}{l}\text { Unlimited, provided the distance between } \\
\text { holes is at least } 2 x \text { their diameter }\end{array}$ \\
\hline $\begin{array}{l}\text { Diameter over } 3 \mathrm{~mm} \text { or where } \\
\text { separated by less than } 2 \mathrm{x} \text { diameter }\end{array}$ & As for knots & As for knots \\
\hline End splits, aggregate length & Not exceeding lesser of $\mathrm{W}$ and $100 \mathrm{~mm}$ & Not exceeding lesser of $1.5 \mathrm{~W}$ and $150 \mathrm{~mm}$ \\
\hline
\end{tabular}

With the Australian Standards changed to more effectively cover that of pine, this can be used before the testing is conducted. Making the above changes creates a higher difficultly for recycled pine to obtain the higher bench mark of No.1 framing timber. This creates more manageable grades for Pine to hold itself against.

The above table uses the red colour to signify the changes that have been made, as each section is reduced by $64 \%$ a reduction based on table 11 . This will allow all pinus radiata to be tested in with the VSG grading.

Table 18 Knowledge from recycling timber

\begin{tabular}{|c|c|c|}
\hline Timber cleaning (Hole) & One-quarter of the cross-section & One-third of the cross-section \\
\hline Movement damage & $\begin{array}{l}\text { (a) one-quarter of the width on the face } \\
\text { (b) one-quarter of the thickness on the } \\
\text { edge }\end{array}$ & $\begin{array}{l}\text { (a) one-quarter of the width on the face } \\
\text { (b) one-quarter of the thickness on the } \\
\text { edge }\end{array}$ \\
\hline
\end{tabular}

With any recycling, there will be damage present when the timber is cleaned (all fixings removed). Due to all the previous codes and compliance VSG's, there is a substantial amount of codes which relate to particular damage. These have been used to create codes for situations which lowered the 
timber MOE through damage. These two sets of codes have been found through Spike knots and double spike knots and wane ${ }^{6}$, each with relative codes.

\subsubsection{Grading Criteria for Recycled Timber}

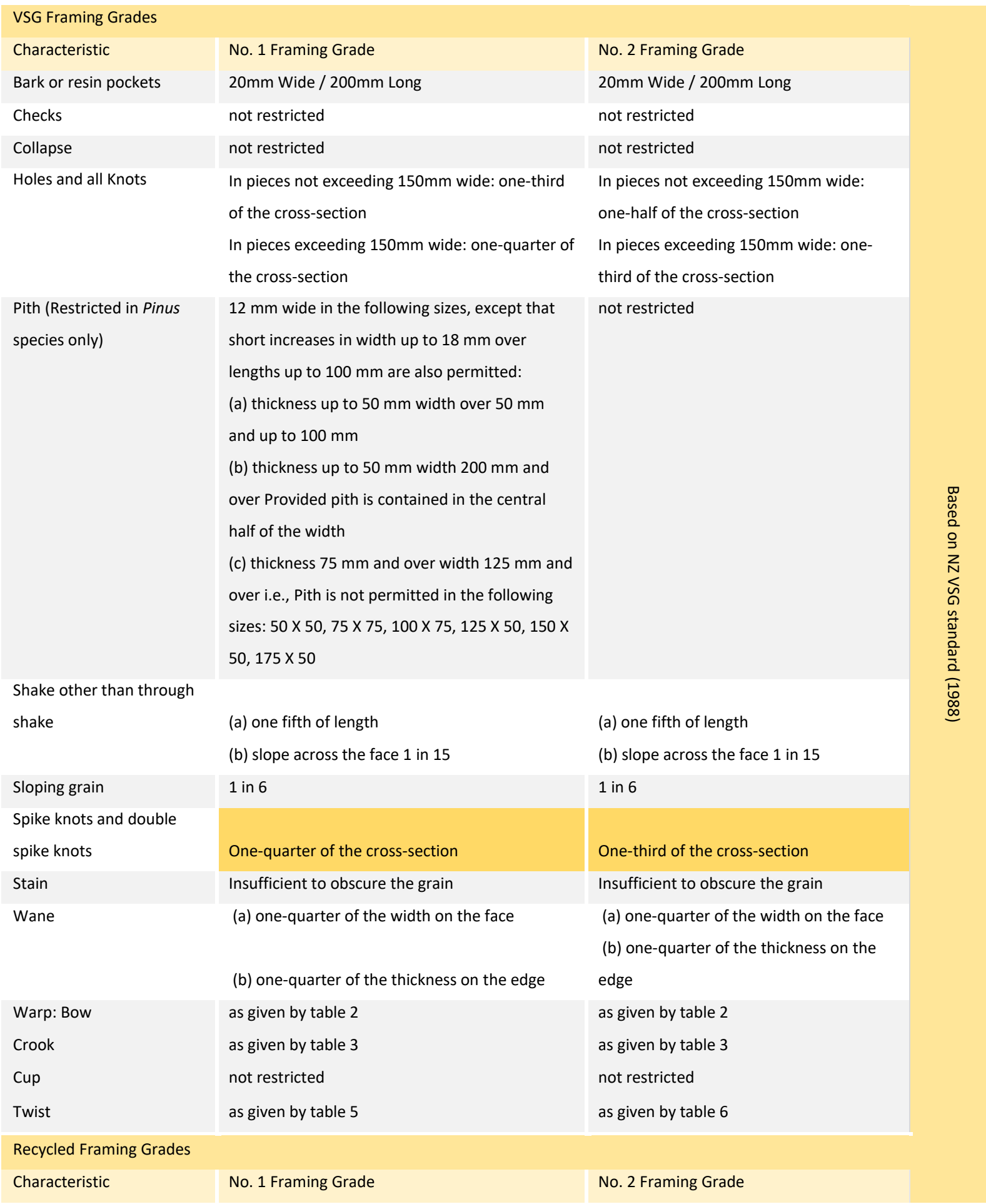

\footnotetext{
${ }^{6}$ Wane: The presence of the original under bark surface with or without bark, on any face or edge of a piece of timber.
} 


\begin{tabular}{|c|c|c|c|}
\hline \multicolumn{3}{|l|}{$\begin{array}{l}\text { Nail, screw, spike and bolt } \\
\text { holes Diameter }\end{array}$} & \\
\hline $\begin{array}{l}\text { Diameter up to and } \\
\text { including } 4 \mathrm{~mm}\end{array}$ & Unlimited & Unlimited & \multirow{12}{*}{ 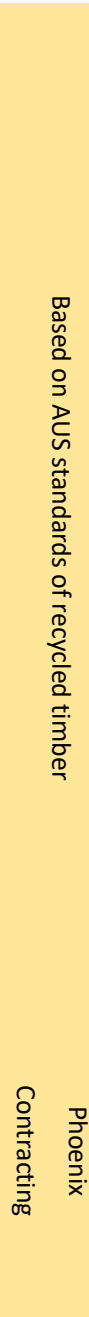 } \\
\hline $\begin{array}{l}\text { Diameter exceeding } 4 \mathrm{~mm} \\
\& \text { not exceeding } 10 \mathrm{~mm}\end{array}$ & 4 holes in any $1.0 \mathrm{~m}$ of the length & 4 holes in any $1.0 \mathrm{~m}$ of the length & \\
\hline $\begin{array}{l}\text { Diameter exceeding } 10 \\
\text { mm \& not exceeding } 20 \\
\text { mm }\end{array}$ & $\begin{array}{l}3 \text { holes in any } 1.0 \mathrm{~m} \text { of the length, only in the } \\
\text { permitted zone shown in Figure } 3.1 \text { if separated } \\
\text { by } 3 \times \text { diameter }\end{array}$ & $\begin{array}{l}3 \text { holes in any } 1.0 \mathrm{~m} \text { of the length, only in } \\
\text { the permitted zone shown in Figure } 3.1 \text { if } \\
\text { separated by } 3 x \text { diameter }\end{array}$ & \\
\hline $\begin{array}{l}\text { Diameter greater than } 20 \\
\mathrm{~mm}\end{array}$ & $\begin{array}{l}3 \text { holes in any } 1.0 \mathrm{~m} \text { of the length not exceeding } \\
1 / 4 \mathrm{~W} \text { on face are permitted only in the } \\
\text { permitted zone, as shown in Figure } 3.1 \text { if } \\
\text { separated by } 5 x \text { diameter }\end{array}$ & $\begin{array}{l}3 \text { holes in any } 1.0 \mathrm{~m} \text { of the length not } \\
\text { exceeding } 3 / 8 \mathrm{~W} \text { on face are permitted } \\
\text { only in the permitted zone, as shown in } \\
\text { Figure } 3.1 \text { if separated by } 5 \mathrm{x} \text { diameter }\end{array}$ & \\
\hline $\begin{array}{l}\text { Borer holes not associated } \\
\text { with decay }\end{array}$ & & & \\
\hline $\begin{array}{l}\text { Diameter up to and } \\
\text { including } 3 \mathrm{~mm}\end{array}$ & Not exceeding 13 holes per 100 x $100 \mathrm{~mm}$ & $\begin{array}{l}\text { Unlimited, provided the distance between } \\
\text { holes is at least } 2 x \text { their diameter }\end{array}$ & \\
\hline $\begin{array}{l}\text { Diameter over } 3 \mathrm{~mm} \text { or } \\
\text { where separated by less } \\
\text { than } 2 \mathrm{x} \text { diameter }\end{array}$ & As for knots & As for knots & \\
\hline \multicolumn{3}{|l|}{ End splits, aggregate } & \\
\hline length & Not exceeding lesser of $\mathrm{W}$ and $100 \mathrm{~mm}$ & Not exceeding lesser of $1.5 \mathrm{~W}$ and $150 \mathrm{~mm}$ & \\
\hline Damage & & & \\
\hline Timber cleaning (Hole) & One-quarter of the cross-section & One-third of the cross-section & \\
\hline Movement damage & $\begin{array}{l}\text { (a) one-quarter of the width on the face } \\
\text { (b) one-quarter of the thickness on the edge }\end{array}$ & $\begin{array}{l}\text { (a) one-quarter of the width on the face } \\
\text { (b) one-quarter of the thickness on the } \\
\text { edge }\end{array}$ & \\
\hline
\end{tabular}

After all the changes involved with this have been conducted, we can derive a set of be final grading rules. These rules will run alongside the testing process, allow all materials to be tested and graded all in one action. 


\subsection{CALibration}

To obtain a full understanding on how the timber is processed in today current market, a field trip to a mill was taken, this was also to acquire samples of all separate grades from comparative tests. This was conducted at the Crighton ITM in Levin through whose workers obtained the four separate samples at MSG6 through to MSG12.

Once at the mill a tour was conducted on the different technologies operating around the shed, such as the hydraulic saw, responsible for sawing down the logs into workable sizes for industry. The boards then passed through a set of lasers which record the size, weight and length of each member. This information could then be coupled with the grading technology of the Acoustic grader Figure 8.

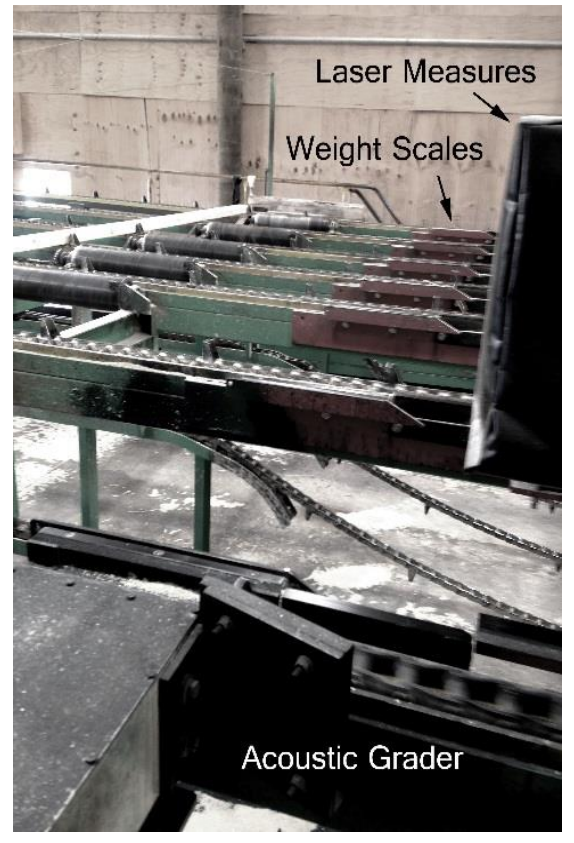

Figure 9 Crighton Mill Acoustic Grader

\subsubsection{Acoustic Output}

Table 19 Acoustic Grading Output based on 10.1 page 92

\begin{tabular}{ccccccccc} 
& Scheduled & Width & Thickness & Length & Weight & Density & MOE & Ecoustic \\
Grade & Dimensions & $(\mathrm{mm})$ & $(\mathrm{mm})$ & $(\mathrm{mm})$ & $(\mathrm{Kg})$ & $\left(\mathrm{Kg} / \mathrm{m}^{2}\right)$ & $(\mathrm{GPa})$ & ID \\
\hline MSG8 & $150 \times 50 \times 10000$ & 151.66 & 51.6 & 6112 & 30.6 & 640.2 & 8.04 & 480 \\
Not graded & thick & 151.18 & 28.53 & 6103 & 22.3 & 848.6 & 0 & 479 \\
MSG10 & $75 \times 50 \times 10000$ & 79.62 & 51.32 & 4935 & 20.2 & 10000 & 10.72 & 478 \\
MSG10 & $150 \times 50 \times 10000$ & 155.46 & 52.38 & 6109 & 47.4 & 952.7 & 9.59 & 477 \\
Not graded & thick & 158.96 & 29.3 & 5595 & 27.9 & 1069.7 & 0 & 476 \\
MSG8 & $150 \times 50 \times 10000$ & 155.26 & 51.22 & 4896 & 31.2 & 801.5 & 8.5 & 475 \\
MSG8 & $100 \times 50 \times 10000$ & 105.19 & 50.81 & 4897 & 27.6 & 1054 & 8.96 & 474 \\
Not graded & thick & 210 & 28.35 & 4895 & 29.1 & 997.3 & 0 & 473 \\
Low & $250 \times 50 \times 10000$ & 255.4 & 51.12 & 4899 & 39.6 & 619.1 & 4.94 & 472 \\
MSG6 & $150 \times 50 \times 10000$ & 156.43 & 52.77 & 4906 & 34.1 & 841.5 & 5.75 & 471
\end{tabular}

The information in Table 20 showing what grades are coming from the current mills production, giving an indication of profit to be made from each timber importer. This graph holds a number of different information, with the beginning showing a rough estimate on the timber dimensions, which are presumed to be planned down to. Then after that is the main three for width, thickness and length all of which are added into the equation and used to find the MOE. Then there is the density and weight 
of the material, both of which are again added into the formula. This formula then gives the MOE results, and an identification number from which the boards can be judged against. All of this addition information adds value to the processed timber, and is constantly improving the profit margin which most New Zealand mills are operating at.

Table 20 Read out of Daily run based on 10.1 page 92

\begin{tabular}{lcl} 
Grade & Amount & \\
\hline na & 1 \\
\hline MSG12 & 11 \\
\hline MSG10 & 95 \\
\hline MSG8 & 201 \\
\hline MSG6 & \\
\hline Low & 50 \\
\hline Not Grad & 21 \\
\hline
\end{tabular}

\subsubsection{Acoustic Grading}

The act of Acoustic Grading is when a machine such as a small metal box is placed at one end of the materials, and that processed to strike the end of the members. This striking produces sound information, which coupled with the above information in Table 8, produces the MOE. Unfortunately at the moment there are no producers who is willing to explain how this performs the MOE.

This testing is being conducted through the use of the three point bending machine, which is not what current industry standards are being conducted on. Mills have changed from this form of measurement to the Acoustic testing. The Acoustic grading technology was alleged to produce more accurate results at a higher rate. With the introduction of this material creating a situation where company managers are saying things such as: 
"The A-Grader has allowed us to produce more higher grade, structurally certified lumber than we otherwise would have been able to do. Without this technology we most probably would not be attempting to produce framing at all."

Mark Hansen, Director Rosvall Sawmill Ltd (SCION, 2008)

This quote states that through the accuracy that this grading tool creates, all timber grader is a correct grade, which is at a "higher grade". This information does create questions, such as: should a grading technology be increasing the grade which timber is being given?

As this is the current industry standard, then the three point bending tester that this thesis is using will need to produce similar to the same results. This required Acoustic graded material to be sourced, thus allow direct correlation.

\subsubsection{Acoustic Companies}

Acquiring an acoustic grader will require the research into two of the main engineering companies which construct the product. Both have a product which is used in industry. Both these companies have different business across New Zealand, and intend to continue to supply their technology (Chung, 2017a; Trowbridge, 2017).

\subsubsection{Products}

The two separate products have identical functions and provide the same information, although the A-grader was produced using the partnership between the engineering company and researching company.

The Acoustic grader works through the use of frequency technology, using a hydraulic hammer which strikes the end of each board. This frequency then travels the length of the board and returns back to the original striking point. Through the length of time and frequency received, coupled with the dimensions and density, a modulus of elasticity $\mathrm{MOE}$ can be derived from the information (conversation with company).

\subsubsection{Differences}

Acoustic technology has a number of different features, compared to the original three point bending test technology. These features allow for different information to be produced as the material moves through the processing line.

\subsubsection{Location}

The first difference is its testing location. Three point bending machines would test timber after it has exited the kiln dryer. This unfortunately wastes a large amount of processing time which could have 
been diverted off at early stages. The Acoustic graders are located directly after the initial sawing location, just after the boards have been cut. Due to how the grading is completed the boards are not required to be dry, and testing can be done whilst they remain in the green stage (Sabatier, 2001). This fast acting grading allows for boards of lower quality to be diverted, and profits to increase drastically.

\subsubsection{Processes}

The three point bending test requires three separate points of contact to operate with meaningful results. This can be taken from the Plessey Computermatic, the Eldeco Dart, Metriguard Continuous Lumber Tester, and the Cook-Bolinder Grader machines, all of which work by running timber members through a set of weight inducing points, which relay the appropriate deflection.

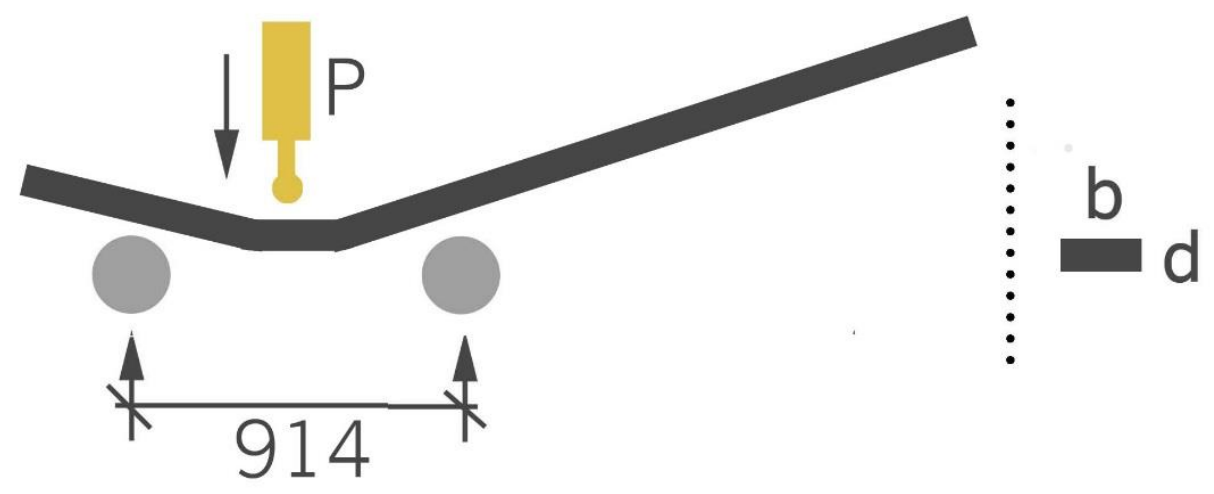

Figure 10 Constant load(authors own) based on (NZ Wood, 2007)

The Acoustic frequency generating process, explains how the system works in a timely fashion.

\subsubsection{Comparison}

Due to the differences in testing, acoustically graded material should be retested using the three point bending machine, in doing so creating confidence between the three point bending machine and industry verified acoustic tests.

\subsection{CALIBRATION TESTING}

Levin Crighton's mill supplied the researcher with samples from each of the MSG grades to be tested with the three point bending test. This material came in the form of a $45 \times 45 \mathrm{~mm}$ piece of each member, which in turn could be tested. 


\subsubsection{Testing Results}

Table 21 MOE comparison between the two testing methods

\begin{tabular}{|c|c|c|c|c|}
\hline & Grade & Colour Mark & $\begin{array}{l}\text { Bending strength } \\
\text { (MPA) }\end{array}$ & $\begin{array}{l}\text { Bending stiffness } \\
\text { (GPA) }\end{array}$ \\
\hline Acoustics & SG6 Wet & Blue & 10 & 6 \\
\hline Three point & SG6 Wet & Blue & 27 & 4.46 \\
\hline Acoustics & SG8 Wet & Black & 14 & 8 \\
\hline Three point & SG8 Wet & Black & 34 & 5.03 \\
\hline Acoustics & SG10 Wet & Green & 20 & 10 \\
\hline Three point & SG10 Wet & Green & 0 & 5.98 \\
\hline Acoustics & SG12 Wet & Purple & 28 & 12 \\
\hline Three point & SG12 Wet & Purple & 28 & 6.39 \\
\hline
\end{tabular}

Table 21 is a comparative tool which is used to compare the bending strength of the samples, to the test conducted here. The Acoustic material was tested using the machine at the saw mill, whilst the material that was tested here has been tested through a three point bending test machine. This table examine the two in comparison to one another.

This shows how each member compares, with the codes and compliance stating that this member must be at a MOE of 6GPA. Whereas when the three point bending test conducted the comparative study the result was 4.46 GPA which does not show a strong enough correlation. When all four different timbers are tested there is even less correlation between the results. Therefore no proof of correlation can be drawn from this experiment.

\subsubsection{Upgrading the Methodology}

Due to this, the members that had been acquired needed to be retested to give the strength for the member at its size. This was done through Calibre Equipment, who took the timber members and tested them on the Acoustic tester that was at their workshop. This retesting gave each member an accurate $\mathrm{MOE}$, which could then be tested against for an understanding on how three point directly compared to Acoustics testing. This was to be done straight after the Acoustic testing had been done, as when the timber dries the structural properties change (Chung, 2017b). 


\subsubsection{Retested Testing Results}

Table 22 MOE retesting comparison between the two methods

\begin{tabular}{llc} 
New or Recycled & Grade & Bending stiffness (GPA) \\
New & Calibre Ecoustics & 8.75 \\
New & VUW 3 point test & 8.34 \\
\hline New & Calibre Ecoustics & 11.05 \\
New & VUW 3 point test & 9.61 \\
\hline New & Calibre Ecoustics & 6.25 \\
New & VUW 3 point test & 6.40 \\
\hline New & Calibre Ecoustics & 9.75 \\
New & VuW 3 point test & 8.00
\end{tabular}

Disregarding the previous test $\mathrm{MOE}$, and testing acoustically for new measurements gave a closer indication on the results show in Table 2210. The inconsistency seems to be coming from how the hydraulic jack works on the small rig. Otherwise the results can be seen to overlay in similar ways, therefore this thesis can move forward into the testing of reusable timber.

\subsection{SOLUTION RIG}

The main problem presented from the calibration stage was human interaction with the hydraulic ram. This generated results which were slightly different from what the Acoustics determined. To fix this problem, the rig was upgraded to one which worked from a machine.

The most problematic component of the pressure system has been the operators input. Removing this allows for a more consistent overlap, with how codes and compliance measure timber (New Zealand Government, 1990). Thus allow for more accurate test to be conducted, along with the increased ram size. Which intern allow for larger members to be tested, and therefore less issues

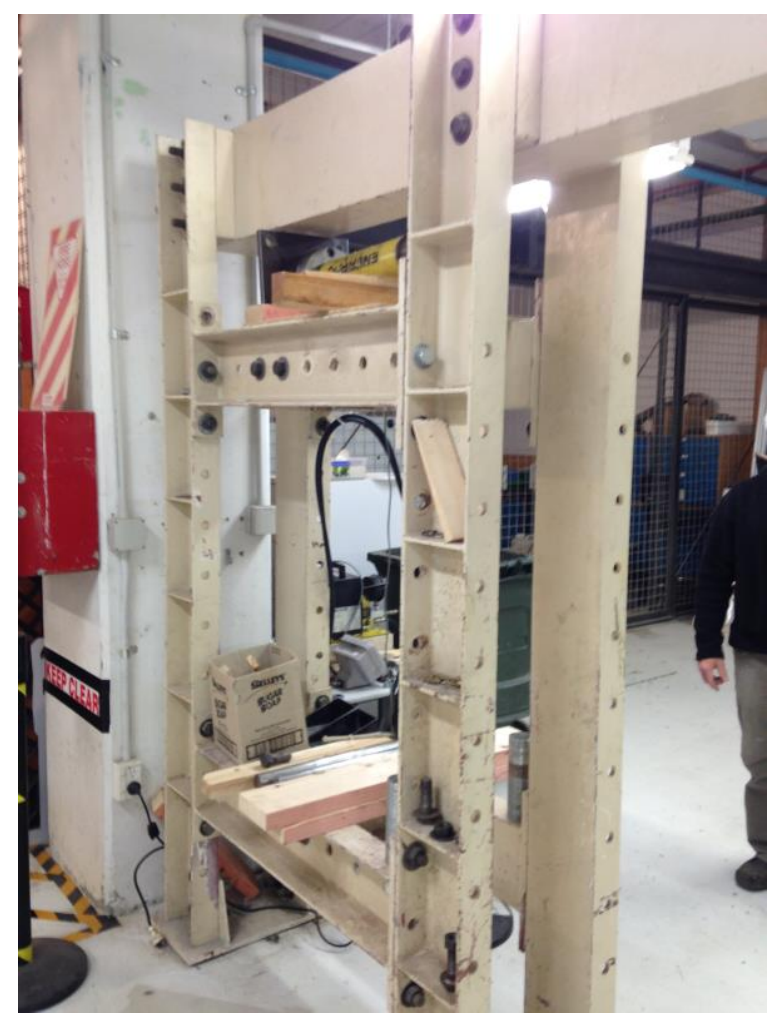

Figure 11 Location for New Rig with the picking-up of samples. 
This solution changed the recording of the load information, as due to the load cell, it is measured in kilograms. This leaves a situation where the calculation required to convert hydraulic pressure into load is not required, streaming the process.
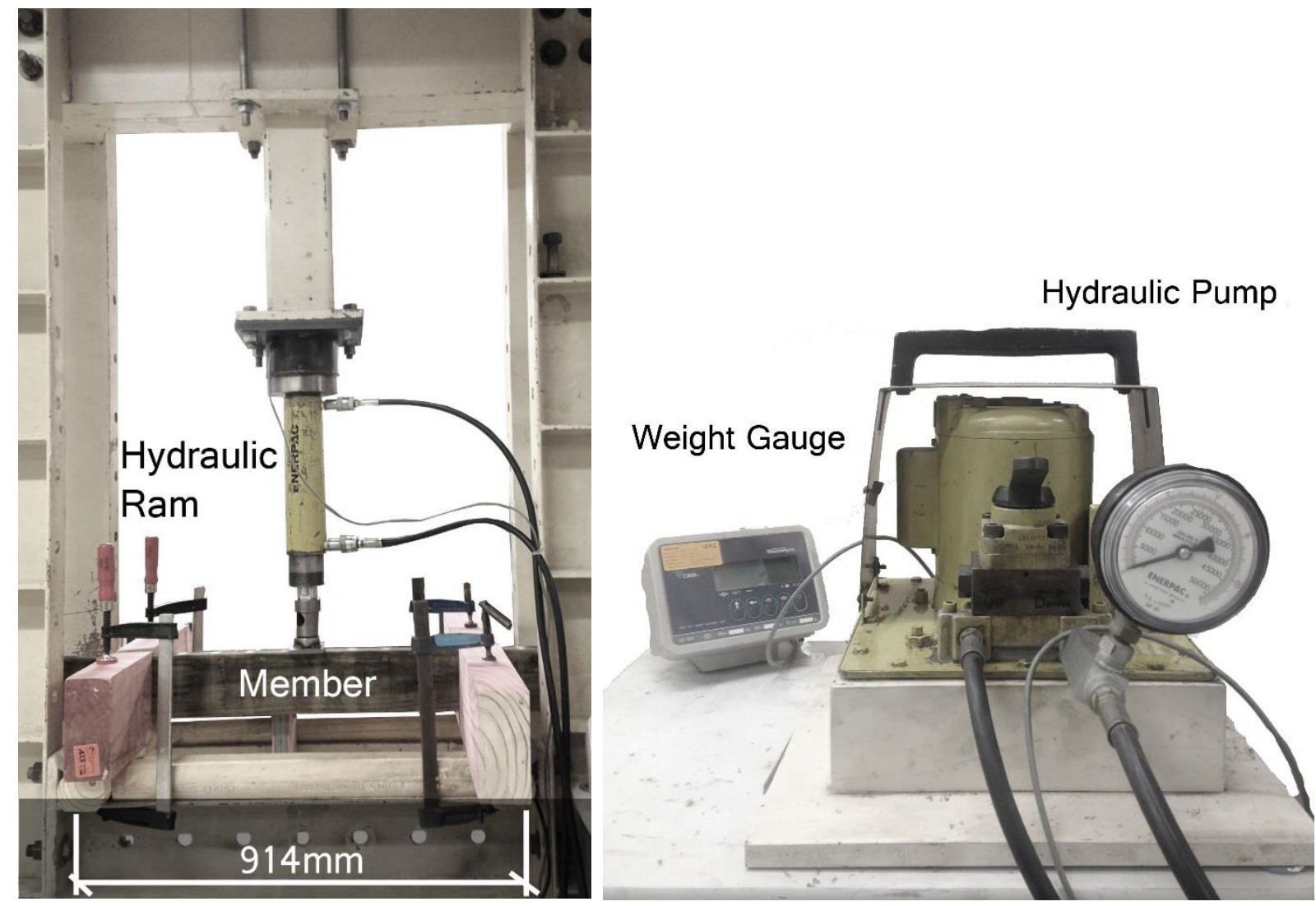

Figure 12 Hydraulic ram and Pressure gauge

\subsubsection{Visual Representative}

Continuing on with the above paragraphs, shown in Figure 11, it can be seen how this rig will function. The distance has been set in accordance with the Plessey Computermatic, and the Eldeco Dart system at $914 \mathrm{~mm}$. The reason for the $914 \mathrm{~mm}$ span, is due to it being converted over from the imperial system, but not wanting to lose all previous testing results. $914 \mathrm{~mm}$ centre are kept (refer to previous imperial measurement of 3 feet). This enable direct compassion to these test, as this system is used in the sample checking of modern assessments (NZ Wood, 2007).

Blocks are located on either side of the member to hold it in the desired location, preventing movement from effecting the result. With the point of contact being a large metal solid tube sections, 
allowing for twist as the deflection begins to happen under the load. This has been changed, and now the blocks are on their sides, thus allowing the timber to be tested on its flat side.

\subsection{SAMPLING}

To gain access to the appropriate samples there are three separate tactics which were taken.

\subsubsection{Demolition Yards}

The first tactic is demolition yards in the Wellington region. These yards will need to have the required treated timber in their position to be purchased. Demolition yards work by being a storage facility for objects of high value to be sold, usually through the internet. The yard often store a lot more than just timber from the framing in buildings, holding entire window sets, door sets and other materials brought from site (conversation with members of a site).

\subsubsection{Limitations}

With all different sampling sources there are limitations with what can be obtained. With acquiring timber from demolition yards there is no way in figuring out where the material has come from, its age and what has happened to it during its time out of the wall. All these factors could play a role in structural properties of the member.

There is no way of counteracting this problem without the demolition companies tracking each timber member. This tracking situation, is something that cannot be asked of the demolition company, but if it was to happen this could provide critical information to this study. Having the knowledge of what has happened to every member before it has even reach the testing area, would allowing a much more strict VSG arrangement.

\section{RDL Demolition Yard (124 Hutt Park Road, Lower Hutt, Wellington)}

After a conversation with a member of RDL, their demolition yard. Although hard to find - did have a number of potentially helpful materials to be tested in this thesis. The only problem for this location was the pricing of each timber member. Each timber piece was priced at $\$ 4$ a metre, whilst new treated pine is only a mere $\$ 6.43$ a metre.

Due to the extensive amount of material needed for testing, potential purchase cost would have been high.

\section{The Building Recyclers (3 Raiha Street, Porirua, Wellington)}

Another Wellington demolition yard was found in Porirua. This yard was portrayed through their website as a large building recyclers, but on inspection was found to be quite small. None of the 
recycled pine was found to be there, and could not be obtained through their services. This ruled them out, and pushed the search for samples elsewhere.

\section{No. 8 Building Recyclers (114 Tirangi Road, Rongotai, Wellington)}

Similar problems occurred with No. 8 Building Recyclers, as their stock is much smaller than was expected through their website. Although this did not require a visit, as Trademe was used to place all the required information.

\section{Phoenix Contracting Recycling (1214 Maraekakaho Road, Hastings, Hawkes Bay)}

Due to the previous three yards being unhelpful, it was thought to focus on a yard in Hawkes Bay. Hawkes Bay provides a better experience when purchasing materials for destruction. This is due to their relax verdict, which allows this thesis to take any materials from within the yard which could

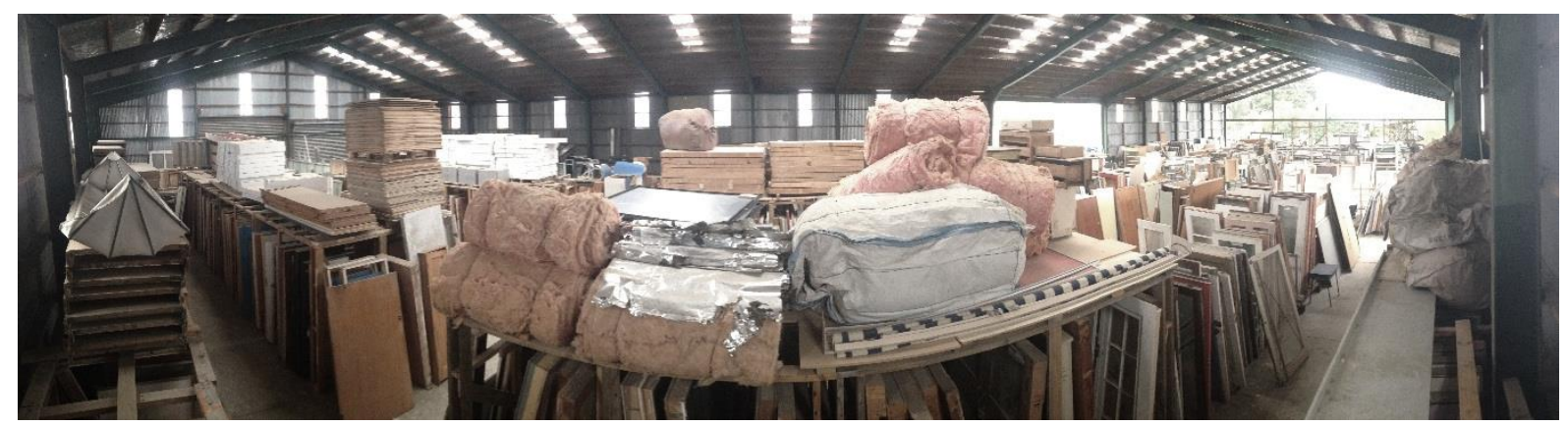

Figure 13 Shed Layout Phoenix Recyclers (imagesource; authors, 2017)

prove useful.

Phoenix's yard has a number of different materials, ranging from corrugated iron to concrete slabs, all reprocessed from demolished buildings shown in Figure 15. There are many yards with similar debris in which can be picked through to find the most appropriate material for testing. This made Phoenix recyclers the best option to obtain some of the timber required for testing.

\subsubsection{Building Companies}

The second tactic for obtaining more material, came from moving directly towards building companies: contacting the builders personally, and finding what they are currently working on. For this to work there only needed to be one builder who is willing to put aside materials that will provide the information through testing.

\section{Mudge Builders Ltd}

After contacting a number of different builders in the Wellington district, Mudge Builders agreed to begin with the process of allocating materials. Unfortunately after attempting to regain contact with this company there was no answer, and no apparent attempt to put aside materials. 


\subsubsection{Scavenging}

With this thesis being conducted in a major city of Wellington, there are many different construction projects around town. This way of obtain materials called "dumpster diving" allows for the materials coming off site to be tested immediately.

\subsubsection{Limitations}

Again this type of scavenging takes the ability to spend a lot of time being in and around dumpsters, whilst also considering the large distance between the sites. Due to this problem the idea was scraped and there was no dumpster diving.

\subsubsection{Solution}

This led to the only possible solution of continuing on with the recycling yard option. This creates an appropriate solution as there are many different factors involved with the timber, and it can be chosen through hand selection. This gives an ability to find samples which display a range of different factors, allowing testing to cover a range of degraded timbers. 


\section{Three Point Bending Testing}

\subsection{TESTING}

The first stage of testing focused on the timber itself, disregarding the external points of influence on the results. The members had been sourced locally, and from a demolition yard in Hawkes Bay for monetary reasons. The timber was gathered by visually grading the timber via information left behind by previous graders. Also other timber sources were introduced, for example a number of Rimu members were sourced from comparative studies against new timbers.

The first main issues which has been found is the lack of CCA treated examples being help by these companies. With also the impossibilities of deciphering what grade treatment it is, and how it has been used in construction. These have created a problem directly off the line with testing samples from treated backgrounds. But for all intents and purposes, there should not be too much difference between a timber member that has been treated and an untreated member which has been held in high standards throughout its life.

But this has allowed for preliminary testing of the VSG's which have been set up to attempt to predetermine timber strength. By predetermining this the test can understand how each grade effects the timber of the length of $914 \mathrm{~mm}$.

\subsection{RESULTS}

Beginning with all member sourced from demolition yards, these members were placed against the current codes and compliance. The grading was done through using VSG rules to grade against, and then checking the comparison.

Table 23 Comparison with the VSG grading rules

\begin{tabular}{l|c|c|cc|c} 
Species & Size & VSG Grading & Strength & Stiffness & VSG Comparison \\
\hline Pinus & $5 \times 2$ & 8 & 55.4 & 14.6 & 6.6 \\
Pinus & $4 \times 2$ & 8 & 54.74 & 14.54 & 6.54 \\
Pinus & $6 \times 2$ & 8 & 56.64 & 11.86 & 3.86 \\
Pinus & $4 \times 2$ & 8 & 63.84 & 11.66 & 3.66 \\
Pinus & $4 \times 2$ & 8 & 51.56 & 10.77 & 2.77 \\
Pinus & $4 \times 2$ & 8 & 56.2 & 10.52 & 2.52 \\
Pinus & $6 \times 2$ & 8 & 81.72 & 10.3 & 2.3
\end{tabular}




\begin{tabular}{|c|c|c|c|c|c|}
\hline Rimu & $4 \times 2$ & 8 & 42.55 & 10.27 & 2.27 \\
\hline Rimu & $4 \times 2$ & 8 & 43.77 & 9.91 & 1.91 \\
\hline Pinus & $4 \times 2$ & 8 & 63.85 & 9.8 & 1.8 \\
\hline Rimu & $4 \times 2$ & 8 & 44.17 & 9.61 & 1.61 \\
\hline Pinus & $4 \times 2$ & 8 & 70.35 & 9.45 & 1.45 \\
\hline Rimu & $4 \times 2$ & 8 & 47.79 & 9.44 & 1.44 \\
\hline Pinus & $4 \times 2$ & 8 & 35.62 & 9.15 & 1.15 \\
\hline Pinus & $4 \times 2$ & 8 & 31.26 & 8.95 & 0.95 \\
\hline Pinus & $4 \times 2$ & 8 & 34.34 & 8.82 & 0.82 \\
\hline Pinus & $6 \times 2$ & 8 & 54.12 & 8.7 & 0.7 \\
\hline Pinus & $4 \times 2$ & 8 & 41.49 & 8.54 & 0.54 \\
\hline Pinus & $4 \times 2$ & 6.1 & 30.29 & 8.39 & 2.29 \\
\hline Pinus & $4 \times 2$ & 8 & 40.14 & 8.37 & 0.37 \\
\hline Pinus & $4 \times 2$ & 8 & 64.12 & 8.36 & 0.36 \\
\hline Pinus & $4 \times 4$ & 8 & 53.78 & 8.35 & 0.35 \\
\hline Pinus & $4 \times 2$ & 8 & 49.44 & 8.28 & 0.28 \\
\hline Pinus & $4 \times 2$ & 8 & 36.27 & 8.12 & 0.12 \\
\hline Pinus & $4 \times 2$ & 6.1 & 54.61 & 8.12 & 2.02 \\
\hline Pinus & $6 \times 2$ & 8 & 39.1 & 8.06 & 0.06 \\
\hline Pinus & $4 \times 2$ & 8 & 47.5 & 7.81 & -0.19 \\
\hline Rimu & $4 \times 2$ & 6.1 & 56.91 & 7.74 & 1.64 \\
\hline Pinus & $4 \times 2$ & 6.1 & 42.27 & 7.7 & 1.6 \\
\hline Pinus & $4 \times 2$ & 6.1 & 47 & 7.5 & 1.4 \\
\hline Pinus & $4 \times 2$ & 6.1 & 33.43 & 7.41 & 1.31 \\
\hline Rimu & $4 \times 2$ & 6.1 & 41.69 & 7.38 & 1.28 \\
\hline Totra & $3 \times 1.5$ & 6.1 & 27.89 & 7.24 & 1.14 \\
\hline Pinus & $4 \times 2$ & 6.1 & 20.63 & 7.07 & 0.97 \\
\hline Pinus & $6 \times 2$ & 6.1 & 20.11 & 7.01 & 0.91 \\
\hline Pinus & $4 \times 2$ & 6.1 & 27.51 & 6.91 & 0.81 \\
\hline Pinus & $4 \times 2$ & 6.1 & 33.54 & 6.9 & 0.8 \\
\hline Pinus & $6 \times 2$ & 6.1 & 28.77 & 6.8 & 0.7 \\
\hline Pinus & $4 \times 2$ & 6.1 & 28.67 & 6.77 & 0.67 \\
\hline Pinus & $4 \times 2$ & 6.1 & 26.29 & 6.76 & 0.66 \\
\hline Pinus & $4 \times 2$ & 6.1 & 41.35 & 6.5 & 0.4 \\
\hline
\end{tabular}




\begin{tabular}{ll|lcc|c} 
Pinus & $6 \times 2$ & 6.1 & 28.95 & 6.39 & 0.29 \\
Pinus & $6 \times 2$ & 6.1 & 25.73 & 6.32 & 0.22 \\
Pinus & $4 \times 2$ & 6.1 & 44.5 & 5.9 & -0.2 \\
Pinus & $6 \times 2$ & N/A & 30.4 & 5.58 & -0.52 \\
Pinus & $4 \times 2$ & N/A & 37.89 & 5.37 & -0.73 \\
Pinus & $4 \times 4$ & N/A & 21.28 & 4.61 & -1.49
\end{tabular}

Through the use of VSG the thesis can see in what scenarios did the system fail, which were all noted as failures. All the materials, apart from the one in the middle section of the table, were visual viewed as lower quality timber, and would not have been used in construction. This was done apart from one, which seemed to be a pass, but after testing was not applicable.

Table 24 Timber test raw Data

\begin{tabular}{|c|c|c|c|}
\hline \multicolumn{4}{|c|}{ Pine Strength and Stiffness } \\
\hline & & Strength & Stiffness \\
\hline \multicolumn{2}{|l|}{ No.1 Framing } & 17.70 & 8 \\
\hline \multicolumn{2}{|l|}{ No.2 Framing } & 13.00 & 6.1 \\
\hline \multicolumn{2}{|l|}{ SG6 } & 10.0 & 6.00 \\
\hline \multicolumn{2}{|l|}{ SG8 } & 14.0 & 8.00 \\
\hline \multicolumn{2}{|l|}{ SG10 } & 20.0 & 10.00 \\
\hline \multicolumn{2}{|l|}{ SG12 } & 28.00 & 12.0 \\
\hline \multicolumn{4}{|l|}{ Pine $4 \times 4$} \\
\hline & 1 & 53.8 & 8.60 \\
\hline & 2 & 21.3 & 4.60 \\
\hline \multicolumn{4}{|l|}{ Pine $6 \times 2$} \\
\hline & 1 & 11.9 & 5.64 \\
\hline & 2 & 81.7 & 10.30 \\
\hline & 3 & 54.1 & 8.70 \\
\hline & 4 & 39.1 & 8.06 \\
\hline & 5 & 28.77 & 6.8 \\
\hline & 6 & 20.11 & 7.01 \\
\hline & 7 & 28.96 & 6.36 \\
\hline & 8 & 25.73 & 6.32 \\
\hline & 9 & 30.4 & 5.58 \\
\hline
\end{tabular}




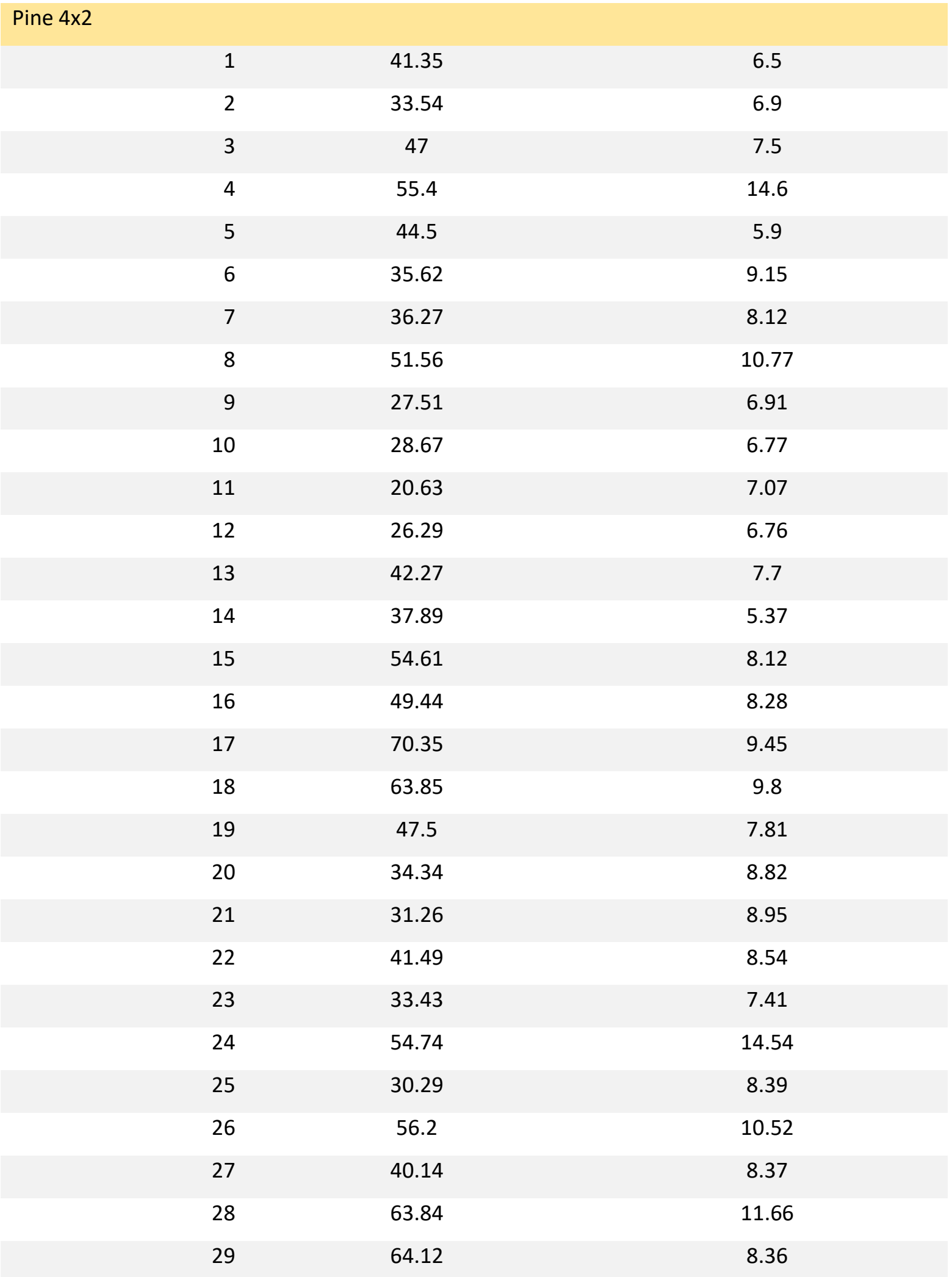

The correlation of these results will continue in the next section. Each result comes from the three point bending test conducted in this university. The above data is broken down into the sizes in which 
was obtained from the recycling yard. Obtaining different sizes reinforces the concept that all pine has the potential to be a part of this testing process.

All this data was graphed against the main codes and compliance data, which was sourced through the codes and compliance data.

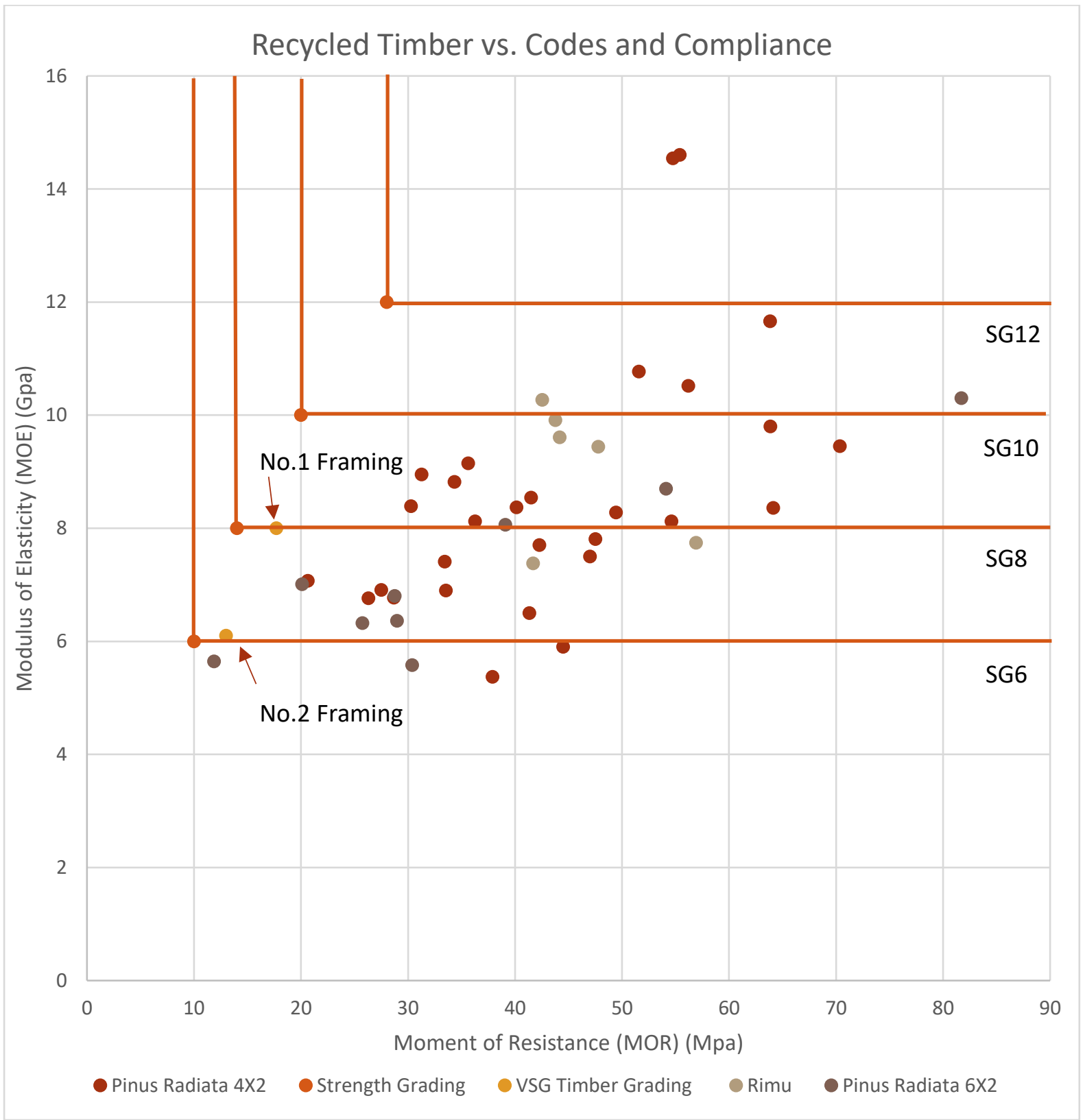

Figure 14 Test results Layout

The above graph is the first outline to understanding the results set out by the three point testing machine. In this graph it is clear to see that the Pinus $4 \times 2$ and $6 \times 2$ are the large plotting, as shown in the colour red and dark green, whilst the Rimu members are plotted in light grey. All of these are mapped against the framing standards, which have been highlighted in orange, making them the focus 
point of the document. This also presents the original VSG results, displayed in yellow, which again almost exactly follow along the strength grading material.

Once all the results have been graphed against one another, it is clear to see how this system is working. To focus this, everything must be brought back to SG6 on the graph, and in particular the bottom line in this area. SG6 is the lowest grade available from the New Zealand Strength Grading area, and is something that a lot of reused timber can bench mark itself against.

As explained in previous sections VSG's grading rules run around Timber Framing grades of 1 and 2 . These two grades run along the lowest SG rules, of 6 and 8 as displayed in the above Figure 146. This again is on the bottom two grading rules and again is meet by a number of the test subjects.

From this it is clear to see that the reusable timber is almost all over the lower quartile of grading standards, which as the samples were picked based on their visual features. Features which both hinder and helped the material, allow the spectrum to be as broad as possible.

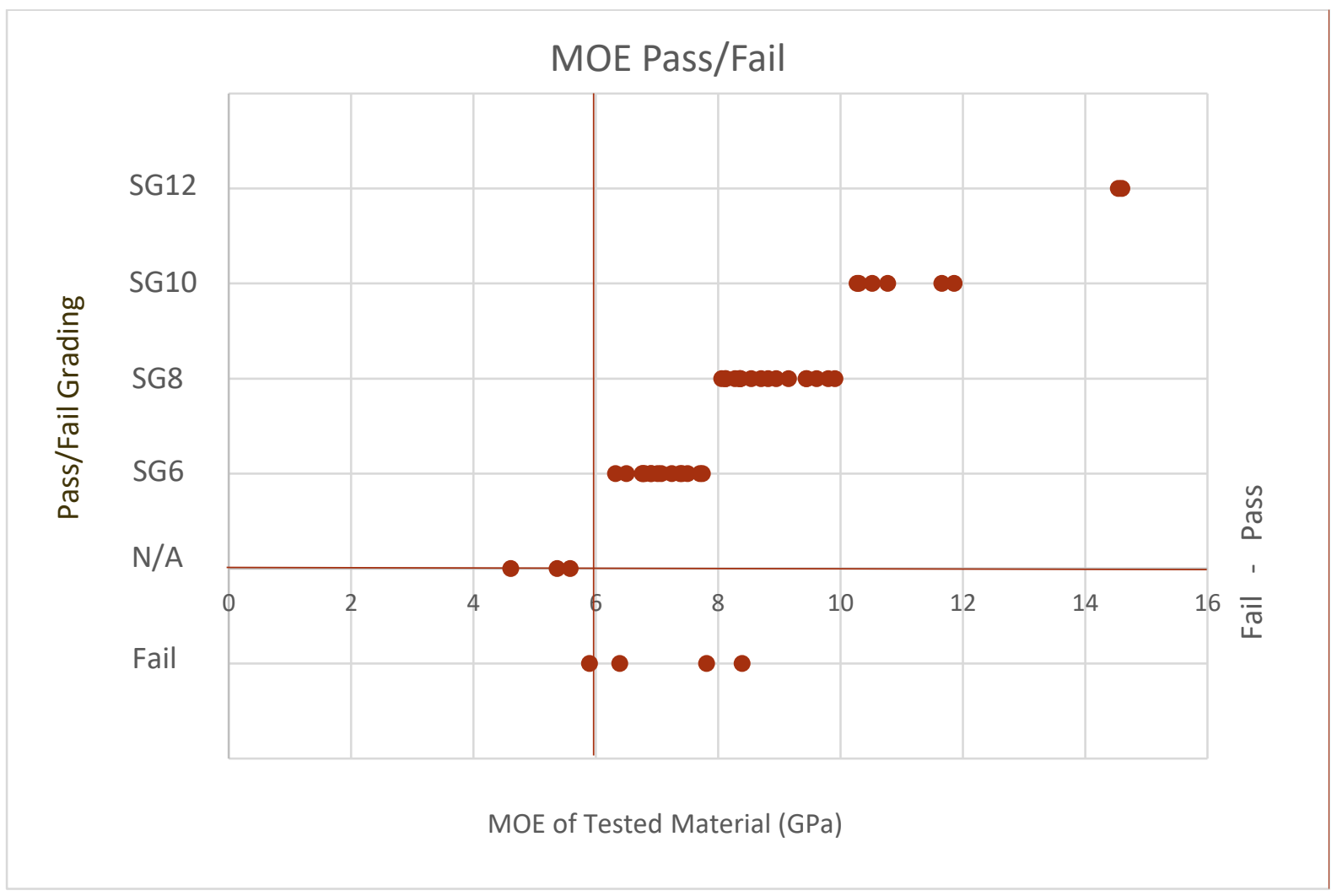

Figure 15 Pass/ Fail grading of tested material

The above graph explains how each material fits into failure or passing Figure 14 . As can be seen in the middle of the graph on bar 6 there is a red line which holds the path between a good piece of timber and a bad piece of timber. This although is not bad as the timber that falls below this line is predominantly on the line of N/A, which has been allocated to timber which did not pass the VSG 
grading material. Some of these figures fall below that line into the failure area, which has been create to hold the members which did pass, but then after the three point bending test failed.

These four members, all of which failed at different intervals, the first of which was a fence post, which was covered in mould, but did have the VSG's versions of a low grade timber member. This unfortunately was wrong, and possible something which could have been picked up on. The second failure happen just after the point break line, with the material showing under the visual inspection mark. This therefore gave a negative mark, as when tested the member performed above the mark, again another point which could have been foreseen, but due to the close proximity of the point break line all can seem to be justified.

The next two were both around the area of change between No.2 and No.1 standard grading. With the first being slightly under the point, and the second being slightly over, two area which could not have been really prevented against. As when going through a timber member the performance can only estimate and therefore not explained in the fullest until the testing.

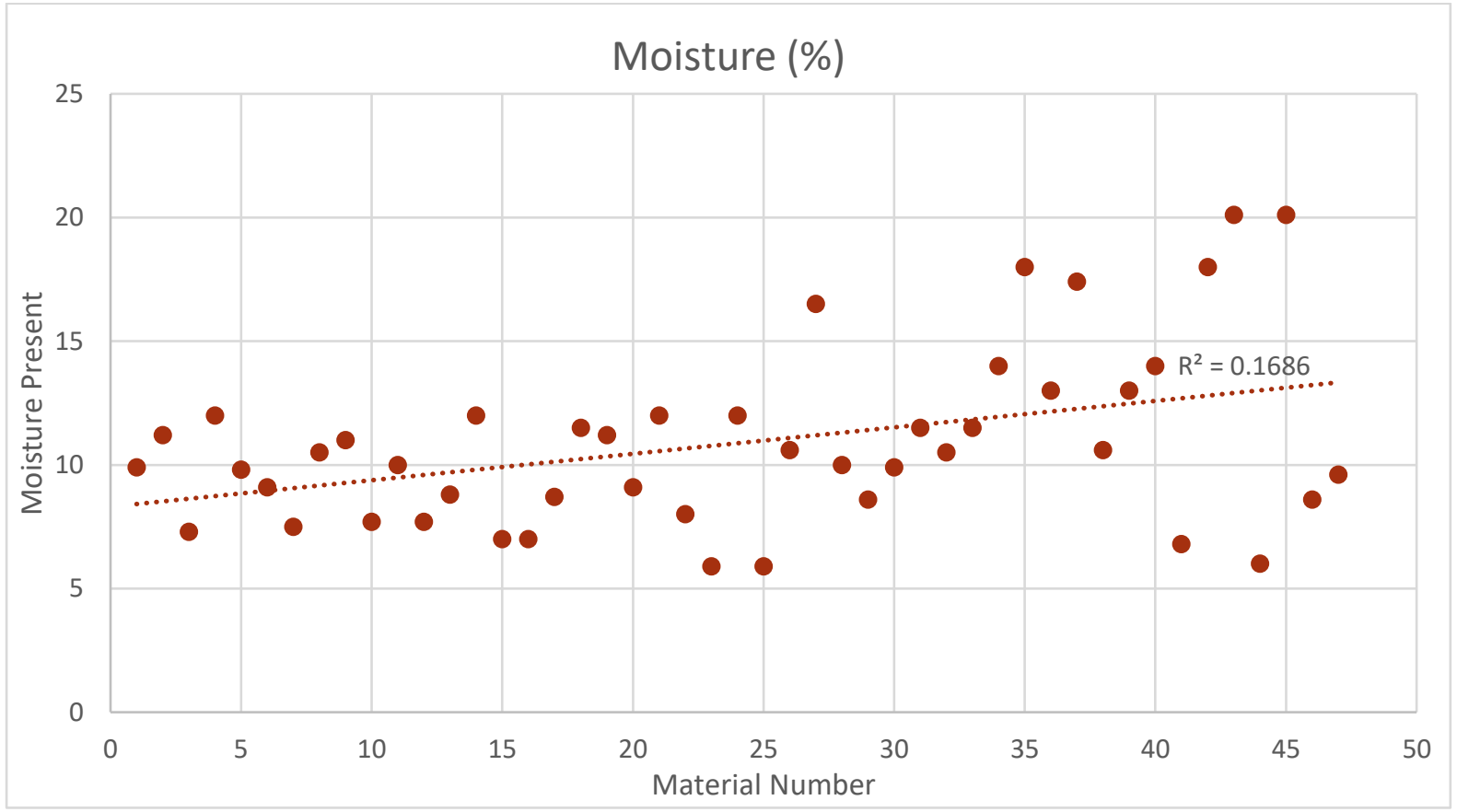

Figure 16 Timber Verses Moisture

One of the ways which could have helped with the ongoing ability for demolition companies to pull aside the correct timber, would be to test it in the building before demolition. Once the data had been tested this did not explain itself as the $\mathrm{R}^{2}$ value displayed was much lower. This therefore create a situation were as through this tested data, there is no possible way to accurately estimate the strength of a member. 
This information should prevent the demolition companies from removing this material, as through the above codes and compliance research there are a number of different possibilities for its reuse.

\subsection{TESTING CONCLUSION}

Over the course of the testing each member has performed itself towards the strength grading criteria. This direct comparison shows in Figure 14 that $91 \%$ of all results were within the strength grade requirements, with 55\% of those being within the SG8 area, which is the most used strength grade that is sold.

This all leads to the verdict that nearly all (91\%) of the reusable timber is within the strength graded requirements and over half is reaching the SG8 strength criteria (55\%), and therefore can be carbon stored in new homes around New Zealand. On top of that the VSG criteria will work if needed, and can be used on site with the builder moving through some kind of educational format that trains them to use the material. 


\section{Summary and Discussion}

\subsection{SUMMARY}

Many of the question asked during the thesis have been answered, with the first being "is this job a profitable one?" There is clear intent that this material can produce profit, the only problem being that it is currently cheaper to place it in landfill, and this is where the problem is for this part of the research.

CCA treated timber is problematic once it comes to the disposal, and there have been many different case studies done on the alternative to disposing of it in landfill. With these documents New Zealand could be another one of the regulators, prevent this material from being used and then being dumped into the landfill.

The overall component of this thesis was to find out about the structural qualities of treated timber, and if they could be used in new construction. This component was found to be true, with $91 \%$ of the timber tested being over the structural strength grade, which is a good outcome for all the testing. This gives a new understanding of what is being throw out, allowing them to go through the recycling yard picking material which will be above the strength grading.

Then if they wish, there is the VSG grading criteria, which can be used on all pinus radiata allowing them to get an understanding on what grade it could be. This is understood to only be an estimate at the moment, but there was a time where all timber was tested in this fashion allowing the majority of materials on site to be visually graded.

\subsection{DISCUSSION}

The entirety of this thesis focused on the prevention of reusable timber being placed into landfill, and doing this through the effective management of reusing it. This is something which New Zealand could have come on to some time ago, but due to the dump fees this has been put to the side. For this to be accepted into the construction industry there needs to be education to builders on the potential that these materials have, allowing them to use reusable timber in the construction.

This is a direct consequence as all timber comes from a saw mill, and has come from them conducting the strength grading. This has sped up the building process, but then the builders have limited understanding of what each member's timber specification is, and are looking over the fact that it could be possible to construct with reusable timber. Therefore the real question is how to educate the 
builder in understanding the quickest easiest way to reuse the material. This should be the next point of research to allow this into the work force, and change the average builder mind-set on reusing CCA treated timber. 


\section{References}

Ahn, S. H., Oh, S. C., Choi, I. gyu, Han, G. seong, Jeong, H. seob, Kim, K. woo, ... Yang, I. (2010). Environmentally friendly wood preservatives formulated with enzymatic-hydrolyzed okara, copper and/or boron salts. Journal of Hazardous Materials, 178(1-3), 604-611. doi:10.1016/j.jhazmat.2010.01.128

Auckland City Council. (2015). Waste Management and Minimisation Plan Update, (July). Retrieved from www.auckland.govt.nz

Beca Carter Holling \& Fertner Ltd. (2002). A Guide to the Management of Cleanfills. Ministry of the Enviroment.

Brancheriau, L., Bailleres, H., \& Guitard, D. (2002). Comparison between modulus of elasticity values calculated using 3 and 4 point bending tests on wooden samples. Wood Science and Technology, 36(5), 367-383. doi:10.1007/s00226-002-0147-3

Brand, P. (2010). Reuse and Restoration. UCLA Encyclopedia of Egyptology, 16.

Brand, S. (2009). Whole Earth Discipline: An Ecopragmatist Manifesto.

BRANZ Limited. (2017). Hazard Classes. Weather Tight. Retrieved from http://www.weathertight.org.nz/new-buildings/timber-treatment/

Building Performance. (2018). Mould. New Zealand Goverment. Retrieved from https://www.building.govt.nz/resolving-problems/resolution-options/weathertightservices/fap/fap-factsheets/mould/\#jumpto-toxic-mould

Bunnings Warehouse. (2017). Results for H3.2. Bunnings. Retrieved from https://www.bunnings.co.nz/search/products?q=H3.2

Burdon, R. D., \& Harris, J. M. (1973). Wood density in radiata pine clones on four different sites. New Zealand Journal of Forestry Science, 3(3), 286-303.

Canterbury, T. (2017). Kate Valley Landfill. transwaste canturbury. Retrieved from https://transwastecanterbury.co.nz/webpage/kate-valley/

Carpenter, P. (2004). Grade Verified Information Sheet What is SG timber eg ., SG8 ?, 7-8.

Chung. (2017a). Calibre Equipment. Calibre Equipment Ltd. Retrieved from http://calibreequipment.com/ 
Chung. (2017b). Ecoustic Technology. In Calibre Equipment Ltd (p. 1).

Cookson, L. J. (2013). Durability of light organic solvent preservative (LOSP) treatments for softwood glulam. International Biodeterioration and Biodegradation, 80, 41-47. doi:10.1016/j.ibiod.2013.02.003

Crews, K. (2007). Development of Visual Grading Rules for Re-cycled Timber Report on Testing, (December), 1-26.

Crews, K., Hayward, D., \& MacKenzie, C. (2008). Interim Industry Standard Recycled Timber - Visually Stress Graded Recycled Timber for Structural Purposes (Vol. 61). Melbourne.

Denne, T., \& Bond-Smith, S. (2012). Economic Factors of Waste Minimisation Final, 10.

Department of building and Housing. (2010). Compliance Document for New Zealand Building Code Handbook Handbook : Document History. New Zealand Codes and Compliance, 0(04), 1-32.

Dictionary. (2017). Economics. Dictionary. Retrieved from http://www.dictionary.com/browse/economics?s=t

Diyamandoglu, V., \& Fortuna, L. M. (2015). Deconstruction of wood-framed houses: Material recovery and environmental impact. Resources, Conservation and Recycling, 100, 21-30. doi:10.1016/j.resconrec.2015.04.006

Dubey, K. M. (2010). Improvements in stability, durability and mechanical properties of radiata pine wood after heat-treatment in a vegetable oil, 1-211.

DZ 3640. (2017). Preservation of timber and wood- based products.

Eldridge, K. G. (1982). Genetic improvements from a radiata pine seed orchard. New Zealand Journal of Forestry Science, 12(2), 404-411.

Elspeth, M. (2013). Ground-breaking research through global connections. Scion, (8), 1. Retrieved from https://www.scionresearch.com/about-us/about-scion/corporate-publications/scionconnections/past-issues-list/issue-8/Ground-breaking-research-through-global-connections

Employment New Zealand. (2017). Previous Minimum Wage rates. New Zealand Goverment. Retrieved from https://www.employment.govt.nz/hours-and-wages/pay/minimumwage/previous-rates/

End-of-life Care. (2010). Best Practice Guideline Best Practice Guideline, (January), 1-7.

Environmental Report Card. (2009). Solid Waste composition. Ministry for the Enviroment, (July). 
European copper in architecture. (2006). The Guide to Copper in Architecture. Copper in Architecture.

European Parliment. (2012). European Union (Energy Performance of Buildings) Regulations 2012.

European Union. (2006). Directive 76/769 EEC.

Forestry, N. Z. (1994). "A brief history of Douglas fir in New Zealand," (May), 28-30.

Fraser, S. (2013). Treated Timber Waste Minimisation Project Timber Identification Tool (Vol. 8).

Gardens, C. of B. (2017). The Plant List. The Plant List. Retrieved from http://www.theplantlist.org/tpl1.1/search?q=pinus

Gaunt, D. (2012). A revolution in structural timber grading. Auckland.

Gezer, E. D., Yildiz, U., Yildiz, S., Dizman, E., \& Temiz, A. (2006). Removal copper, chromium and arsenic from CCA-treated yellow pine by oleic acid. Building and Environment, 41(3), 380-385. doi:10.1016/j.buildenv.2005.02.014

Googlemaps. (2017). Building Recyclers New Zealand. Google. Retrieved from https://www.google.co.nz/

Gorby, M. S. (1988). Arsenic poisoning. The Western Journal of Medicine, 149(3), 308-15. doi:10.1016/j.jaad.2006.10.635

Hedley, M. D. (1997). An assessment of risks associated with use of CCA-treated timber in sensitive environments and options for its substitution with alternative timber materials.

Horrigan, A., Crews, K., \& Boughton, G. (n.d.). in-Grade Testing of Utility Poles in Australia. NZ Timber Design Journal, 9(2), 17-24.

Inglis, M. (2009). Ministry for the Environment, 23 Kate Sheppard Place, Wellington., 1-12.

Investopedia. (2017). Market Value. Investopedia. Retrieved from https://www.investopedia.com/terms/m/marketvalue.asp

Is dam lining. (2017). Hampton Downs Landfill. I.S. Dam Lining. Retrieved from https://isdamlining.co.nz/completed-projects/hampton-downs-landfill-stage-3b-northwaikato/

Jayawickrama, K. J. S., \& Low, C. B. (1999). Pinus radiata selections from different regions of New ZeaLand differ in branch habit, form, and growth rate. New Zealand Journal of Forestry Science, 29(1), 3-24. 
Lebow, S. (2004). Alternatives to chromated copper arsenate for residential construction., 1-9. Retrieved from google/scholar

Lizarralde, G. (2011). Stakeholder participation and incremental housing in subsidized housing projects in Colombia and South Africa. Habitat International, 35(2), 175-187. doi:10.1016/j.habitatint.2010.08.001

Marston, N., \& Singh, T. (2013). Treated Timber Waste Minimisation Project. Environment Canterbury.

Mercer, T. G., \& Frostick, L. E. (2014). Evaluating the potential for environmental pollution from chromated copper arsenate (CCA)-treated wood waste: A new mass balance approach. Journal of Hazardous Materials, 276, 10-18. doi:10.1016/j.jhazmat.2014.05.006

Ministry for Primary Industry. (2017). Generic Log Type \& Pricing Point. Ministry for Primary Industry. Retrieved from http://www.mpi.govt.nz/news-and-resources/open-data-andforecasting/forestry/wood-product-markets/historic-indicative-new-zealand-radiata-pine-logprices/

Ministry of the Enviroment. (2001). Guide to Landfill Consent Conditions. Ministry of the Enviroment. Ministry of the Enviroment. (2012). Quantity of solid waste sent to landfill indicator update. Ministry of the Enviroment. Retrieved from http://www.mfe.govt.nz/more/environmentalreporting/reporting-act/waste/solid-waste-disposal-indicator/quantity-solid-waste

Moisture and Mold in My Home. (2018). H.E.L.P, 12(6), 4.

Mujika, F. (2006). On the difference between flexural moduli obtained by three-point and four-point bending tests. Polymer Testing, 25(2), 214-220. doi:10.1016/j.polymertesting.2005.10.006

Murphy, C. (2010). Cost effective quality : next generation building controls ? Annual Conference of the Architectural Science Association, 44th, 8.

New Zealand Government. (1990). Timber Structures Standard NZS3603:1990.

New Zealand Government. (1998). NZS 3631:1988. Retrieved from 1988.pdf

Nowak, D. J., \& Crane, D. E. (2002). Carbon storage and sequestration by urban trees in the USA. Environmental Pollution, 116(3), 381-389. doi:10.1016/S0269-7491(01)00214-7

NZ Parliamentary library. (2002). Leaky buildings, (2002/10), 1-23.

NZ Wood. (2007). Structural Materials. 
NZ Wood. (2013). Information Sheet: Eucalypts, 1-2. Retrieved from http://www.nzwood.co.nz/wpcontent/uploads/2013/07/Species-Eucalypts.pdf

NZ Wood. (2017). Forestry. Nz Wood. Retrieved from http://www.nzwood.co.nz/forestry-2/radiatapine/

NZ Wood. (2018). What alternatives are there to pine? NZwood. Retrieved from http://www.nzwood.co.nz/faqs/what-alternatives-are-there-to-pine/

Pay Scale. (2017). Builder Salary. Pay Scale. Retrieved from https://www.payscale.com/research/NZ/Job=Builder/Hourly_Rate

Read, D. (2003). Report on copper, chromium and arsenic (CCA) treated timber. New Zealand Environmental Risk Management Authority Report. (Vol. ISBN 0-478).

Sabatier, P. (2001). Wood Quality, 504-512.

Salmond, J. (2010). Tanalising timber. te Ara (The Encyclopedia of new Zealand). Retrieved from https://teara.govt.nz/en/photograph/25091/tanalising-timber

SCION. (2008). A-Grader, A timely innovation for New Zealand's wood processing industry. Retrieved from Next Generation Biomaterials

Scion research. (2017). Scion: Who are we. http://www.scionresearch.com. Retrieved from http://www.scionresearch.com/about-us/about-scion/who-we-are

Shelton, R., \& Beattie, G. (2011). Timber Framed Buildings and NZS 3604, (Nzs 3604), 5. Retrieved from www.timberdesign.org.nz/files/00556 Roger Shelton.pdf

Standards New Zealand. (1988). NZS 3631 New Zealand timber grading rules.

Standards New Zealand. (2003). NZS 3602:2003 Timber and wood-based products for use in building.

Thiagarajan, S. (1997). Removal Of Copper, Chromium And Arsenic From The Tannery And Timber Treatment Effluents And Remediation Of Chromium Cont Amina Ted Soil. Massey University.

Thomas, P. A. (2000). Trees: Their Natural History. doi:10.1017/СВ09780511790522

Trade me. (2017). Recycled Buildings. trade me. Retrieved from http://www.trademe.co.nz/

Tran, V. (2017). Evaluating The Economics Of Construction And Demolition Waste Minimisation And Zero Waste In The New Zealand Construction Industry.

Trowbridge, G. (2017). Falcon Engineering. Falcon Engineering Ltd. Retrieved from 
http://www.falcon-eng.co.nz

TUFF-BRITE. (1999). For Control of Sapstain and Mold in Freshly Cut Lumber and Timbers.

U.S. Consumer Product Safety Commission. (2004). CCA-Pressure Treated Wood Guidance for Outdoor Wooden Structures.

University of Wollongong. (2017). North America. Treated Timber. Retrieved from https://www.uow.edu.au/ sharonb/CCAtimber/regulations/America.html

US Department of Labor. (2006). Health Effects of Hexavalent Chromium. OSHA Fact Sheet, 2014(1st October), 1-2. Retrieved from https://www.osha.gov/OshDoc/data_General_Facts/hexavalent_chromium.pdf

Walford, G. B. (2001). What Timber, What Grade, What Size, What Stresses? NZ Timber Design Journal, 13-15.

Walmsley, M. (2017a). Phoenix Contracting.

Walmsley, M. (2017b). Phoenix Contracting.

Zealand, N. (2018). WOODmark INFORMATION.

Zhang, J., Kim, H., Dubey, B., \& Townsend, T. (2017). Arsenic leaching and speciation in C\&amp;D debris landfills and the relationship with gypsum drywall content. Waste Management, 59, 324-329. doi:10.1016/j.wasman.2016.10.023 


\subsection{ACOUSTIC GRADING OUTPUT}

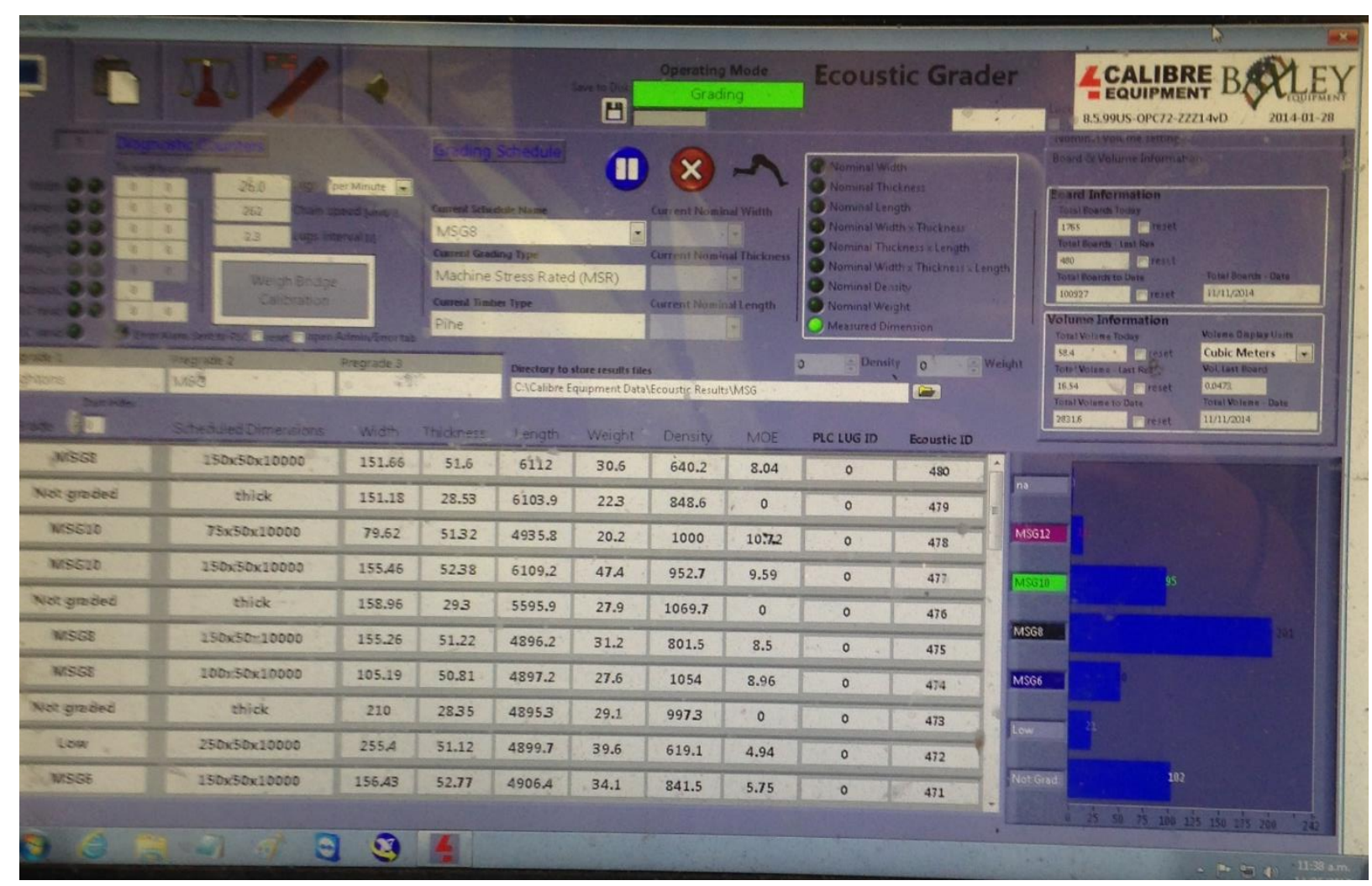

Figure 17 Acoustic Grading output 


\subsection{Testing Results}

Table 25 testing Results

\begin{tabular}{|c|c|c|c|c|c|c|c|c|c|}
\hline Species & Size & $\begin{array}{l}\text { Breadth } \\
(\mathrm{mm})\end{array}$ & $\begin{array}{l}\text { Height } \\
(\mathrm{mm})\end{array}$ & $\begin{array}{l}\text { Density } \\
\text { (Kg/m3) }\end{array}$ & $\begin{array}{l}\text { Moisture } \\
\text { (\%) }\end{array}$ & $\begin{array}{l}\text { VSG } \\
\text { Grading }\end{array}$ & $\begin{array}{c}\text { Strength } \\
\text { (Mpa) }\end{array}$ & $\begin{array}{c}\text { Stiffness } \\
\text { (Gpa) }\end{array}$ & VSG Comparison \\
\hline Pinus & $5 \times 2$ & 90 & 45 & 564 & 9.9 & 8 & 55.4 & 14.6 & 6.6 \\
\hline Pinus & $4 \times 2$ & 91 & 45 & 510 & 11.2 & 8 & 54.74 & 14.54 & 6.54 \\
\hline Pinus & $6 \times 2$ & 132 & 45 & 437 & 7.3 & 8 & 56.64 & 11.86 & 3.86 \\
\hline Pinus & $4 \times 2$ & 113 & 46 & 553 & 12 & 8 & 63.84 & 11.66 & 3.66 \\
\hline Pinus & $4 \times 2$ & 90 & 46 & 473 & 9.8 & 8 & 51.56 & 10.77 & 2.77 \\
\hline Pinus & $4 \times 2$ & 91 & 45 & 478 & 9.1 & 8 & 56.2 & 10.52 & 2.52 \\
\hline Pinus & $6 \times 2$ & 140 & 46 & 692 & 7.5 & 8 & 81.72 & 10.3 & 2.3 \\
\hline Rimu & $4 \times 2$ & 93 & 47 & 520 & 10.5 & 8 & 42.55 & 10.27 & 2.27 \\
\hline Rimu & $4 \times 2$ & 95 & 47 & 529 & 11 & 8 & 43.77 & 9.91 & 1.91 \\
\hline Pinus & $4 \times 2$ & 90 & 45 & 556 & 7.7 & 8 & 63.85 & 9.8 & 1.8 \\
\hline Rimu & $4 \times 2$ & 95 & 50 & 585 & 10 & 8 & 44.17 & 9.61 & 1.61 \\
\hline Pinus & $4 \times 2$ & 90 & 45 & 556 & 7.7 & 8 & 70.35 & 9.45 & 1.45 \\
\hline Rimu & $4 \times 2$ & 93 & 47 & 636 & 8.8 & 8 & 47.79 & 9.44 & 1.44 \\
\hline Pinus & $4 \times 2$ & 94 & 47 & 556 & 12 & 8 & 35.62 & 9.15 & 1.15 \\
\hline Pinus & $4 \times 2$ & 88 & 44 & 459 & 7 & 8 & 31.26 & 8.95 & 0.95 \\
\hline Pinus & $4 \times 2$ & 88 & 44 & 459 & 7 & 8 & 34.34 & 8.82 & 0.82 \\
\hline Pinus & $6 \times 2$ & 135 & 45 & 431 & 8.7 & 8 & 54.12 & 8.7 & 0.7 \\
\hline Pinus & $4 \times 2$ & 89 & 45 & 476 & 11.5 & 8 & 41.49 & 8.54 & 0.54 \\
\hline Pinus & $4 \times 2$ & 91 & 45 & 510 & 11.2 & 8 & 30.29 & 8.39 & 2.29 \\
\hline Pinus & $4 \times 2$ & 91 & 45 & 478 & 9.1 & 8 & 40.14 & 8.37 & 0.37 \\
\hline Pinus & $4 \times 2$ & 113 & 46 & 553 & 12 & 8 & 64.12 & 8.36 & 0.36 \\
\hline Pinus & $4 \times 4$ & 90 & 85 & 480 & 8 & 8 & 53.78 & 8.35 & 0.35 \\
\hline Pinus & $4 \times 2$ & 90 & 45 & 499 & 5.9 & 8 & 49.44 & 8.28 & 0.28 \\
\hline Pinus & $4 \times 2$ & 94 & 47 & 556 & 12 & 8 & 36.27 & 8.12 & 0.12 \\
\hline Pinus & $4 \times 2$ & 90 & 45 & 499 & 5.9 & 6.1 & 54.61 & 8.12 & 2.02 \\
\hline Pinus & $6 \times 2$ & 142 & 45 & 510 & 10.6 & 8 & 39.1 & 8.06 & 0.06 \\
\hline Pinus & $4 \times 2$ & 93 & 46 & 565 & 16.5 & 8 & 47.5 & 7.81 & -0.19 \\
\hline Rimu & $4 \times 2$ & 92 & 47 & 630 & 10 & 6.1 & 56.91 & 7.74 & 1.64 \\
\hline Pinus & $4 \times 2$ & 88 & 45 & 457 & 8.6 & 6.1 & 42.27 & 7.7 & 1.6 \\
\hline Pinus & $4 \times 2$ & 85 & 45 & 471 & 9.9 & 6.1 & 47 & 7.5 & 1.4 \\
\hline Pinus & $4 \times 2$ & 89 & 45 & 476 & 11.5 & 6.1 & 33.43 & 7.41 & 1.31 \\
\hline Rimu & $4 \times 2$ & 92 & 47 & 567 & 10.5 & 6.1 & 41.69 & 7.38 & 1.28 \\
\hline Totra & $3 \times 1.5$ & 62 & 33 & 621 & 11.5 & 6.1 & 27.89 & 7.24 & 1.14 \\
\hline Pinus & $4 \times 2$ & 101 & 49 & 561 & 14 & 6.1 & 20.63 & 7.07 & 0.97 \\
\hline Pinus & $6 \times 2$ & 142 & 45 & 471 & 18 & 6.1 & 20.11 & 7.01 & 0.91 \\
\hline Pinus & $4 \times 2$ & 101 & 49 & 452 & 13 & 6.1 & 27.51 & 6.91 & 0.81 \\
\hline
\end{tabular}




\begin{tabular}{|ll|rrrrr|r|r|r|}
\hline Pinus & $4 \times 2$ & 87 & 44 & 507 & 17.4 & 6.1 & 33.54 & 6.9 & 0.8 \\
\hline Pinus & $6 \times 2$ & 142 & 45 & 510 & 10.6 & 6.1 & 28.77 & 6.8 & 0.7 \\
\hline Pinus & $4 \times 2$ & 101 & 49 & 452 & 13 & 6.1 & 28.67 & 6.77 & 0.67 \\
\hline Pinus & $4 \times 2$ & 101 & 49 & 561 & 14 & 6.1 & 26.29 & 6.76 & 0.66 \\
\hline Pinus & $4 \times 2$ & 96 & 48 & 643 & 6.8 & 6.1 & 41.35 & 6.5 & 0.4 \\
\hline Pinus & $6 \times 2$ & 142 & 45 & 471 & 18 & N/A & 28.95 & 6.39 & \#VALUE! \\
\hline Pinus & $6 \times 2$ & 142 & 45 & 466 & 20.1 & 6.1 & 25.73 & 6.32 & 0.22 \\
\hline Pinus & $4 \times 2$ & 100 & 47 & 759 & 6 & 6.1 & 44.5 & 5.9 & -0.2 \\
\hline Pinus & $6 \times 2$ & 142 & 45 & 466 & 20.1 & N/A & 30.4 & 5.58 & \#VALUE! \\
\hline Pinus & $4 \times 2$ & 88 & 45 & 457 & 8.6 & N/A & 37.89 & 5.37 & \#VALUE! \\
\hline Pinus & $4 \times 4$ & 100 & 75 & 378 & 9.6 & N/A & 21.28 & 4.61 & \#VALUE! \\
\hline
\end{tabular}




\subsection{PINE VSG SCALES}

Table 26 VSG layout for testing

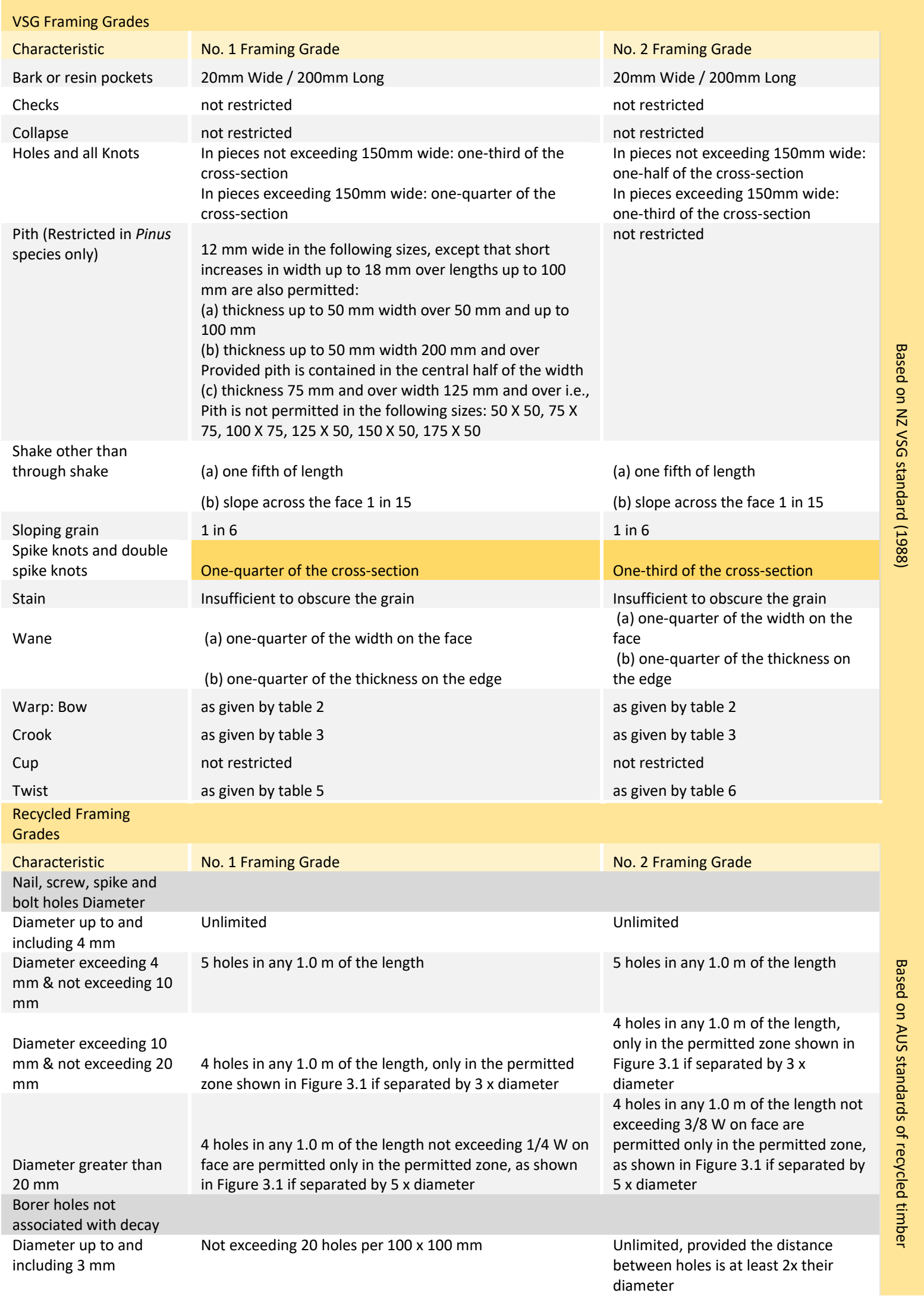




\begin{tabular}{|c|c|c|c|}
\hline $\begin{array}{l}\text { Diameter over } 3 \mathrm{~mm} \text { or } \\
\text { where separated by less } \\
\text { than } 2 \mathrm{x} \text { diameter }\end{array}$ & As for knots & As for knots & \\
\hline $\begin{array}{l}\text { End splits, aggregate } \\
\text { length }\end{array}$ & Not exceeding lesser of $\mathrm{W}$ and $100 \mathrm{~mm}$ & $\begin{array}{l}\text { Not exceeding lesser of } 1.5 \mathrm{~W} \text { and } 150 \\
\mathrm{~mm}\end{array}$ & \\
\hline Damage & & & \\
\hline Movement damage & $\begin{array}{l}\text { (a) one-quarter of the width on the face } \\
\text { (b) one-quarter of the thickness on the edge }\end{array}$ & $\begin{array}{l}\text { (a) one-quarter of the width on the } \\
\text { face } \\
\text { (b) one-quarter of the thickness on } \\
\text { the edge }\end{array}$ & \\
\hline
\end{tabular}

All the following test were based on the VSG tested result explained above. 


\subsection{PINE 4X2}

Table 27 testing one Pine $4 \times 2$

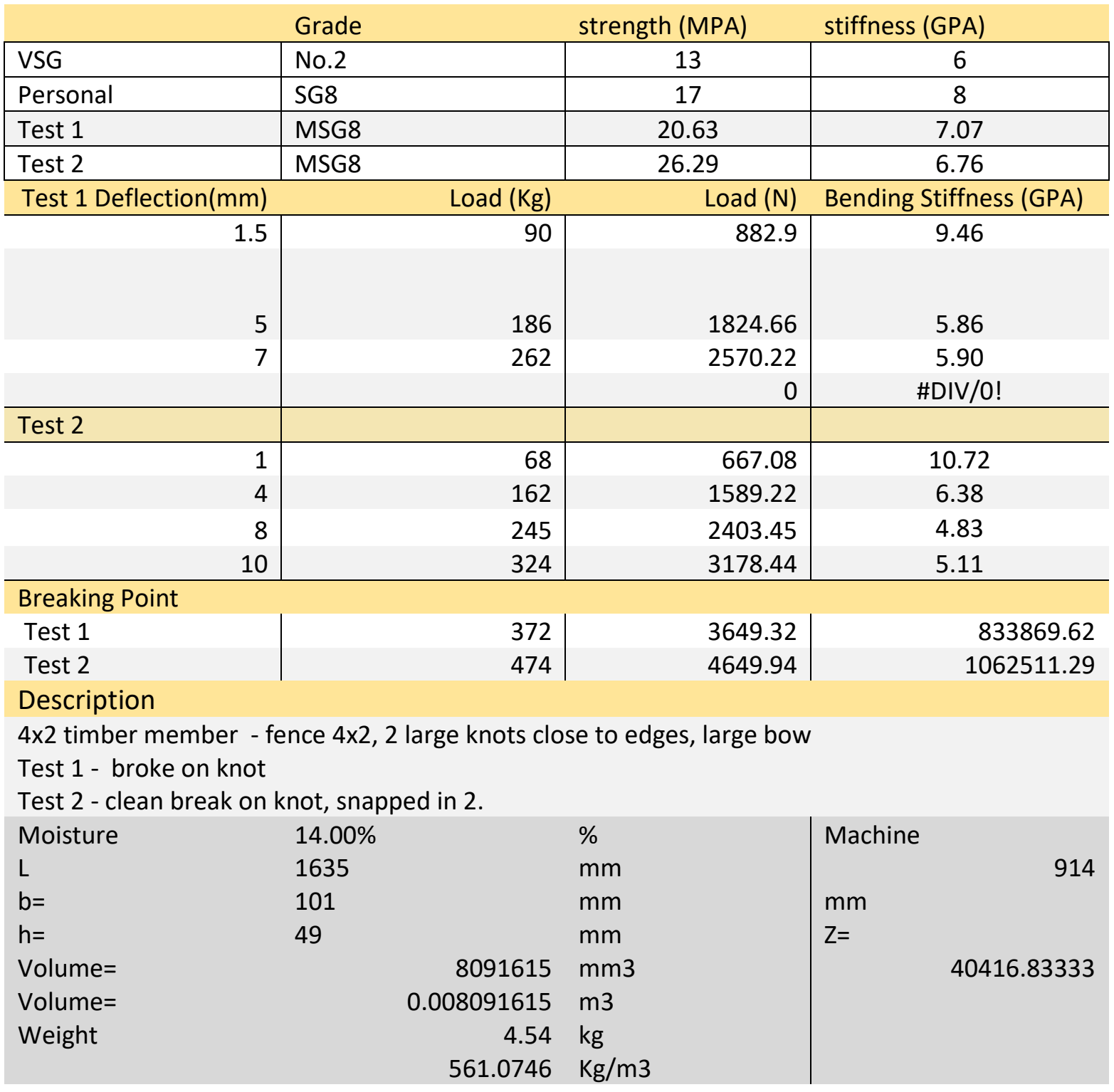

Table 28 test two Pine $4 \times 2$

\begin{tabular}{|c|c|c|c|}
\hline & Grade & strength (MPA) & stiffness (GPA) \\
\hline VSG & No.1 & 13 & 6 \\
\hline Personal & SG8 & 13 & 6 \\
\hline Test 1 & MSG8 & 27.51 & 6.91 \\
\hline Test 2 & MSG8 & 28.67 & 6.77 \\
\hline Test 1 Deflection(mm) & Load (Kg) & Load (N) & $\begin{array}{l}\text { Bending Stiffness } \\
\text { (GPA) }\end{array}$ \\
\hline 1.5 & 76 & 745.56 & 7.98 \\
\hline 4 & 164 & 1608.84 & 6.46 \\
\hline 6 & 268 & 2629.08 & 7.04 \\
\hline
\end{tabular}




\begin{tabular}{|c|c|c|c|c|}
\hline & 9 & 351 & 3443.31 & 6.15 \\
\hline \multicolumn{5}{|l|}{ Test 2} \\
\hline & 2 & 85 & 833.85 & 6.70 \\
\hline & 4 & 170 & 1667.7 & 6.70 \\
\hline & 6 & 275 & 2697.75 & 7.22 \\
\hline & 9 & 369 & 3619.89 & 6.46 \\
\hline \multicolumn{5}{|c|}{ Breaking Point } \\
\hline Test 1 & & 496 & 4865.76 & 1111826.16 \\
\hline Test 2 & & 517 & 5071.77 & 1158899.445 \\
\hline \multicolumn{5}{|c|}{ Description } \\
\hline \multicolumn{5}{|c|}{$\begin{array}{l}4 \times 2 \text { timber member - fence } 4 \times 2,3 \text { knots } 20 \mathrm{~mm} \\
\text { Test } 1 \text { - broke at knot, } 150 \mathrm{~mm} \text { away, very unclean break } \\
\text { Test } 2 \text { - broke directly on knot }\end{array}$} \\
\hline Moisture & & $13.00 \%$ & $\%$ & Machine \\
\hline $\mathrm{L}$ & & 1695 & $\mathrm{~mm}$ & 914 \\
\hline$b=$ & & 101 & $\mathrm{~mm}$ & $\mathrm{~mm}$ \\
\hline$h=$ & & 49 & $\mathrm{~mm}$ & $Z=$ \\
\hline Volume= & & 8388555 & $\mathrm{~mm} 3$ & 40416.83333 \\
\hline Volume= & & 0.008388555 & m3 & \\
\hline \multirow[t]{2}{*}{ Weight } & & 3.8 & kg & \\
\hline & & 452.9982 & $\mathrm{Kg} / \mathrm{m} 3$ & \\
\hline
\end{tabular}

Table 29 test three Pine $4 \times 2$

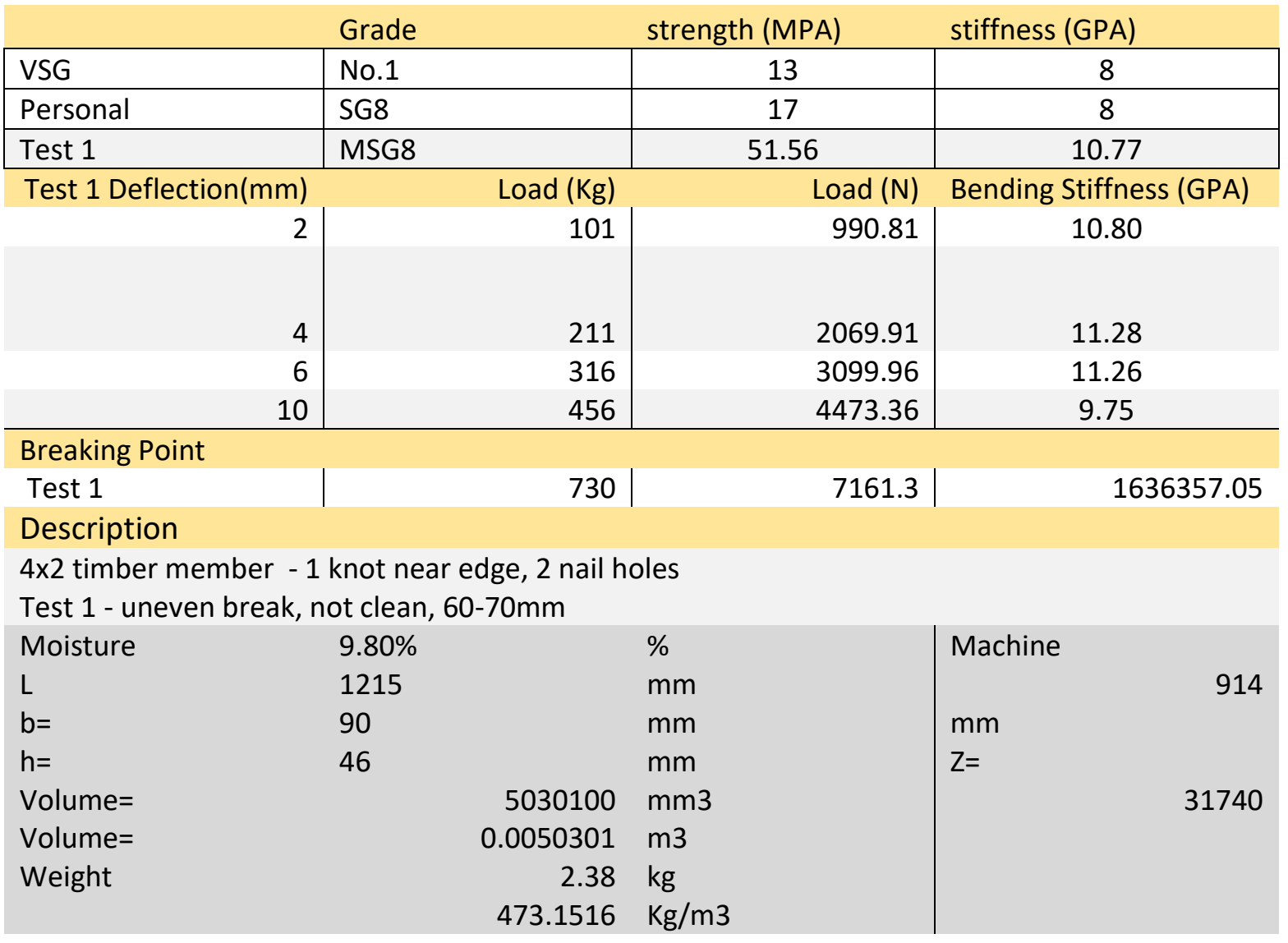


Table 30 Table four Pine $4 \times 2$

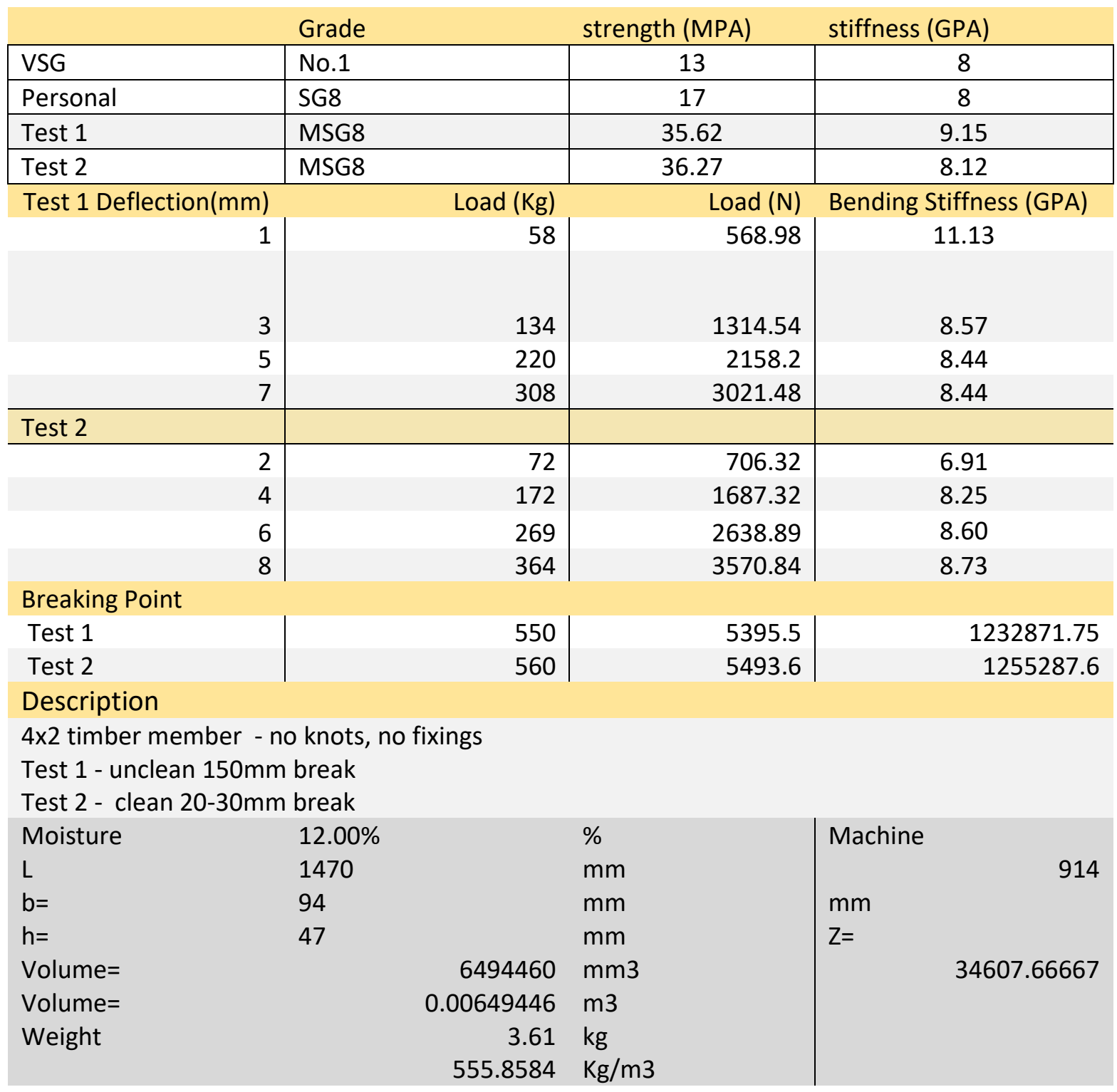

Table 31 table five Pine $4 \times 2$

\begin{tabular}{|c|c|c|c|}
\hline & Grade & strength (MPA) & stiffness (GPA) \\
\hline VSG & No.2 & 13 & 6 \\
\hline Personal & SG10 & 13 & 6 \\
\hline Test 1 & MSG8 & 44.45 & 5.87 \\
\hline Test 1 Deflection(mm) & Load (Kg) & Load $(\mathrm{N})$ & Bending Stiffness (GPA) \\
\hline 3 & 77 & 755.37 & 4.63 \\
\hline 5 & 177 & 1736.37 & 6.38 \\
\hline 8 & 267 & 2619.27 & 6.02 \\
\hline 10 & 358 & 3511.98 & 6.46 \\
\hline \multicolumn{4}{|l|}{ Breaking Point } \\
\hline Test 1 & 730 & 7161.3 & 1636357.05 \\
\hline \multicolumn{4}{|l|}{ Description } \\
\hline Pine $4 \times 2$ & & & \\
\hline
\end{tabular}


Fence post, covered in mould, sever weathering and decay, treated H3

\begin{tabular}{|c|c|c|c|c|}
\hline Moisture & $6.00 \%$ & & $\%$ & Machine \\
\hline $\mathrm{L}$ & 1020 & & $\mathrm{~mm}$ & 914 \\
\hline$b=$ & 100 & & $\mathrm{~mm}$ & $\mathrm{~mm}$ \\
\hline$h=$ & 47 & & $\mathrm{~mm}$ & $Z=$ \\
\hline Volume= & & 4794000 & $\mathrm{~mm} 3$ & 36816.66667 \\
\hline Volume= & & 0.004794 & m3 & \\
\hline \multirow[t]{2}{*}{ Weight } & & 3.64 & kg & \\
\hline & & 759.2824 & $\mathrm{Kg} / \mathrm{m} 3$ & \\
\hline
\end{tabular}

Table 32 Table six Pine $4 \times 2$

\begin{tabular}{|c|c|c|c|}
\hline & Grade & strength (MPA) & stiffness (GPA) \\
\hline VSG & No.1 & 17 & 8 \\
\hline Personal & SG8 & 17 & 8 \\
\hline Test 1 & MSG8 & 55.35 & 14.69 \\
\hline Test 1 Deflection(mm) & Load (Kg) & Load (N) & Bending Stiffness (GPA) \\
\hline 1.5 & 86 & 843.66 & 13.09 \\
\hline 3 & 200 & 1962 & 15.22 \\
\hline 4 & 280 & 2746.8 & 15.98 \\
\hline 6 & 380 & 3727.8 & 14.46 \\
\hline 8 & 480 & 4708.8 & 13.70 \\
\hline \multicolumn{4}{|l|}{ Breaking Point } \\
\hline & 750 & 7357.5 & 1681188.75 \\
\hline
\end{tabular}

\section{Description}

Pine $4 \times 2$

Pinus

Recycled damage to structure

\begin{tabular}{lll|ll} 
Moisture & $9.90 \%$ & & Machine & \\
$\mathrm{L}$ & 1650 & & $\mathrm{~mm}$ & \\
$\mathrm{~b}=$ & 90 & $\mathrm{~mm}$ & $\mathrm{~mm}$ & \\
$\mathrm{~h}=$ & 45 & $\mathrm{~mm}$ & $\mathrm{Z}=$ & 30375 \\
Volume $=$ & & 6682500 & $\mathrm{~mm}$ & \\
Volume $=$ & & 0.0066825 & $\mathrm{~m} 3$ & \\
Weight & & 3.77 & $\mathrm{~kg}$ &
\end{tabular}

Table 33 Table seven Pine $4 \times 2$

\begin{tabular}{|c|c|c|c|}
\hline & Grade & strength (MPA) & stiffness (GPA) \\
\hline VSG & No.1 & 13 & 8 \\
\hline Personal & SG8 & 17 & 8 \\
\hline Test 1 & MSG8 & 46.88 & 7.50 \\
\hline VSG On timber & VSG8 & 17 & 8 \\
\hline Test 1 Deflection $(\mathrm{mm})$ & Load (Kg) & Load (N) & Bending Stiffness (GPA) \\
\hline 1.5 & 50 & 490.5 & 8.06 \\
\hline 3.5 & 104 & 1020.24 & 7.18 \\
\hline 5 & 155 & 1520.55 & 7.49 \\
\hline
\end{tabular}




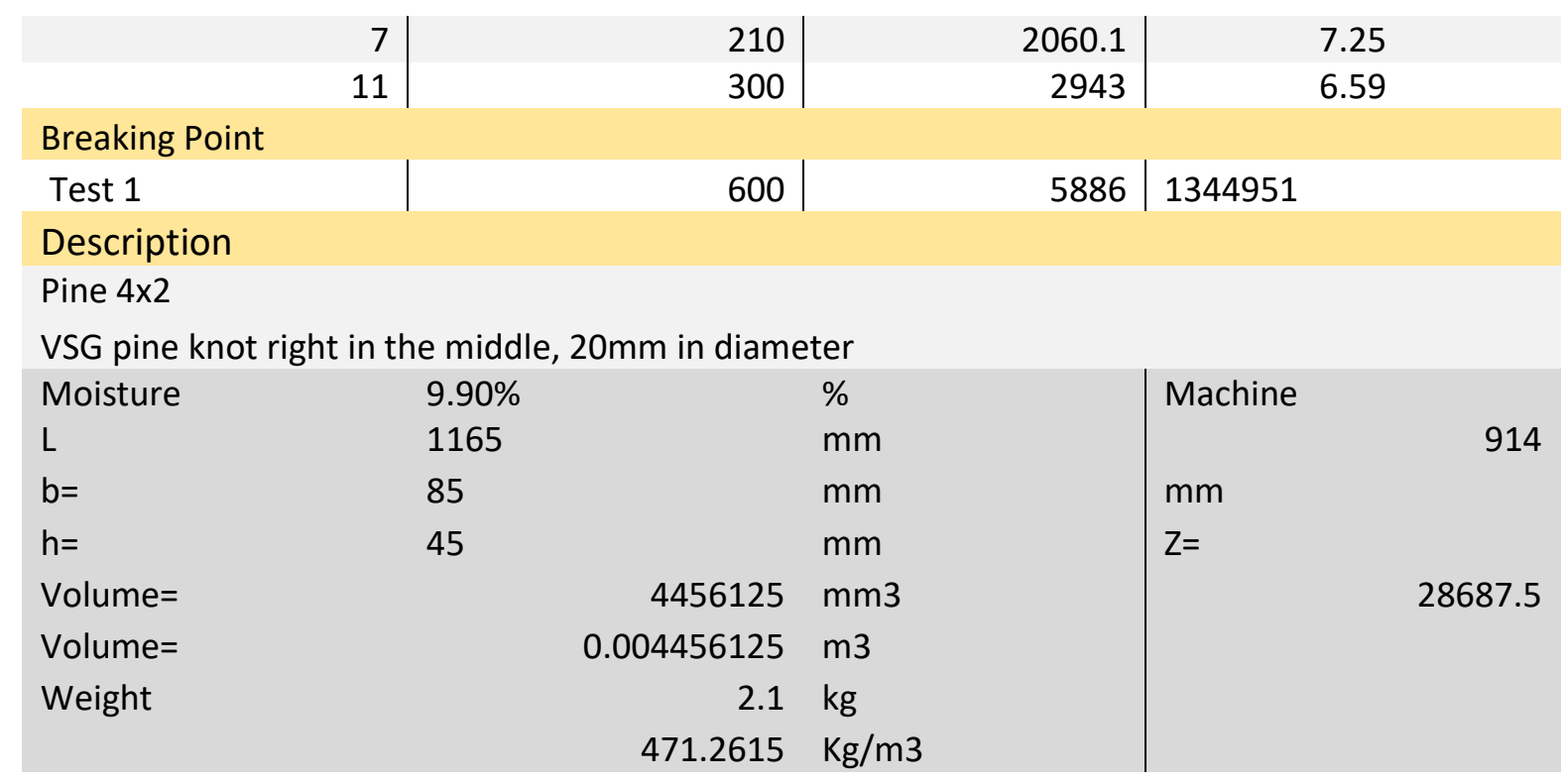

Table 34 Table eight Pine $4 \times 2$

\begin{tabular}{|c|c|c|c|c|}
\hline \multicolumn{2}{|r|}{ Grade } & \multicolumn{3}{|l|}{ strength (MPA) } \\
\hline VSG & No.2 & 10 & & 6.00 \\
\hline Personal & SG8 & 14 & & 8 \\
\hline Test 1 & MSG6 & 33.54 & & 6.87 \\
\hline Test 1 Deflection(mm) & Load (Kg) & Load $(N)$ & \multicolumn{2}{|c|}{ Bending Stiffness (GPA) } \\
\hline 2 & 49 & 480.69 & & 6.19 \\
\hline 5 & 142 & 1393.02 & & 7.18 \\
\hline 8 & 235 & 2305.35 & & 7.42 \\
\hline 12 & 318 & 3119.58 & & 6.70 \\
\hline 15 & 381 & 3737.61 & & 6.42 \\
\hline \multicolumn{5}{|l|}{ Breaking Point } \\
\hline Test 1 & 420 & 4120.2 & 941465.7 & \\
\hline \multicolumn{5}{|l|}{ Description } \\
\hline \multicolumn{5}{|l|}{ Pine post } \\
\hline \multicolumn{5}{|c|}{$\begin{array}{l}12 \mathrm{~mm} \text { break next to one of the knots, but not through no cracking until break } \\
\text { VSG graded pine member, } 4 \text { knots, } 3 \text { on half the member side knot on bottom }\end{array}$} \\
\hline Moisture & $17.40 \%$ & $\%$ & Machine & \\
\hline L & 1390 & $\mathrm{~mm}$ & & 914 \\
\hline$b=$ & 87 & $\mathrm{~mm}$ & $\mathrm{~mm}$ & \\
\hline$h=$ & 44 & $\mathrm{~mm}$ & $Z=$ & \\
\hline Volume= & 5320920 & $\mathrm{~mm} 3$ & & 28072 \\
\hline Volume= & 0.00532092 & $\mathrm{~m} 3$ & & \\
\hline Weight & 2.7 & $\mathrm{~kg}$ & & \\
\hline & 507.4310 & $\mathrm{Kg} / \mathrm{m} 3$ & & \\
\hline
\end{tabular}

Table 35 Table ten Pine $4 \times 2$

\begin{tabular}{|c|c|c|c|}
\hline & Grade & strength (MPA) & \\
\hline VSG & No.2 & 10 & 6.00 \\
\hline
\end{tabular}




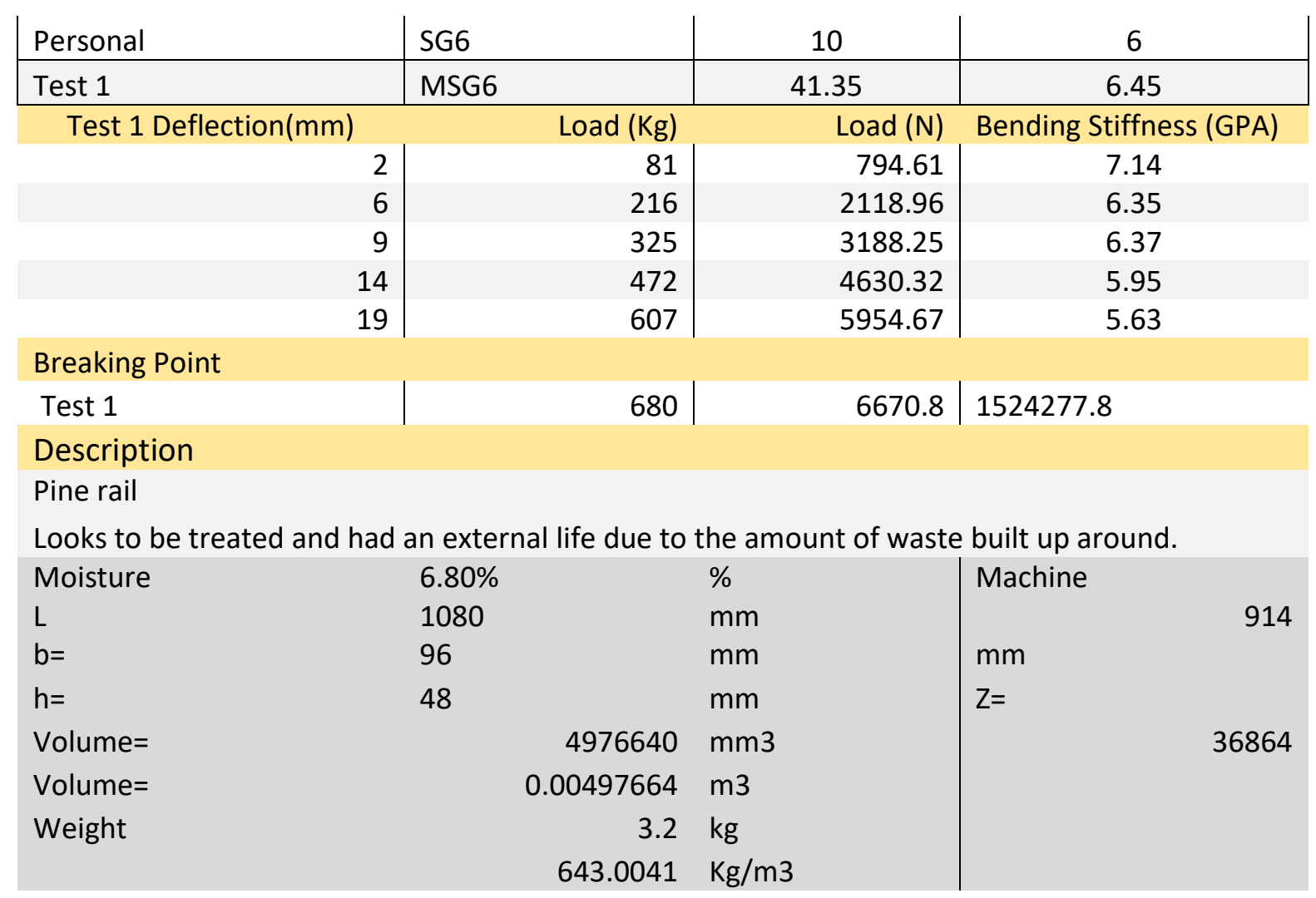

Table 36 Table nine Pine $4 \times 2$

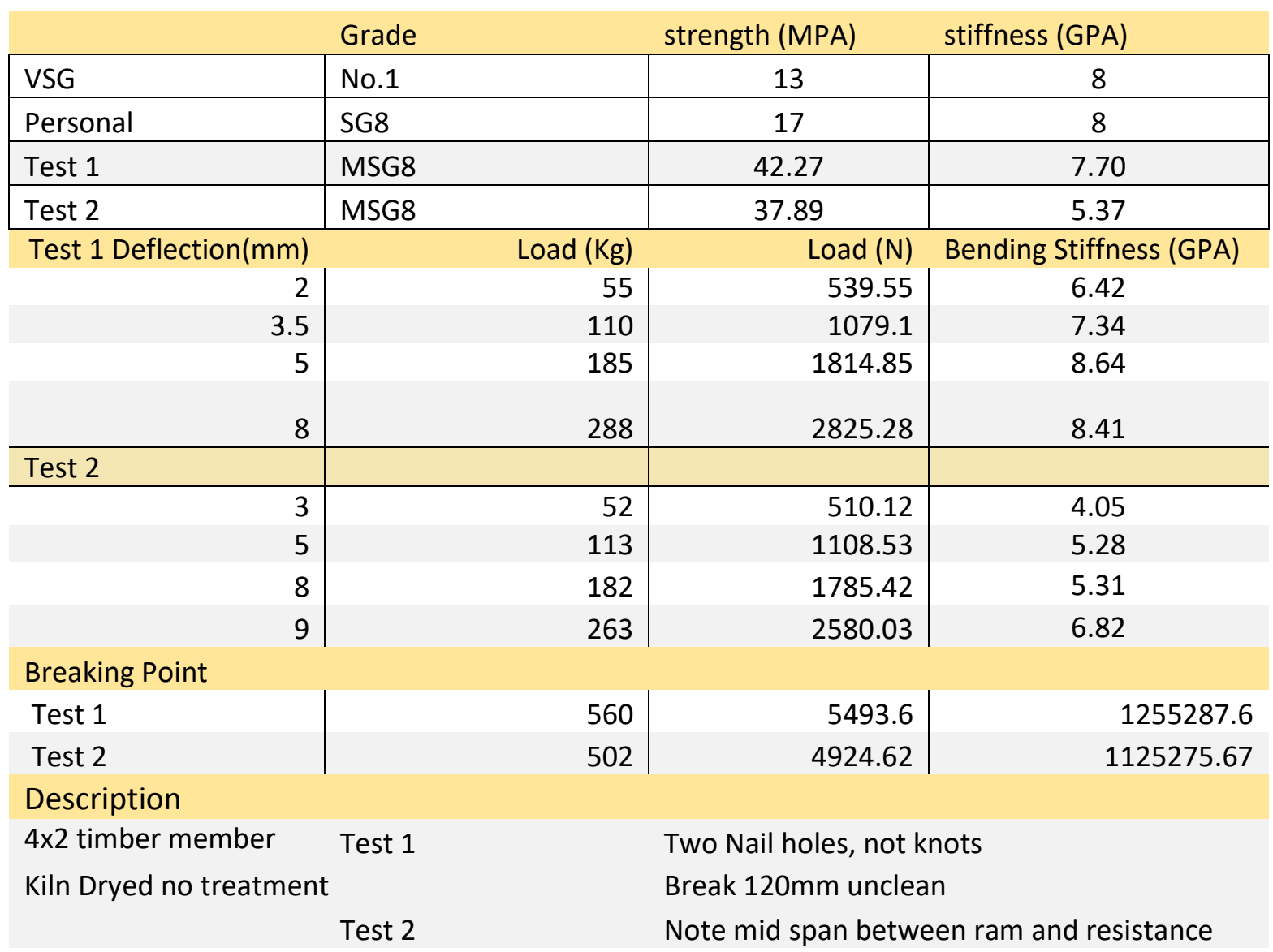




\begin{tabular}{|c|c|c|c|c|c|}
\hline \multirow[b]{2}{*}{ Moisture } & \multirow[b]{2}{*}{$8.60 \%$} & & \multicolumn{3}{|c|}{$\begin{array}{l}\text { Clean break, towards knot, about } 100 \mathrm{~mm} \\
\text { across. }\end{array}$} \\
\hline & & & $\%$ & Machine & \\
\hline $\mathrm{L}$ & 1570 & & $\mathrm{~mm}$ & & 914 \\
\hline$b=$ & 88 & & $\mathrm{~mm}$ & $\mathrm{~mm}$ & \\
\hline$h=$ & 45 & & $\mathrm{~mm}$ & $Z=$ & \\
\hline Volume= & & 6217200 & $\mathrm{~mm} 3$ & & 29700 \\
\hline Volume= & & 0.0062172 & m3 & & \\
\hline Weight & & 2.84 & kg & & \\
\hline & & 456.7973 & $\mathrm{Kg} / \mathrm{m} 3$ & & \\
\hline
\end{tabular}

Table 37 Table ten Pine $4 \times 2$

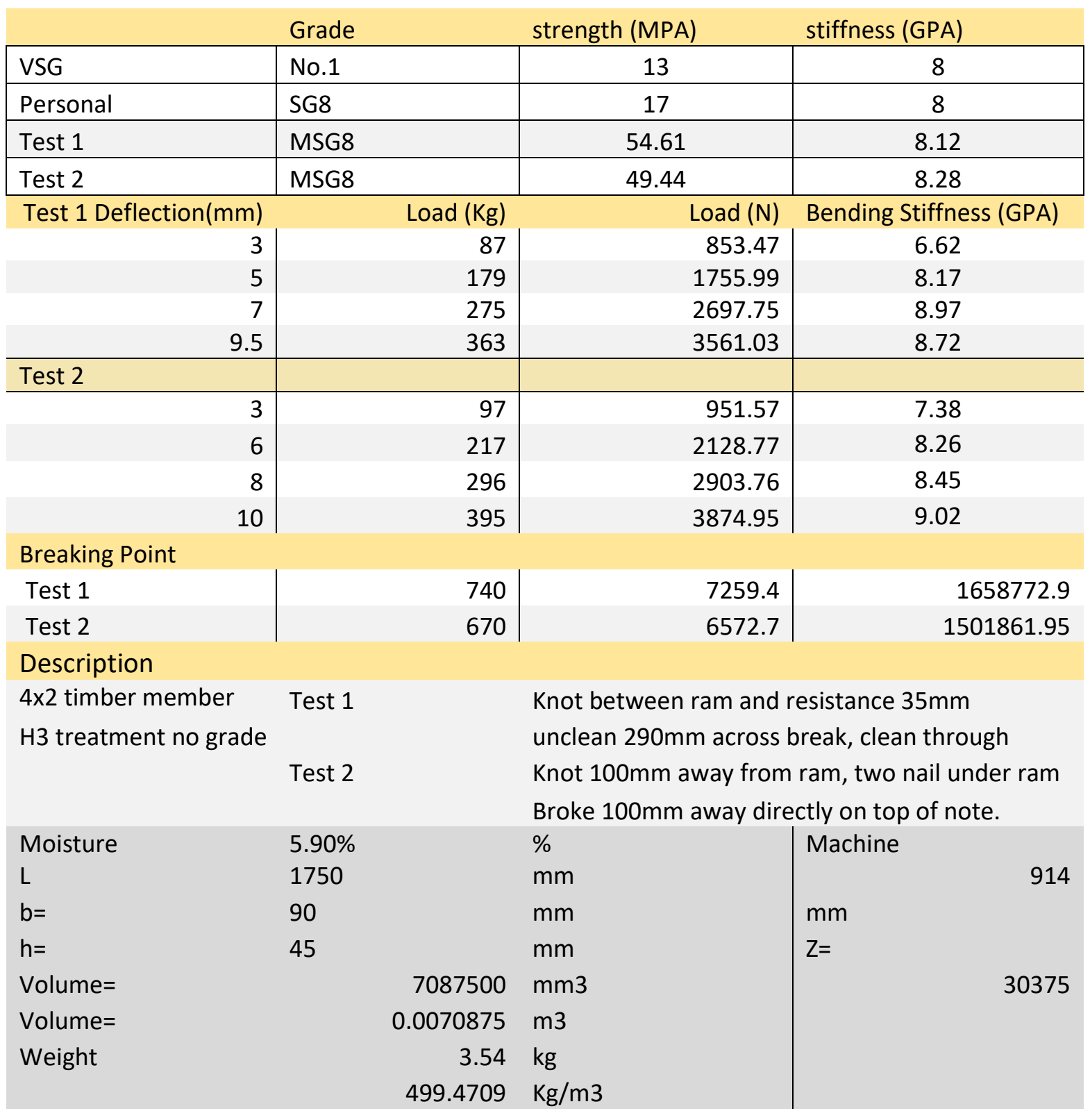




\begin{tabular}{|c|c|c|c|}
\hline & Grade & strength (MPA) & stiffness (GPA) \\
\hline VSG & No.1 & 13 & 8 \\
\hline Personal & SG8 & 17 & 8 \\
\hline Test 1 & MSG8 & 70.85 & 9.45 \\
\hline Test 2 & MSG8 & 63.83 & 9.80 \\
\hline Test 1 Deflection(mm) & Load (Kg) & Load $(N)$ & Bending Stiffness (GPA) \\
\hline 2.5 & 87 & 853.47 & 7.95 \\
\hline 4.5 & 198 & 1942.38 & 10.05 \\
\hline 6.5 & 284 & 2786.04 & 9.98 \\
\hline 8.5 & 366 & 3590.46 & 9.83 \\
\hline \multicolumn{4}{|l|}{ Test 2} \\
\hline 1 & 60 & 588.6 & 13.70 \\
\hline 5 & 183 & 1795.23 & 8.36 \\
\hline 7 & 269 & 2638.89 & 8.77 \\
\hline 10 & 367 & 3600.27 & 8.38 \\
\hline \multicolumn{4}{|l|}{ Breaking Point } \\
\hline Test 1 & 960 & 9417.6 & 2151921.6 \\
\hline Test 2 & 865 & 8485.65 & 1938971.025 \\
\hline \multicolumn{4}{|l|}{ Description } \\
\hline \multirow[t]{2}{*}{$\begin{array}{l}4 \times 2 \text { timber member } \\
\text { h1.2 sg8 }\end{array}$} & Test 1 & \multicolumn{2}{|c|}{$\begin{array}{l}\text { lots of fixing but none over the } 4 \mathrm{~mm} \text { mark } \\
\text { clean break right beneath the ram }\end{array}$} \\
\hline & Test 2 & \multicolumn{2}{|c|}{$\begin{array}{l}\text { Large not right beneath ram, similar fixings } \\
\text { clean break under ram }\end{array}$} \\
\hline Moisture & $7.70 \%$ & $\%$ & Machine \\
\hline $\mathrm{L}$ & 1430 & $\mathrm{~mm}$ & 914 \\
\hline$b=$ & 90 & $\mathrm{~mm}$ & $\mathrm{~mm}$ \\
\hline$h=$ & 45 & $\mathrm{~mm}$ & $Z=$ \\
\hline Volume= & 5791500 & $\mathrm{~mm} 3$ & 30375 \\
\hline Volume= & 0.0057915 & m3 & \\
\hline Weight & 3.22 & $\mathrm{~kg}$ & \\
\hline & 555.9872 & $\mathrm{Kg} / \mathrm{m} 3$ & \\
\hline
\end{tabular}

Table 39 Table twelve Pine $4 \times 2$

\begin{tabular}{|c|c|c|c|}
\hline & Grade & strength (MPA) & stiffness (GPA) \\
\hline VSG & No.1 & 13 & 8 \\
\hline Personal & SG8 & 17 & 8 \\
\hline Test 1 & MSG8 & 47.50 & 7.81 \\
\hline Test 1 Deflection(mm) & Load (Kg) & Load (N) & Bending Stiffness (GPA) \\
\hline 2 & 74 & 725.94 & 7.65 \\
\hline 5 & 185 & 1814.85 & 7.65 \\
\hline 7 & 258 & 2530.98 & 7.62 \\
\hline 9 & 362 & 3551.22 & 8.32 \\
\hline
\end{tabular}


Test 1

Description

$4 \times 2$ timber member

Test 1

$16.50 \%$

1344

93

46

$\mathrm{h}=$

Volume $=$

Volume $=$

Weight no knots no fixings

\begin{tabular}{l|l}
$\%$ & Machine
\end{tabular}

$\mathrm{mm}$

914

$\mathrm{mm}$

$\mathrm{Z}=$

32798

$0.005749632 \mathrm{~m} 3$

$3.25 \mathrm{~kg}$

$565.2536 \mathrm{Kg} / \mathrm{m} 3$

Table 40 Table thirteen Pine $4 \times 2$

\begin{tabular}{|c|c|c|c|}
\hline & Grade & strength (MPA) & stiffness (GPA) \\
\hline VSG & No.1 & 13 & 8 \\
\hline Personal & SG8 & 17 & 8 \\
\hline Test 1 & MSG8 & 34.34 & 8.82 \\
\hline Test 2 & MSG8 & 31.26 & 8.95 \\
\hline Test 1 Deflection(mm) & \multicolumn{2}{|l|}{ Load $(\mathrm{Kg})$} & Bending Stiffness (GPA) \\
\hline 2.5 & 76 & 745.56 & 7.59 \\
\hline 5 & 183 & 1795.23 & 9.14 \\
\hline 8 & 287 & 2815.47 & 8.96 \\
\hline 10 & 383 & 3757.23 & 9.57 \\
\hline \multicolumn{4}{|l|}{ Test 2} \\
\hline 2 & 73 & 716.13 & 9.12 \\
\hline 5 & 175 & 1716.75 & 8.74 \\
\hline 7 & 255 & 2501.55 & 9.10 \\
\hline 10 & 354 & 3472.74 & 8.84 \\
\hline \multicolumn{4}{|l|}{ Breaking Point } \\
\hline Test 1 & 435 & 4267.35 & 975089.475 \\
\hline Test 2 & 396 & 3884.76 & 887667.66 \\
\hline \multicolumn{4}{|l|}{ Description } \\
\hline \multirow{3}{*}{$\begin{array}{l}4 \times 2 \text { timber member } \\
\text { NO information }\end{array}$} & Test 1 & \multicolumn{2}{|c|}{$\begin{array}{l}\text { fixing directly under ram, no other problems } \\
\text { clean break through fixing holes }\end{array}$} \\
\hline & \multirow[t]{2}{*}{ Test 2} & \multicolumn{2}{|c|}{ Fixing under ram position } \\
\hline & & \multicolumn{2}{|c|}{ broke clean on fixing again } \\
\hline Moisture & $7.00 \%$ & $\%$ & Machine \\
\hline $\mathrm{L}$ & 1750 & $\mathrm{~mm}$ & 914 \\
\hline$b=$ & 88 & $\mathrm{~mm}$ & $\mathrm{~mm}$ \\
\hline$h=$ & 44 & $\mathrm{~mm}$ & $Z=$ \\
\hline Volume $=$ & 6776000 & $\mathrm{~mm} 3$ & 28394.66667 \\
\hline Volume = & 0.006776 & m3 & \\
\hline Weight & 3.11 & $\mathrm{~kg}$ & \\
\hline & 458.9728 & $\mathrm{Kg} / \mathrm{m} 3$ & \\
\hline
\end{tabular}




\begin{tabular}{|c|c|c|c|}
\hline & Grade & strength (MPA) & stiffness (GPA) \\
\hline VSG & No.1 & 13 & 8 \\
\hline Personal & SG8 & 17 & 8 \\
\hline Test 1 & MSG8 & 41.49 & 8.54 \\
\hline Test 2 & MSG8 & 33.43 & 7.41 \\
\hline Test 1 Deflection(mm) & Load $(\mathrm{Kg})$ & Load (N) & Bending Stiffness (GPA) \\
\hline 2 & 68 & 667.08 & 7.85 \\
\hline 4 & 150 & 1471.5 & 8.66 \\
\hline 6.5 & 249 & 2442.69 & 8.85 \\
\hline 9 & 344 & 3374.64 & 8.83 \\
\hline \multicolumn{4}{|l|}{ Test 2} \\
\hline 2 & 70 & 686.7 & 8.08 \\
\hline 5 & 150 & 1471.5 & 6.93 \\
\hline 7 & 240 & 2354.4 & 7.92 \\
\hline 12 & 348 & 3413.88 & 6.70 \\
\hline \multicolumn{4}{|l|}{ Breaking Point } \\
\hline Test 1 & 556 & 5454.36 & 1246321.26 \\
\hline Test 2 & 448 & 4394.88 & 1004230.08 \\
\hline \multicolumn{4}{|l|}{ Description } \\
\hline \multicolumn{2}{|l|}{$4 \times 2$ timber member } & \multicolumn{2}{|c|}{$\begin{array}{l}\text { Knots between resistance and ram, fixing hole breather } \\
\text { ram }\end{array}$} \\
\hline \multirow[t]{2}{*}{ H3 sg8 } & & \multicolumn{2}{|c|}{ broke clean on fixing holes } \\
\hline & Test 2 & \multicolumn{2}{|c|}{$\begin{array}{l}\text { two large holes beneath ram, } \\
\text { broke clean through the hole below }\end{array}$} \\
\hline Moisture & $11.50 \%$ & $\%$ & Machine \\
\hline $\mathrm{L}$ & 1591 & $\mathrm{~mm}$ & 914 \\
\hline$b=$ & 89 & $\mathrm{~mm}$ & $\mathrm{~mm}$ \\
\hline$h=$ & 45 & $\mathrm{~mm}$ & $Z=$ \\
\hline Volume $=$ & 6371955 & $\mathrm{~mm} 3$ & 30037.5 \\
\hline Volume $=$ & 0.006371955 & m3 & \\
\hline Weight & 3.03 & $\mathrm{~kg}$ & \\
\hline & 475.5212 & $\mathrm{Kg} / \mathrm{m} 3$ & \\
\hline
\end{tabular}

Table 42 Table fifteen Pine $4 \times 2$

\begin{tabular}{|c|c|c|c|}
\hline & Grade & strength (MPA) & stiffness (GPA) \\
\hline VSG & No.1 & 13 & 8 \\
\hline Personal & SG8 & 17 & 8 \\
\hline Test 1 & MSG8 & 54.74 & 14.54 \\
\hline Test 2 & MSG8 & 30.29 & 8.39 \\
\hline Test 1 Deflection(mm) & Load (Kg) & Load $(\mathrm{N})$ & Bending Stiffness (GPA) \\
\hline 1 & 98 & 961.38 & 22.13 \\
\hline 4 & 235 & 2305.35 & 13.27 \\
\hline 7 & 357 & 3502.17 & 11.52 \\
\hline 10 & 498 & 4885.38 & 11.25 \\
\hline Test 2 & & & \\
\hline
\end{tabular}




\begin{tabular}{r|r|r|r}
2 & 73 & 716.13 & 8.24 \\
5 & 179 & 1755.99 & 8.08 \\
7 & 276 & 2707.56 & 8.90 \\
10 & 369 & 3619.89 & 8.33
\end{tabular}

Breaking Point

Test 1

Test 2

750

7357.5

1681188.75

415

4071.15

930257.775

Description

$4 \times 2$ timber member

Test 1

3 nail holes along, no knots to influence

No identification

Test 2

clean break under ram

knot to right of am, bad note along towards

resistance

Broke beneath on knot

\begin{tabular}{|c|c|c|c|}
\hline Moisture & $11.20 \%$ & $\%$ & Machine \\
\hline $\mathrm{L}$ & 1610 & $\mathrm{~mm}$ & 914 \\
\hline$b=$ & 91 & $\mathrm{~mm}$ & $\mathrm{~mm}$ \\
\hline$h=$ & 45 & $\mathrm{~mm}$ & $Z=$ \\
\hline Volume= & 6592950 & $\mathrm{~mm} 3$ & 30712.5 \\
\hline Volume= & 0.00659295 & m3 & \\
\hline Weight & 3.36 & $\mathrm{~kg}$ & \\
\hline & 509.6353 & $\mathrm{Kg} / \mathrm{m} 3$ & \\
\hline
\end{tabular}

Table 43 Table sixth teen Pine $4 \times 2$

\begin{tabular}{|c|c|c|c|}
\hline & Grade & strength (MPA) & stiffness (GPA) \\
\hline VSG & No.1 & 13 & 8 \\
\hline Personal & SG8 & 17 & 8 \\
\hline Test 1 & MSG8 & 56.20 & 10.52 \\
\hline Test 2 & MSG8 & 40.14 & 8.37 \\
\hline \multicolumn{2}{|l|}{ Test 1 Deflection(mm) } & Load $(\mathrm{N})$ & Bending Stiffness (GPA) \\
\hline 3 & 116 & 1137.96 & 8.73 \\
\hline 7 & 297 & 2913.57 & 9.58 \\
\hline 9 & 467 & 4581.27 & 11.72 \\
\hline 11 & 587 & 5758.47 & 12.05 \\
\hline \multicolumn{4}{|l|}{ Test 2} \\
\hline 4 & 150 & 1471.5 & 8.47 \\
\hline 7 & 260 & 2550.6 & 8.39 \\
\hline 10 & 361 & 3541.41 & 8.15 \\
\hline 12 & 451 & 4424.31 & 8.49 \\
\hline \multicolumn{4}{|l|}{ Breaking Point } \\
\hline Test 1 & 770 & 7553.7 & 1726020.45 \\
\hline Test 2 & 550 & 5395.5 & 1232871.75 \\
\hline \multicolumn{4}{|l|}{ Description } \\
\hline \multirow{3}{*}{$\begin{array}{l}4 \times 2 \text { timber member } \\
\text { Douglas fir }\end{array}$} & Test 1 & \multirow{3}{*}{\multicolumn{2}{|c|}{$\begin{array}{l}\text { small note } 1 / 4 \text { along } \\
\text { shear under ram, held } 400 \mathrm{~kg} \text { for } 20 \mathrm{~mm} \\
\text { Knot on either side, closet if } 40 \mathrm{~mm}\end{array}$}} \\
\hline & & & \\
\hline & Test 2 & & \\
\hline Moisture & $9.10 \%$ & $\%$ & Machine \\
\hline
\end{tabular}




\begin{tabular}{lll|lr}
$\mathrm{L}$ & 1620 & $\mathrm{~mm}$ & & 914 \\
$\mathrm{~b}=$ & 91 & $\mathrm{~mm}$ & $\mathrm{~mm}$ & \\
$\mathrm{~h}=$ & 45 & $\mathrm{~mm}$ & $\mathrm{Z}=$ & \\
Volume= & & 6633900 & $\mathrm{~mm} 3$ & \\
Volume= & & 0.0066339 & $\mathrm{m3}$ & \\
Weight & 3.17 & $\mathrm{~kg}$ & \\
& & 477.8486 & $\mathrm{Kg} / \mathrm{m3}$ &
\end{tabular}


11.5 PINE 5X2

Table 44 Table one Pine 5x2

\begin{tabular}{|c|c|c|c|}
\hline & Grade & strength (MPA) & stiffness (GPA) \\
\hline VSG & No.1 & 13 & 8 \\
\hline Personal & SG8 & 17 & 8 \\
\hline Test 1 & MSG8 & 63.84 & 11.66 \\
\hline Test 2 & MSG8 & 64.12 & 8.36 \\
\hline Test 1 Deflection(mm) & Load (Kg) & $\operatorname{Load}(\mathrm{N})$ & Bending Stiffness (GPA) \\
\hline 1.5 & 106 & 1039.86 & 12.03 \\
\hline 5 & 321 & 3149.01 & 10.93 \\
\hline 7 & 499 & 4895.19 & 12.14 \\
\hline 10 & 678 & 6651.18 & 11.54 \\
\hline \multicolumn{4}{|l|}{ Test 2} \\
\hline 2 & 76 & 745.56 & 6.47 \\
\hline 5 & 256 & 2511.36 & 8.72 \\
\hline 7 & 360 & 3531.6 & 8.76 \\
\hline 8.5 & 475 & 4659.75 & 9.51 \\
\hline \multicolumn{4}{|l|}{ Breaking Point } \\
\hline Test 1 & 1135 & 11134.35 & 2544198.975 \\
\hline Test 2 & 1140 & 11183.4 & 2555406.9 \\
\hline \multicolumn{4}{|l|}{ Description } \\
\hline $5 \times 2$ timber member & Test 1 & \multicolumn{2}{|c|}{$\begin{array}{l}\text { knot } 100 \mathrm{~mm} \text { away from ram, } \\
\text { broke towards knot, but was the reason for the } \\
\text { release } \\
\text { Large knot } 1 / 4 \text { along large knot } 1 / 4 \text { along other } \\
\text { side. }\end{array}$} \\
\hline Moisture & $12.00 \%$ & $\%$ & Machine \\
\hline L & 1670 & $\mathrm{~mm}$ & 914 \\
\hline$b=$ & 113 & $\mathrm{~mm}$ & $\mathrm{~mm}$ \\
\hline$h=$ & 46 & $\mathrm{~mm}$ & $Z=$ \\
\hline Volume= & 8680660 & $\mathrm{~mm} 3$ & 39851.33333 \\
\hline Volume $=$ & 0.00868066 & m3 & \\
\hline Weight & 4.8 & $\mathrm{~kg}$ & \\
\hline & 552.9533 & $\mathrm{Kg} / \mathrm{m} 3$ & \\
\hline
\end{tabular}




\subsection{PINE 6X2}

Table 45 Table one Pine $6 \times 2$

\begin{tabular}{|c|c|c|c|c|c|c|}
\hline \multicolumn{3}{|c|}{ Grade } & \multicolumn{4}{|c|}{ strength (MPA) } \\
\hline VSG & No.2 & & \multicolumn{2}{|c|}{10} & \multicolumn{2}{|c|}{6.00} \\
\hline Personal & SG6 & & \multicolumn{2}{|r|}{10} & \multicolumn{2}{|c|}{6} \\
\hline Test 1 & MSG6 & & \multicolumn{2}{|c|}{5.64} & \multicolumn{2}{|c|}{11.86} \\
\hline \multicolumn{2}{|c|}{ Test 1 Deflection(mm) } & \multicolumn{3}{|l|}{ Load (Kg) } & \multicolumn{2}{|c|}{ Bending Stiffness (GPA) } \\
\hline \multicolumn{2}{|c|}{1} & 89 & & 873.09 & \multicolumn{2}{|c|}{13.86} \\
\hline \multicolumn{2}{|c|}{3} & 203 & & 1991.43 & \multicolumn{2}{|c|}{10.53} \\
\hline \multicolumn{2}{|c|}{5} & 359 & & 3521.79 & \multicolumn{2}{|c|}{11.18} \\
\hline \multicolumn{2}{|c|}{7} & 534 & & 5238.54 & \multicolumn{2}{|c|}{11.88} \\
\hline \multicolumn{2}{|c|}{11} & 752 & & 7377.12 & \multicolumn{2}{|c|}{10.64} \\
\hline \multicolumn{7}{|c|}{ Breaking Point } \\
\hline Test 1 & & 1100 & & 1100 & \multicolumn{2}{|l|}{251350} \\
\hline \multicolumn{7}{|c|}{ Description } \\
\hline \multicolumn{7}{|c|}{ Pine beam } \\
\hline \multicolumn{3}{|c|}{ Break up centre of timber } & \multicolumn{4}{|c|}{ cracking at $840 \mathrm{~kg}$} \\
\hline Moisture & $7.30 \%$ & & $\%$ & & Machine & \\
\hline L & 1965 & & $\mathrm{~mm}$ & & & 914 \\
\hline$b=$ & 132 & & $\mathrm{~mm}$ & & $\mathrm{~mm}$ & \\
\hline$h=$ & 45 & & $\mathrm{~mm}$ & & $Z=$ & \\
\hline Volume= & & 11672100 & mm3 & & & 44550 \\
\hline Volume= & & 0.0116721 & m3 & & & \\
\hline \multirow[t]{2}{*}{ Weight } & & 5.1 & $\mathrm{~kg}$ & & & \\
\hline & & 436.9394 & $\mathrm{Kg} / \mathrm{m} 3$ & & & \\
\hline
\end{tabular}

Table 46 Table two Pine 6x2

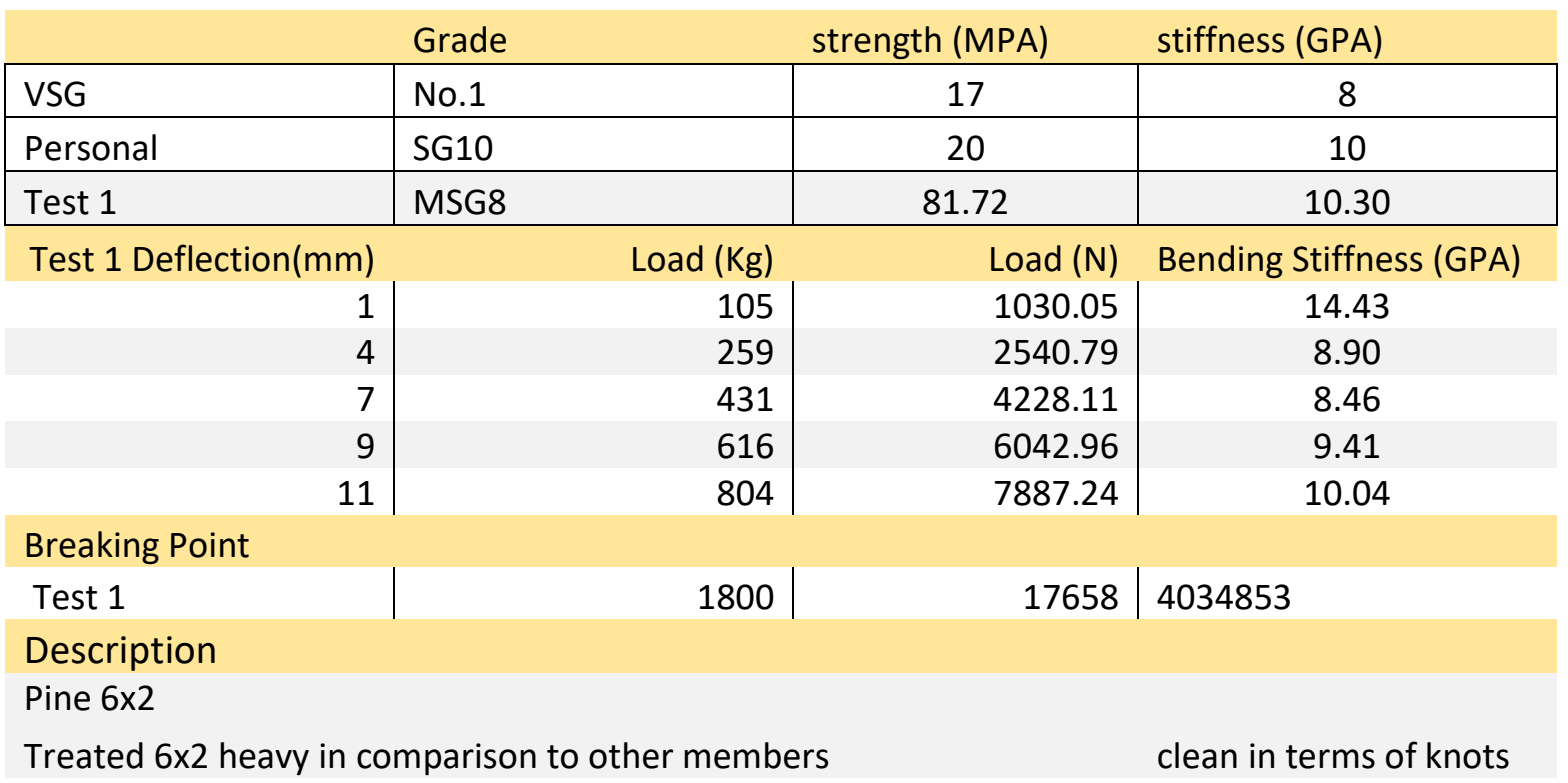




\begin{tabular}{|c|c|c|c|c|}
\hline clean bre & & & & and damage \\
\hline Moisture & $7.50 \%$ & & $\%$ & Machine \\
\hline $\mathrm{L}$ & 1930 & & $\mathrm{~mm}$ & 914 \\
\hline$b=$ & 140 & & $\mathrm{~mm}$ & $\mathrm{~mm}$ \\
\hline$h=$ & 46 & & $\mathrm{~mm}$ & $Z=$ \\
\hline Volume= & & 12429200 & $\mathrm{~mm} 3$ & 49373.33333 \\
\hline Volume= & & 0.0124292 & m3 & \\
\hline Weight & & 8.6 & kg & \\
\hline & & 691.9190 & $\mathrm{Kg} / \mathrm{m} 3$ & \\
\hline
\end{tabular}

Table 47 Table three Pine $6 \times 2$

\begin{tabular}{|c|c|c|c|}
\hline & Grade & strength (MPA) & stiffness (GPA) \\
\hline VSG & No.1 & 17 & 8 \\
\hline Personal & SG10 & 20 & 10 \\
\hline Test 1 & MSG8 & 54.12 & 8.70 \\
\hline Test 1 Deflection $(\mathrm{mm})$ & Load (Kg) & Load $(\mathrm{N})$ & Bending Stiffness (GPA) \\
\hline 2 & 135 & 1324.35 & 10.27 \\
\hline 4 & 205 & 2011.05 & 7.80 \\
\hline 6 & 332 & 3256.92 & 8.42 \\
\hline 8 & 436 & 4277.16 & 8.30 \\
\hline 10 & 550 & 5395.5 & 8.37 \\
\hline \multicolumn{4}{|l|}{ Breaking Point } \\
\hline Test 1 & 1100 & 10791 & 2465743.5 \\
\hline \multicolumn{4}{|l|}{ Description } \\
\hline \multicolumn{4}{|l|}{ Pine $6 \times 2$} \\
\hline \multicolumn{4}{|c|}{$\begin{array}{l}\text { Wood seems relatively weathered, with cracks and discolouration. Large pine growth, minimum } \\
\text { nail implication } \\
\text { unclean beam, held strength }\end{array}$} \\
\hline Moisture & $8.70 \%$ & $\%$ & Machine \\
\hline $\mathrm{L}$ & 1390 & $\mathrm{~mm}$ & 914 \\
\hline$b=$ & 135 & $\mathrm{~mm}$ & $\mathrm{~mm}$ \\
\hline $\mathrm{h}=$ & 45 & $\mathrm{~mm}$ & $Z=$ \\
\hline Volume $=$ & 8444250 & $\mathrm{~mm} 3$ & 45562.5 \\
\hline Volume $=$ & 0.00844425 & m3 & \\
\hline Weight & $\begin{array}{r}3.64 \\
431.0626\end{array}$ & $\begin{array}{l}\mathrm{kg} \\
\mathrm{Kg} / \mathrm{m} 3\end{array}$ & \\
\hline
\end{tabular}

Table 48 Table four Pine $6 \times 2$

\begin{tabular}{|c|c|c|c|}
\hline & Grade & strength (MPA) & stiffness (GPA) \\
\hline VSG & No.1 & 13 & 8 \\
\hline Personal & SG8 & 17 & 8 \\
\hline Test 1 & MSG8 & 39.10 & 8.06 \\
\hline Test 2 & MSG8 & 28.77 & 6.80 \\
\hline Test $1 \mathrm{De}$ & \multicolumn{2}{|c|}{ Load $(\mathrm{Kg})$} & Bending Stiffness (GPA) \\
\hline & & & 9.26 \\
\hline
\end{tabular}




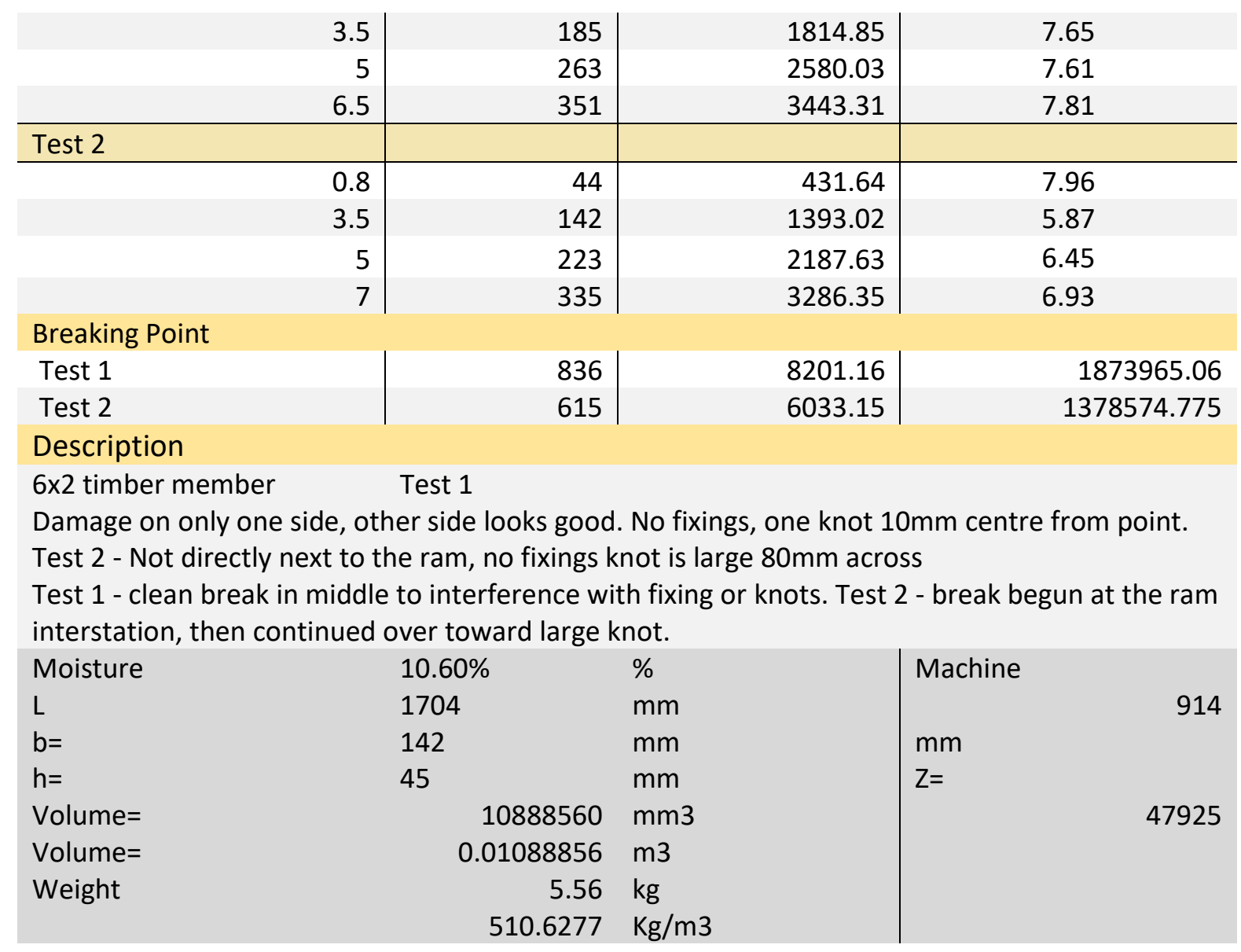

Table 49 Table five Pine 6x2

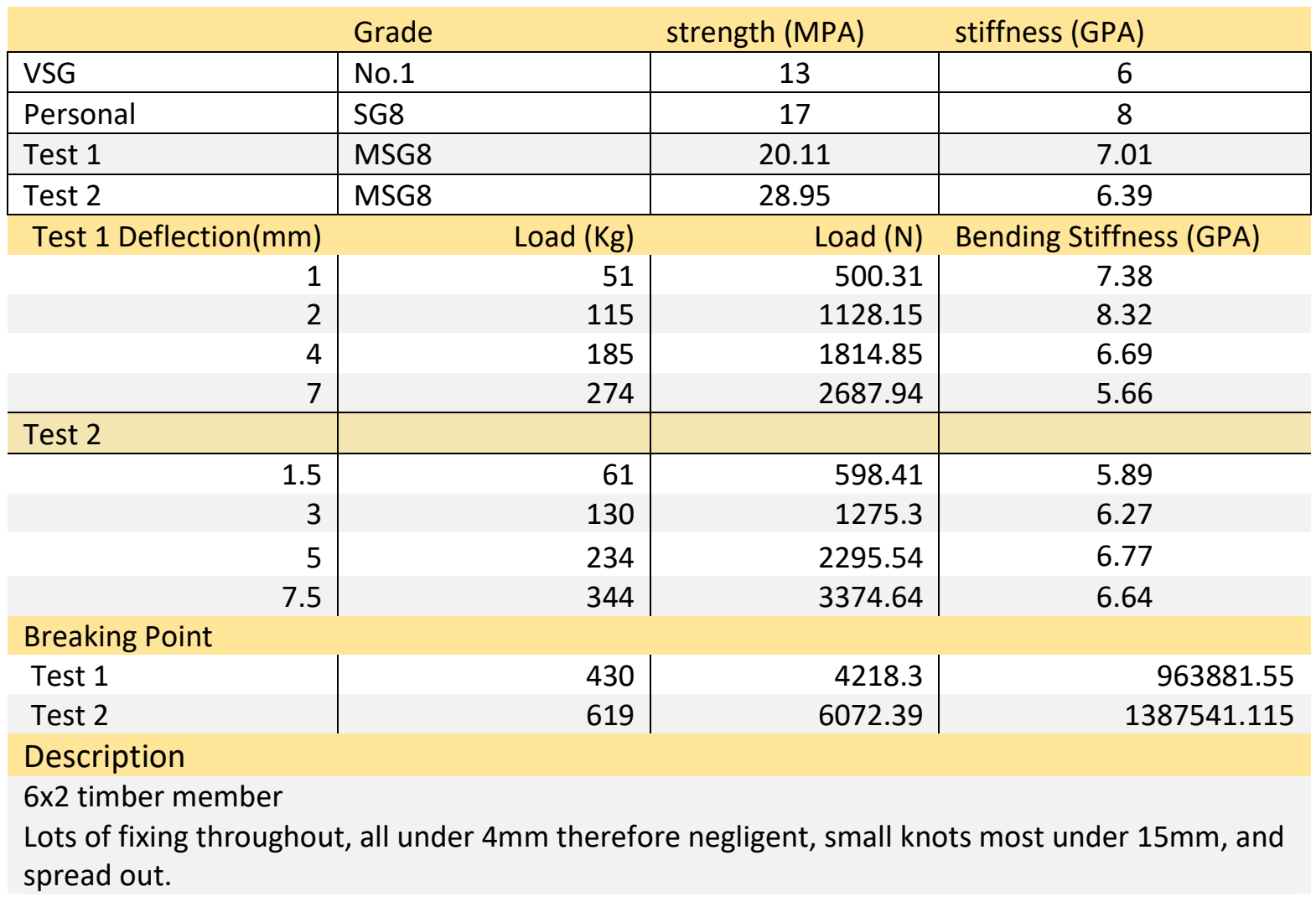


Test 2 - small knots along, no fixings

Test 1 - broke with $120 \mathrm{~mm}$ wide break, unclean. Test 2 broke on knot, $100 \mathrm{~mm}$ away from the ram head, unclean break

\begin{tabular}{|c|c|c|c|c|}
\hline Moisture & $18.00 \%$ & $\%$ & Machine & \\
\hline $\mathrm{L}$ & 1675 & $\mathrm{~mm}$ & & 914 \\
\hline$b=$ & 142 & $\mathrm{~mm}$ & $\mathrm{~mm}$ & \\
\hline$h=$ & 45 & $\mathrm{~mm}$ & $Z=$ & \\
\hline Volume $=$ & 10703250 & $\mathrm{~mm} 3$ & & 47925 \\
\hline Volume= & 0.01070325 & m3 & & \\
\hline Weight & 5.04 & kg & & \\
\hline & 470.8850 & $\mathrm{Kg} / \mathrm{m} 3$ & & \\
\hline
\end{tabular}

Table 50 table six Pine $6 \times 2$

\begin{tabular}{|c|c|c|c|}
\hline \multicolumn{2}{|r|}{ Grade } & strength (MPA) & stiffness (GPA) \\
\hline VSG & No.1 & 13 & 6 \\
\hline Personal & SG8 & 17 & 8 \\
\hline Test 1 & MSG8 & 25.73 & 6.32 \\
\hline Test 2 & MSG8 & 30.40 & 5.58 \\
\hline Test 1 Deflection(mm) & Load (Kg) & Load $(\mathrm{N})$ & Bending Stiffness (GPA) \\
\hline 1.5 & 63 & 618.03 & 6.08 \\
\hline 3 & 138 & 1353.78 & 6.66 \\
\hline 5 & 224 & 2197.44 & 6.48 \\
\hline 8 & 336 & 3296.16 & 6.08 \\
\hline \multicolumn{4}{|l|}{ Test 2} \\
\hline 2 & 82 & 804.42 & 5.93 \\
\hline 5 & 196 & 1922.76 & 5.67 \\
\hline 8 & 297 & 2913.57 & 5.37 \\
\hline 10 & 370 & 3629.7 & 5.35 \\
\hline \multicolumn{4}{|l|}{ Breaking Point } \\
\hline Test 1 & 550 & 5395.5 & 1232871.75 \\
\hline Test 2 & 650 & 6376.5 & 1457030.25 \\
\hline \multicolumn{4}{|l|}{ Description } \\
\hline \multicolumn{4}{|c|}{$\begin{array}{l}\text { Knots on top, do not all transfer through to bottom. } \\
\text { Test } 2 \text { clean section no fixings or knots } \\
\text { Test } 1 \text { unclean break, did not branch to knots the Test } 2 \text { unclean break did not branch to any } \\
\text { knots }\end{array}$} \\
\hline Moisture & $20.10 \%$ & $\%$ & Machine \\
\hline $\mathrm{L}$ & 1735 & $\mathrm{~mm}$ & 914 \\
\hline$b=$ & 142 & $\mathrm{~mm}$ & $\mathrm{~mm}$ \\
\hline$h=$ & 45 & $\mathrm{~mm}$ & $Z=$ \\
\hline Volume $=$ & 11086650 & $\mathrm{~mm} 3$ & 47925 \\
\hline Volume= & 0.01108665 & m3 & \\
\hline Weight & $\begin{array}{r}5.17 \\
466.3266\end{array}$ & $\begin{array}{l}\mathrm{kg} \\
\mathrm{Kg} / \mathrm{m} 3\end{array}$ & \\
\hline
\end{tabular}




\subsection{PINE 4X4}

Table 51 Table one Pine $4 \times 4$

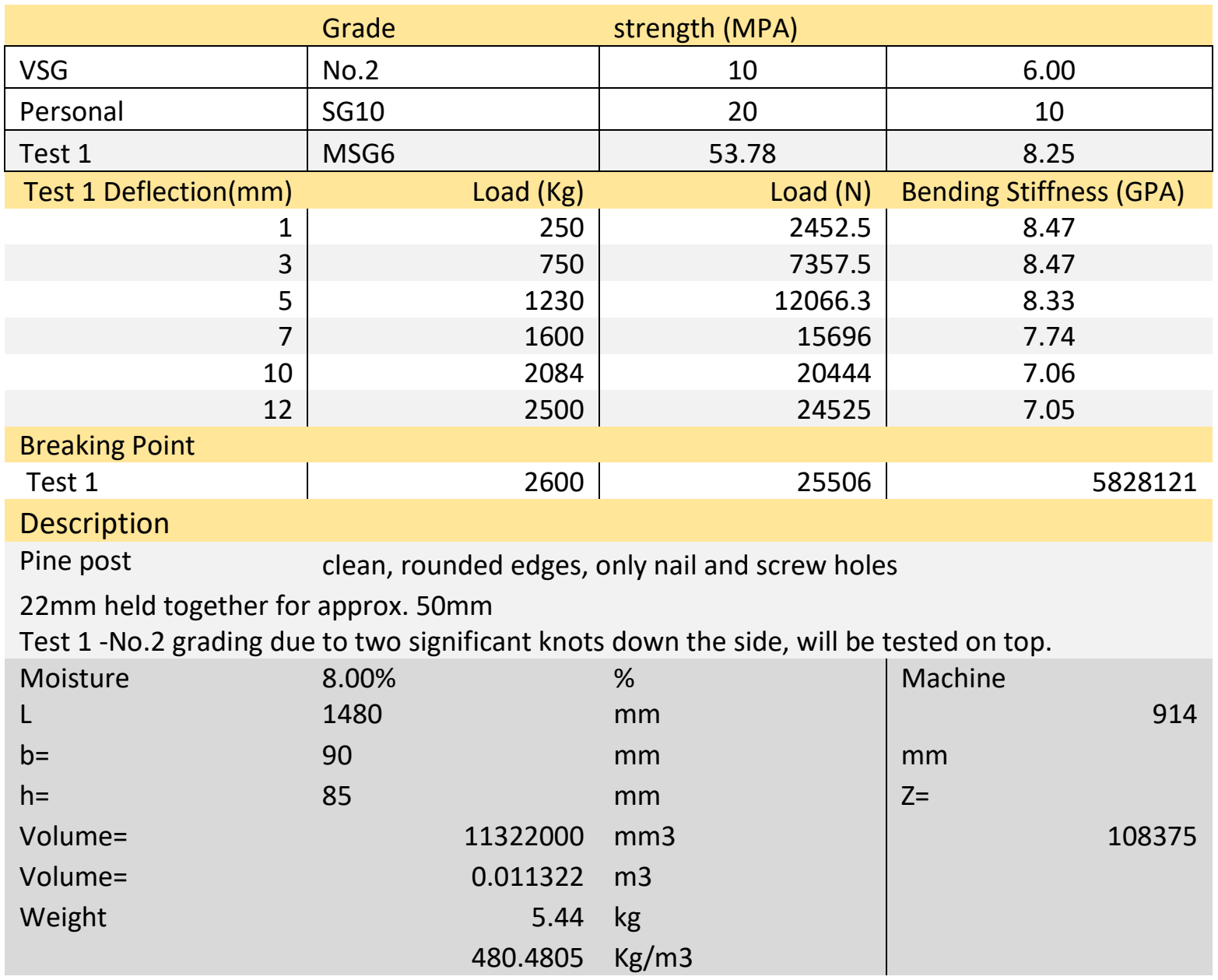

Table 52 Table two Pine $4 x 4$

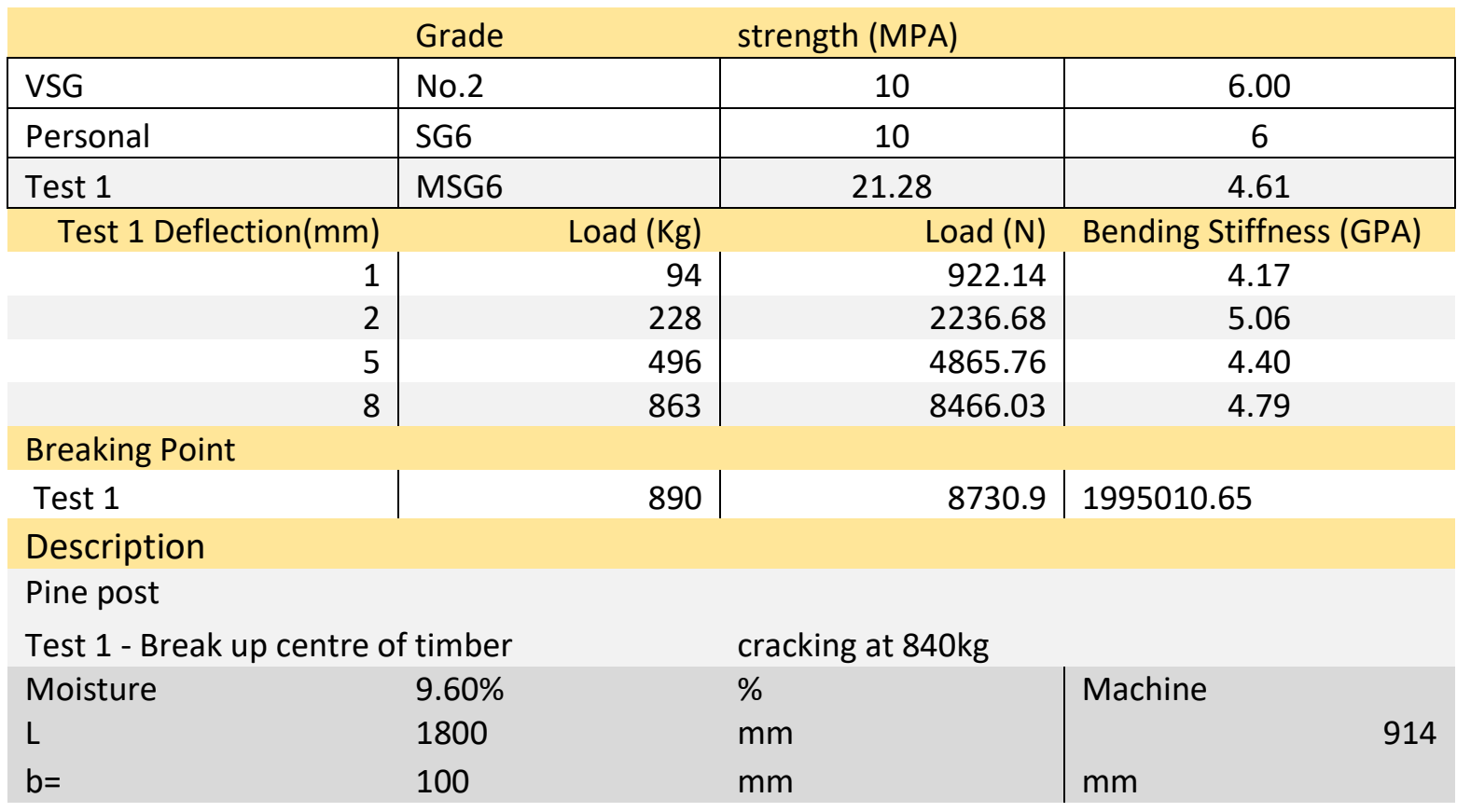


$\mathrm{h}=$

Volume $=$

Volume $=$

Weight
75

$\mathrm{mm}$

$0.0135 \mathrm{~m} 3$

$5.1 \mathrm{~kg}$

$377.7778 \mathrm{Kg} / \mathrm{m} 3$
$\mathrm{Z}=$

93750 


\subsection{RIMU $4 \times 2$}

Table 53 Table one Rimu 4x2

\begin{tabular}{|c|c|c|c|}
\hline & Grade & strength (MPA) & stiffness (GPA) \\
\hline VSG & No.1 & 13 & 6.1 \\
\hline Personal & SG8 & 17 & 8 \\
\hline Test 1 & MSG8 & 41.69 & 7.38 \\
\hline Test 1 Deflection(mm) & Load (Kg) & Load $(\mathrm{N})$ & Bending Stiffness (GPA) \\
\hline $\begin{array}{ll}1\end{array}$ & 42 & 412.02 & 8.23 \\
\hline 3 & 107 & 1049.67 & 6.99 \\
\hline 5 & 179 & 1755.99 & 7.02 \\
\hline 8 & 297 & 2913.57 & 7.28 \\
\hline 11 & 386 & 3786.66 & 6.88 \\
\hline \multicolumn{4}{|l|}{ Breaking Point } \\
\hline Test 1 & 630 & 6180.3 & 1412198.55 \\
\hline \multicolumn{4}{|l|}{ Description } \\
\hline \multicolumn{4}{|l|}{ Rimu $4 \times 2$} \\
\hline \multicolumn{4}{|c|}{4 nail holes down member, sign of heart among member, broke on nail holes } \\
\hline Moisture & $10.50 \%$ & $\%$ & Machine \\
\hline $\mathrm{L}$ & 1195 & $\mathrm{~mm}$ & 914 \\
\hline$b=$ & 92 & $\mathrm{~mm}$ & $\mathrm{~mm}$ \\
\hline$h=$ & 47 & $\mathrm{~mm}$ & $\mathrm{Z}=$ \\
\hline Volume $=$ & 5167180 & $\mathrm{~mm} 3$ & \multirow[t]{4}{*}{33871.33333} \\
\hline Volume $=$ & 0.00516718 & m3 & \\
\hline Weight & 2.93 & kg & \\
\hline & 567.0404 & $\mathrm{Kg} / \mathrm{m} 3$ & \\
\hline
\end{tabular}

Table 54 Table two Rimu 4x2

\begin{tabular}{|c|c|c|c|}
\hline & Grade & strength (MPA) & stiffness (GPA) \\
\hline VSG & No.2 & 14 & 6.00 \\
\hline Personal & SG8 & 14 & 8 \\
\hline Test 1 & MSG8 & 56.91 & 7.74 \\
\hline Test 1 Deflection(mm) & Load (Kg) & Load $(\mathrm{N})$ & Bending Stiffness (GPA) \\
\hline 1 & 45 & 441.45 & 8.82 \\
\hline 3 & 110 & 1079.1 & 7.19 \\
\hline 5 & 186 & 1824.66 & 7.29 \\
\hline 7 & 274 & 2687.94 & 7.67 \\
\hline 10 & 393 & 3855.33 & 7.70 \\
\hline \multicolumn{4}{|l|}{ Breaking Point } \\
\hline Test 1 & 860 & 8436.6 & 1927763.1 \\
\hline \multicolumn{4}{|l|}{ Description } \\
\hline $\begin{array}{l}\text { Rimu } 4 \times 2 \\
\text { the odd split throughou }\end{array}$ & \multicolumn{3}{|c|}{$\begin{array}{l}\text { explosive break on nail holes } \\
\text { the timber, } 3 \text { nail holes in centre }\end{array}$} \\
\hline Moisture & $\begin{array}{l}10.00 \% \\
1146\end{array}$ & $\begin{array}{l}\% \\
\mathrm{~mm}\end{array}$ & Machine \\
\hline
\end{tabular}




\begin{tabular}{lrl|ll}
$\mathrm{b}=$ & 92 & $\mathrm{~mm}$ & $\mathrm{~mm}$ & \\
$\mathrm{~h}=$ & 47 & $\mathrm{~mm}$ & $\mathrm{Z}=$ & \\
Volume= & & 4955304 & $\mathrm{~mm} 3$ & \\
Volume $=$ & & 0.004955304 & $\mathrm{m3}$ & \\
Weight & 3.12 & $\mathrm{~kg}$ & \\
& & 629.6284 & $\mathrm{Kg} / \mathrm{m3}$ &
\end{tabular}

Table 55 Table three Rimu $4 \times 2$

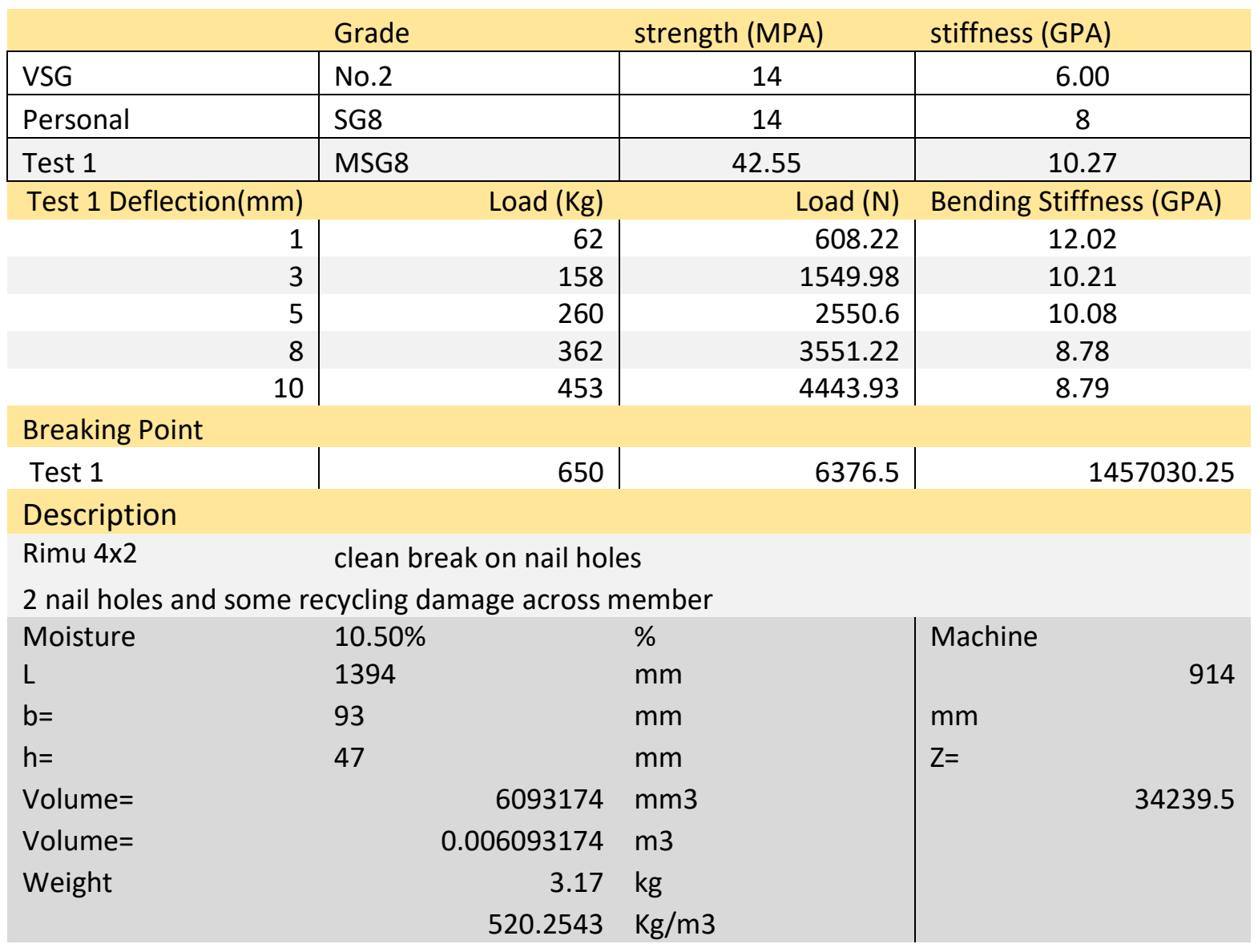

Table 56 Table four Rimu 4x2

\begin{tabular}{|c|c|c|c|}
\hline & Grade & strength (MPA) & stiffness (GPA) \\
\hline VSG & No.2 & 14 & 6.00 \\
\hline Personal & SG8 & 14 & 8 \\
\hline Test 1 & MSG8 & 47.79 & 9.44 \\
\hline Test 1 Deflection(mm) & Load (Kg) & Load $(\mathrm{N})$ & Bending Stiffness (GPA) \\
\hline 1 & 68 & 667.08 & 13.19 \\
\hline 3 & 120 & 1177.2 & 7.76 \\
\hline 5 & 233 & 2285.73 & 9.04 \\
\hline 8 & 320 & 3139.2 & 7.76 \\
\hline 9 & 422 & 4139.82 & 9.09 \\
\hline 11 & 511 & 5012.91 & 9.00 \\
\hline
\end{tabular}




\begin{tabular}{|c|c|c|c|c|}
\hline \multirow{2}{*}{$\begin{array}{l}\text { Test } 1 \\
\text { Description }\end{array}$} & 730 & 7161.3 & \multicolumn{2}{|r|}{1636357.05} \\
\hline & & & & \\
\hline Rimu 4×2 & \multicolumn{4}{|l|}{ broke inside timber } \\
\hline 9 nail holes & \multicolumn{4}{|c|}{ didn't break on nail holes } \\
\hline Moisture & $8.80 \%$ & $\%$ & Machine & \\
\hline $\mathrm{L}$ & 1206 & $\mathrm{~mm}$ & & 914 \\
\hline$b=$ & 93 & $\mathrm{~mm}$ & $\mathrm{~mm}$ & \\
\hline$h=$ & 47 & $\mathrm{~mm}$ & $Z=$ & \\
\hline Volume $=$ & 5271426 & $\mathrm{~mm} 3$ & & 34239.5 \\
\hline Volume= & 0.005271426 & m3 & & \\
\hline Weight & 3.35 & $\mathrm{~kg}$ & & \\
\hline & 635.5017 & $\mathrm{Kg} / \mathrm{m} 3$ & & \\
\hline
\end{tabular}


11.9 TOTARA $5 \times 2$

\begin{tabular}{|c|c|c|c|}
\hline & Grade & strength (MPA) & stiffness (GPA) \\
\hline VSG & No.1 & 17.7 & 8.00 \\
\hline Personal & SG8 & 14 & 8 \\
\hline Test 1 & MSG8 & 27.89 & 7.24 \\
\hline Test 1 Deflection(mm) & Load (Kg) & $\operatorname{Load}(\mathrm{N})$ & Bending Stiffness (GPA) \\
\hline 8 & 62 & 608.22 & 6.51 \\
\hline 9 & 80 & 784.8 & 7.47 \\
\hline 12 & 115 & 1128.15 & 8.05 \\
\hline 17 & 140 & 1373.4 & 6.92 \\
\hline \multicolumn{4}{|l|}{ Breaking Point } \\
\hline & 140 & 1373.4 & 313821.9 \\
\hline \multicolumn{4}{|l|}{ Description } \\
\hline \multicolumn{4}{|l|}{ Totra Member } \\
\hline \multicolumn{2}{|l|}{ 38mm clean break } & \multicolumn{2}{|l|}{ Cracking at $140 \mathrm{Kg}$} \\
\hline Moisture & $11.50 \%$ & $\%$ & Machine \\
\hline $\mathrm{L}$ & 1055 & $\mathrm{~mm}$ & 914 \\
\hline$b=$ & 62 & $\mathrm{~mm}$ & $\mathrm{~mm}$ \\
\hline$h=$ & 33 & $\mathrm{~mm}$ & $Z=$ \\
\hline Volume= & 2158530 & $\mathrm{~mm} 3$ & 11253 \\
\hline Volume= & 0.00215853 & m3 & \\
\hline Weight & 1.34 & $\mathrm{~kg}$ & \\
\hline & 620.7929 & $\mathrm{Kg} / \mathrm{m} 3$ & \\
\hline
\end{tabular}

